\title{
Economic evaluation of hearing aid fitting
}

Citation for published version (APA):

Joore, M. A. (2002). Economic evaluation of hearing aid fitting. [Doctoral Thesis, Maastricht University]. Universiteit Maastricht. https://doi.org/10.26481/dis.20020919mj

Document status and date:

Published: 01/01/2002

DOI:

10.26481/dis.20020919mj

Document Version:

Publisher's PDF, also known as Version of record

\section{Please check the document version of this publication:}

- A submitted manuscript is the version of the article upon submission and before peer-review. There can be important differences between the submitted version and the official published version of record.

People interested in the research are advised to contact the author for the final version of the publication, or visit the DOI to the publisher's website.

- The final author version and the galley proof are versions of the publication after peer review.

- The final published version features the final layout of the paper including the volume, issue and page numbers.

Link to publication

\footnotetext{
General rights rights.

- You may freely distribute the URL identifying the publication in the public portal. please follow below link for the End User Agreement:

www.umlib.nl/taverne-license

Take down policy

If you believe that this document breaches copyright please contact us at:

repository@maastrichtuniversity.nl

providing details and we will investigate your claim.
}

Copyright and moral rights for the publications made accessible in the public portal are retained by the authors and/or other copyright owners and it is a condition of accessing publications that users recognise and abide by the legal requirements associated with these

- Users may download and print one copy of any publication from the public portal for the purpose of private study or research.

- You may not further distribute the material or use it for any profit-making activity or commercial gain

If the publication is distributed under the terms of Article $25 \mathrm{fa}$ of the Dutch Copyright Act, indicated by the "Taverne" license above, 
Economic Evaluation
of

Hearing Aid Fitting 
Economic Evaluation of Hearing Aid Fitting. Manuela Joore. Thesis. Maastricht University.

ISBN: 90-9016018-3

○ 2002, Manuela A. Joore, university hospital Maastricht, Department of Clinical Epidemiology and Medical Technology Assessment, PO Box 5800, 6202 AZ Maastricht, The Netherlands. E-mail mjo@aozg.azm.nl. Telephone +31-43-3875434.

All rights reserved. No part of this thesis may be reproduced or transmitted in any form or by any means, electronic or mechanical, including photocopy, recording, or any information storage and retrieval system, without permission in writing from the copyright owner. 


\title{
Economic Evaluation of
}

\section{Hearing Aid Fitting}

\begin{abstract}
PROEFSCHRIFT
ter verkrijging van de graad van doctor aan de Universiteit Maastricht, op gezag van de Rector Magnificus,

Prof. Dr. A.C. Nieuwenhuijzen Kruseman volgens het besluit van het College van Decanen, in het openbaar te verdedigen op donderdag 19 september 2002 om 16.00 uur
\end{abstract}

door

Manuela Antoinette Joore 


\section{Promotor}

Prof. dr. H.J.M. Peters

\section{Co-promotor}

Dr. L.J.C. Anteunis

\section{Beoordelingscommissie}

Prof. dr. P.P. Wakker (voorzitter)

Prof. dr. J.J. Manni

Prof. dr. J.G.A. van Mierlo

Prof. dr. J.L. Severens

The studies described in this thesis are in part supported by grants from the European Hearing Instruments Manufacturers Association (EHIMA), the Heinsius Houbolt Foundation, and the ENT Research Foundation Maastricht.

Publication and distribution of this thesis was financially supported by the Stichting Atze Spoor Fonds. 


\begin{abstract}
ik draai een kleine revolutie af ik draai een kleine mooie revolutie af ik ben niet langer van land $i k$ ben weer water ik draag schuimende koppen op mijn hoofd ik draag schietende schimmen in mijn hoofd op mijn rug rust een zeemeermin op mijn rug rust de wind de wind en de zeemeermin zingen de schuimende koppen ruisen de schietende schimmen vallen

ik draai een kleine mooie ritselende revolutie af en ik val en ik ruis en ik zing
\end{abstract}

Lucebert 


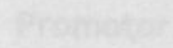

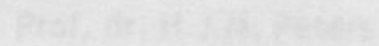

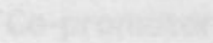

(2)

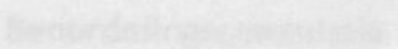

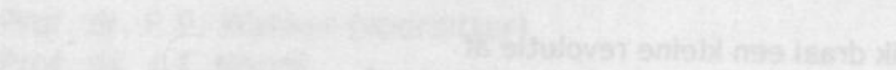

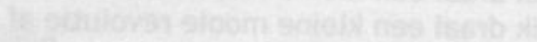

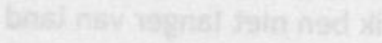

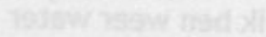

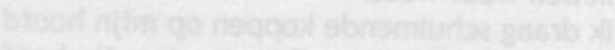

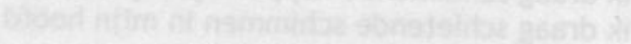

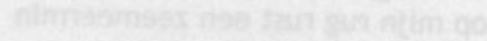

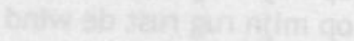

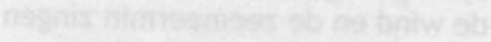

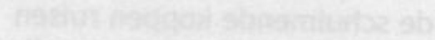

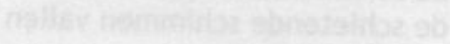

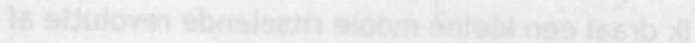

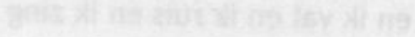




\section{Contents}


Introduction $\quad 13$

Hearing $\quad 13$

Physiology of hearing $\quad 13$

Hearing impairment $\quad 14$

Epidemiology of hearing impairment $\quad 14$

Hearing disability and handicap $\quad 15$

Hearing rehabilitation $\quad 15$

$\begin{array}{ll}\text { Economic evaluation in health care } & 17\end{array}$

Methodology of economic evaluation in health care 17

Economic evaluation of hearing aid fitting 18

Objective and outline of the thesis $\quad 19$

\section{Chapter 2 Societal effects of hearing aid fitting among} the moderately hearing-impaired

Joore MA, Brunenberg DEM, Chenault MN, Anteunis LJC.

International Journal of Audiology. Accepted for publication.

Introduction $\quad 23$

Methods $\quad 24$

Study design $\quad 24$

Study population $\quad 25$

Outcome measurement 26

$\begin{array}{ll}\text { Statistical analysis } & 28\end{array}$

Results $\quad 28$

Overall health related quality of life 28

Subjective auditory disability and handicap $\quad 30$

Hearing aid satisfaction and use $\quad 31$

Loss of productivity $\quad 31$

Medical consumption 33

Conclusion and discussion $\quad 33$

Chapter 3 Development of a questionnaire to measure hearing related health state framed in an overall health perspective

Joore MA, Brunenberg DEM, Zank $H$, van der Stel $H$, Anteunis LJC, Boas GM, Peters HJM. International Journal of Technology

Assessment in Health Care, 2002; 18(3): 528-539.

$\begin{array}{ll}\text { Introduction } & 37\end{array}$

Methods $\quad 38$

Development of the ADPI 38

Prospective evaluation study $\quad 41$

Statistical analysis $\quad 43$

Results $\quad 43$

Description of the study population $\quad 43$

ADPI results $\quad 44$

EQ-5D results $\quad 46$

$\begin{array}{ll}\text { Conclusion and discussion } & 47\end{array}$ 
Chapter 4 Response shift in the measurement of quality of life after hearing aid fitting Joore MA, Potjewijd J, Timmerman AA, Anteunis LJC. Quality of Life Research. 2002; 11: 299-307.

Introduction 53

Methods 54

Design and study population $\quad 54$

Outcome measurement 55

Hypotheses $\quad 56$

Statistical analysis $\quad 56$

Results 57

Description of the study population 57

Then-test items 57

Control items 58

Conclusion and discussion $\quad 59$

Chapter 5 The influence of illness experience on health state valuations

Joore MA, Potjewijd J, Anteunis LJC. Submitted.

Introduction $\quad 65$

Methods 66

Design and study population 66

$\begin{array}{ll}\text { Data collection } & 67\end{array}$

Analysis $\quad 68$

Results 69

Description of the study population 69

Between-group differences $\quad 70$

Differential use of the VAS anchor point $\quad 70$

Valuation compression $\quad 70$

Controlling for age, gender, education level $\quad 71$

$\begin{array}{ll}\text { Conclusion and discussion } & 72\end{array}$

Chapter 6 The cost-effectiveness of hearing aid fitting in the Netherlands

Joore MA, van der Stel H, Peters HJM, Boas GM, Anteunis LJC. Archives of Otolaryngology Head and Neck Surgery. In review process.

$\begin{array}{ll}\text { Introduction } & 79\end{array}$

Methods $\quad 79$

Model of hearing aid fitting $\quad 79$

Quality of life assessment and QALY calculation $\quad 81$

Probabilities $\quad 82$

Costs $\quad 84$

Analysis $\quad 86$

Results $\quad 86$

Quality of life and costs outcomes 86

Cost / QALY outcomes 88

Results on the cost-effectiveness plane $\quad 89$

Sensitivity analysis $\quad 89$

Conclusion and discussion $\quad 90$ 
Chapter 7 Conclusions and discussion

$\begin{array}{lr}\text { Introduction } & 95 \\ \text { Main findings } & 95 \\ \text { Methodological issues } & 98 \\ \text { Policy implications } & 100 \\ \text { Areas of future research } & 100 \\ \text { Concluding remarks } & 101\end{array}$

$\begin{array}{ll}\text { References } & 105\end{array}$

$\begin{array}{lr}\text { Subject Index } & 117\end{array}$

$\begin{array}{ll}\text { Summary } & 123\end{array}$

$\begin{array}{lr}\text { Samenvatting } & 131\end{array}$

$\begin{array}{lr}\text { Co-authors and affiliations } & 139\end{array}$

$\begin{array}{ll}\text { Dankwoord } & 143\end{array}$

$\begin{array}{lr}\text { Publication list } & 147\end{array}$

$\begin{array}{ll}\text { Curriculum Vitae } & 149\end{array}$ 


\section{Chapter 1}

\section{Introduction}





\section{Introduction}

Resources in health care are scarce. Even among interventions that are proven effective, inevitably choices are made concerning the allocation of people, time, facilities, equipment and knowledge (Drummond, 1997). Economic evaluation is a tool to systematically consider the factors underlying these decisions. The outcomes of economic evaluation studies inform policy makers, insurers, patients and other parties of the relative value of health care interventions. This thesis focuses on the economic evaluation of hearing aid fitting in hearing-impaired adults. Besides the outcomes of the economic evaluation study, it deals with methodological aspects of measuring preferences for health states in hearing impairment.

The physiology of hearing is considered briefly in this chapter, together with the causes, definition, prevalence and adverse effects of hearing impairment. The options for hearing rehabilitation are given, and the methodology of economic evaluation in health care, and its application on hearing aid fitting in this thesis is introduced. The final part of this chapter states the general objective and research questions of the study, and provides an outline of this thesis.

\section{Hearing}

\section{Physiology of hearing}

Hearing is a process that involves the transformation of sound into electric pulses and the processing of these pulses by the brain into the sounds of the world around us (Jerger et al, 1995). The auditory system is divided into the outer ear, the middle ear, the cochlea, the eighth cranial nerve, and central auditory system. The outer ear collects the sound and conducts the sound through the auditory canal to the middle ear. In the middle ear the sound waves make the tympanic membrane vibrate. The rate and magnitude of the vibration is proportional to the frequency and the intensity of the sound. The ossicular chain, a series of three small bones (the mallues, incus and stapes), transfers the vibration of the tympanic membrane to the cochlea. This transformation of the sound waves into mechanical force sets the fluid in the cochlea in motion. The motion in the cochlea stimulates the organ of Corti with its hair cells. These cells give pulses through the eighth cranial nerve to the central auditory system, where the actual hearing takes place. This is the normal way of sound travelling to the ear, and it is called air conduction. It is also possible to hear sound through bone conduction. Sound waves, in this case vibrations, are then transferred to the cochlea through the cranium. 


\section{Hearing impairment}

Defects of the outer ear and the middle ear cause the intensity of the sound conducted to the cochlea to drop: as a result sound is perceived less loud. This is called a conductive hearing loss. In defects of the cochlea or the eighth cranial nerve the intensity of the sound is altered. Soft sounds may not be heard due to a loss of sensitivity and loud sounds may sound even louder. Moreover, the sound is distorted. This is called sensori-neural hearing loss. According to the World Health Organization classification hearing loss can be qualified as an impairment: a loss or abnormality of psychological, physiological or anatomical structure or function (WHO, 1980.

There are a number of known causes of hearing impairment: congenital defects (genetic or due to infections or trauma during pregnancy), viral infections (Mumps, Influenza B, and Chickenpox for instance), bacterial meningitis, ototoxic drugs, noise and ageing. Old age is the most important cause of hearing impairment. In old age hearing impairment is in most cases caused by presbyacusis: a gradually progressive bilateral sensorineural hearing loss, in which the highest frequencies are affected first and the lower follow gradually (Weinstein, 1994). The first signs of age-related hearing loss are already present at the age of thirty.

The intensity of sound is expressed in decibels $(\mathrm{dB})$, on a logarithmic scale. Whispering has an intensity of $30 \mathrm{~dB}$, a normal conversation $60 \mathrm{~dB}$, shouting 80 $\mathrm{dB}$, and an electric drill $110 \mathrm{~dB}$. Apart from a different intensity, sounds also have a different frequency, expressed in Hertz $(\mathrm{Hz})$. In speech for instance, most voiceless consonants have a higher frequency than most vowels. A hearing impairment of $25-40 \mathrm{~dB}$ is regarded as a mild hearing impairment, although a hearing impairment of $30 \mathrm{~dB}$ can lead to problems in speech intelligibility. A hearing impairment of $40-55 \mathrm{~dB}$ is considered as moderate, and an impairment of $55-90 \mathrm{~dB}$ as severe. Deafness is defined as a hearing impairment of at least $90 \mathrm{~dB}$ (Chorus et al, 1995).

\section{Epidemiology of hearing impairment}

Hearing impairment is one of the most frequent health problems in western societies, with an estimated prevalence of $10 \%$ in the general population (Chorus et al, 1995). According to figures of the World Health Organization there are 250 million persons affected by hearing loss worldwide (WHO press release, 2001). The use of different audiometrical and subjective definitions of hearing impairment can lead to a substantial variation in prevalence figures (Duijvestijn et al, 1999). A best ear pure tone average (BEPTA) hearing loss of at least $35 \mathrm{~dB}$ at $0.5,1,2 \mathrm{kHz}$ is found in $11 \%$, a BEPTA hearing loss of at least $35 \mathrm{~dB}$ at $1,2,4 \mathrm{kHz}$ in $26 \%$, and subjective hearing impairment in $38 \%$ of the Dutch population of 55 years and older (Duijvestijn et al, 1999). 
Hearing impairment is clearly an age associated condition: $25 \%$ of the Dutch population aged over 57 years and $75 \%$ of the population older than 80 years has a hearing loss of at least $35 \mathrm{~dB}$, averaged across 1,2 and $4 \mathrm{kHz}$ at the best ear (van den Brink, 1995; Abutan et al, 1993). Due to the still increasing length of the average human lifespan, the number of hearing-impaired persons will grow further in the future decades.

\section{Hearing disability and handicap}

Hearing impairment affects communication and as a result, according to the 1980 WHO classification, may cause disability and handicap (WHO, 1980). Auditory disability is concerned with the restriction to perform activities in daily life as a result of hearing impairment. Auditory handicap is concerned with restrictions in the fulfilment of a role (as normal for that individual depending on age, gender, and social and cultural factors) as a result of hearing impairment. In the new WHO International Classification of Functioning, Disability and Health the accent has moved from consequences of disease to components of health (WHO, 2001). When designing this study in 1998 the concepts from the 1980 WHO classification were used.

Severe hearing loss has been associated with decreased physical and psychosocial functioning (Bess et al, 1989). In another study a lower general health status, and lower social functioning was found only in hearing-impaired persons who also reported hearing disability or handicap (Parving et al, 2001). When using more specific measures a hearing deficit has been associated with a low mood level, loss of self sufficiency in daily living activities and poor social relationships (Bess et al, 1989; Appollonio et al, 1995; Carabellese et al, 1994; Mulrow et al, 1990). A mild to moderate hearing impairment is also associated with lower verbal memory performance, even though the volume was adapted and background noise was minimized (van Boxtel et al, 2000). As a consequence, verbal memory function may be underestimated in hearingimpaired persons. When comparing hearing-impaired persons with paid labour with their normally hearing counterparts, it is found that they complain more about lack of energy and social isolation, but that no differences in other aspects of quality of life are present (Grimby \& Ringdahl, 2000). Hearing impairment, when functionally relevant, has also been associated with a higher mortality rate, at least in men, even after adjusting for possible confounders like demographic variables and physical health (Appollonio et al, 1995). The mortality rate might be influenced by hearing impairment through an effect on aspects of quality of life (Appollonio et al, 1995).

\section{Hearing rehabilitation}

The first reference in writing of the use of a aid for hearing was made as early as in the first century before Christ, in Homer's epic poem on Odysseus wanderings (Beem, 1997). It took until the Second World War before the 
profession of audiological rehabilitation developed, for soldiers who had lost their hearing in the war (Canfield \& Morrisett, 1947).

In sensorineural hearing in most cases the only option for rehabilitation are hearing aids. When hearing loss is due to outer ear or middle ear deficits in some cases surgery is also an option. In cases of deafness cochlear implants are an option. To give an indication: in recent years annually in the Netherlands approximately 200 cochlear implants were performed, whereas 110.000 hearing aids were sold. Hearing aids can be used to improve hearing by amplifying sound, and passing it on to the ear. There are different types of hearing aids: behind-the-ear, in-the-ear and completely-in-the-canal hearing aids. The behind-the-ear hearing aid consists of two parts: a device worn behind the ear (containing the battery, microphone, amplifier and receiver) and an ear mould that is worn in the ear. The main disadvantages of this type of hearing aid are the sensitivity to wind noise and cosmetic aspects. In in-the-ear hearing aid all parts are miniaturized, enabling the construction of a much smaller hearing aid that can be worn in the auricle or in the auditory canal. This type of aid is cosmetically more attractive, but is also sensitive to wind noise and suffers more from moisture and earwax. The completely-in-the-canal hearing aid is even smaller than the in-the-ear hearing aid. An advantage is that this type is less sensitive to wind noise, disadvantages are that it is less adjustable, and much more expensive. The actual sound processing can be analogue, and/or digital. An analogue hearing aid processes sound by converting it into an electric signal, which is then manipulated with a series of electrical components (Yueh, 2000). In a digital hearing aid the electric signal is digitised into a series of numbers, which is then manipulated in a microprocessor. Digital hearing aids are much more adaptable than analogue ones. Furthermore digital hearing aids may accommodate additional algorithms to reduce background noise, and may be able to perform self-monitoring functions and automatically adjust to changing environments (Yueh, 2000). Despite the theoretical advantages of digital hearing aids the evidence that they are more effective, and thus justify the considerable extra costs, compared to analogue ones is not yet established.

In the Netherlands a minimum hearing loss of $35 \mathrm{~dB}$ averaged across 1,2 and 4 $\mathrm{kHz}$ at the best ear is required to be eligible for a hearing aid refund from the health insurers. Exceptions are sometimes made for persons whit paid labour in whom it can be made plausible that hearing aids improve the work process. Of the population with hearing problems, only approximately $20 \%$ is fitted with hearing aids (Duijvestijn et al, 1999). For the Netherlands this means that approximately 380.000 persons wear hearing aids. Based on figures from the Ministry of Health, in 1999 the government costs for hearing devices amounted to $€ 55$ million (CVZ, 2001). The non-refundable part of the price of the hearing aid, and the total costs of hearing aids fitted in persons who are privately insured are not included in this amount. 


\section{Economic evaluation in health care}

\section{Methodology of economic evaluation in health care}

In the mid-1960s most western countries began to experience rising expenditures for health care. Since then, governments have tried to control health care costs by encouraging greater efficiency in the production and use of health care technology (EUR-ASSESS, 1997). Health Care Technology Assessment (HTA) or Medical Technology Assessment (MTA), has developed since then. MTA is a form of policy research that systematically examines consequences of the application of a technology. The goal of MTA is to inform decision making. MTA consists of the following independent phases: identification and priority setting, testing, synthesis, and dissemination and implementation (Oortwijn, 2000).

Economic evaluation is a tool for MTA. Economic analysis involves the comparative analysis of alternative courses of action in terms of both their costs and consequences (Drummond, 1997). Modelling is a technique to create a framework for an economic evaluation study (Russell, 1999). The assessment of the impact of health care technology on the health state of individuals, by its very nature requires the use of a dynamic modelling approach, such as Markov modelling. People get sick, undergo treatment, and may become better or worse after treatment, and so on. In a dynamic model the population is divided over different health states, and over time persons move from one health class to another according to certain transition probabilities that can be assessed empirically. These transitions may be associated with medical interventions or other factors. Economic and societal costs and benefits can be associated with these transitions, in terms of health, health care costs, but also for instance in terms of productivity losses and gains.

Based on the way the consequences are valued, we can distinguish between four different techniques of economic evaluation: cost-minimization analysis, cost-effectiveness analysis, cost-utility analysis and cost-benefit analysis (Drummond, 1997). A cost-minimization analysis is performed when the alternatives are equally effective, and is essentially an incremental cost analysis. In cost-benefit analysis (CBA) both costs and effects are expressed in monetary terms. As assigning monetary values to health outcomes is controversial, this type of analysis is not used very often yet. In a costeffectiveness analysis (CEA) the incremental effectiveness of an intervention is quantified and compared with the incremental costs. Cost-utility analysis (CUA) has many similarities with CEA, and is sometimes regarded a special form of the latter (Gold et al, 1996). A difference between CEA and CUA is that in CUA the measure of effectiveness is a quality-adjusted-life-year (QALY). QALYs are a combined measure of quality of life and duration of life. Preferences for health states are used as quality weights in the calculation of 
QALYs. When the elicitation of health state preferences incorporates choice and uncertainty the preferences are utilities, without choice and uncertainty the preferences are values. Health state preferences can be obtained in patients actually experiencing the health state, or in other groups. In an economic evaluation study from a societal perspective the preferences should be obtained in a representative sample of the general public. The rationale behind this is that when the costs of the interventions are borne by society as a whole, the effects should be obtained in a sample of that society as well. Preferences for health states tend to differ between patients and other groups (De Wit et al, 2000). Another prerequisite for assessing health state preferences for use in QALY calculation is that measurement should take place on the overall health continuum, ranging from worst to best imaginable health state.

\section{Economic evaluation of hearing aid fitting}

The growing number of hearing-impaired persons together with the increasing technological possibilities and price of hearing aids prioritise hearing aid fitting for economic evaluation. Nevertheless, in the MTA field hearing impairment and hearing aids have clearly not been a research priority: only three studies calculated both costs and effects associated with hearing aid fitting (Brickley et al, 1996; Tonning et al, 1995; Parving et al, 1997), but none of these studies focussed on the societal costs and effects of fitting hearing aids, and no study performed a full economic analysis. Of all economic analyses published in major otolaryngology journals between 1990 and 1999 ( $n=71)$ only 18 studies focused on interventions for hearing impairment (Kezirian \& Yueh, 2001). Most of the studies on hearing impairment evaluated cochlear implants $(n=12)$. This reflects the medical research agenda in general: research on age associated conditions has been a Cinderella compared with the conditions of early and middle life (Metz, 2000). The positive effects of hearing aid fitting in elderly hearing-impaired persons on social, emotional, communication and cognitive function, and on depression have been demonstrated (Mulrow et al, 1990). The effects of hearing aid fitting are however difficult to capture with generic health status instruments. The only generic questionnaires used to evaluate hearing aids are the Sickness Impact Profile (SIP) and the Medical Outcomes Study Short Form 36 (MOS SF36) (Ware \& Sherbourne, 1992). The SIP showed some improvement and the MOS SF-36 showed no change after hearing aid fitting (Crandell, 1996). Both questionnaires are not suitable for use in QALY calculation.

In this study both CEA and CUA are used to explore the implications of hearing aid fitting in hearing-impaired adults. Preferences for hearing related health states before and after hearing aid fitting were obtained in both patient and non patient groups. A dynamic model was used to explore the value of investing for hearing aid fitting. 


\section{Objective and outline of the thesis}

General objective of this thesis is to estimate the incremental costeffectiveness of hearing aid fitting in hearing impaired adults compared to not fitting hearing aids. This thesis consists of several studies that deal with aspects of the economic evaluation of fitting hearing aids in hearing-impaired adults, with special attention to the measurement of the effects of hearing aid fitting on health status, and the use of modelling in economic evaluation.

This thesis starts with an outline of the societal consequences of hearing aid fitting, in terms of generic quality of life, hearing specific quality of life, direct medical costs and productivity losses, obtained in a prospective evaluation study of first-time hearing aid fitting in hearing impaired adults (Chapter 2).

In Chapter 3 the development of a multi-attribute questionnaire to measure hearing related health state preferences is presented, together with the results of a first application of the questionnaire in a study of fitting hearing aids in hearing-impaired adults.

Hearing impairment is in most cases a slowly progressive condition, which makes the presence of mechanisms like adaptation and coping plausible. As a result, the repeated measurement of quality of life in hearing-impaired persons may be biased by the response shift phenomenon. In Chapter 4 the occurrence of response shift in the measurement of quality of life after hearing aid fitting is described. Another issue in the measurement of the effect of health care interventions is whose values to use. Experience is known to cause between-group-preference-differences for health states. In Chapter 5 the influence of illness experience on the valuation of both generic health states and health states related to hearing impairment and hearing aid fitting is reported.

The results of the cost-effectiveness analysis of hearing aid fitting in hearingimpaired adults are presented in Chapter 6.

Chapter 7 contains an overview of this thesis. The results of each chapter are examined within the context of the thesis and the achievements of the thesis are placed in the context of recent and future developments in the field of hearing impairment and hearing aid fitting. Also some areas of further research are identified. 



\section{Chapter 2}

Societal effects of hearing aid fitting among the moderately hearing-impaired 
Joore MA, Brunenberg DEM, Chenault MN, Anteunis LJC. Societal effects of hearing aid fitting among the moderately hearing-impaired. International Journal of Audiology. Accepted for publication. 


\section{Introduction}

In this study hearing aid fitting was evaluated from a societal point of view, instead of the more traditional patient perspective. All costs and benefits of hearing aid fitting for society as a whole should be determined, regardless of who pays the costs, or perceives the benefits. This kind of evaluation is also called economic evaluation. Economic evaluations provide important information to guide the allocation of scarce resources such as personnel, equipment, time and know-how (Drummond, 1997). Decisions concerning the allocation of health care resources for hearing aid fitting are made, and have for instance in the Netherlands resulted in a decrease in the reimbursement for hearing aids. It is important that information concerning the economic effects of hearing aids to society becomes available to make informed allocation decisions. In this study the economic effects and costs of hearing aid fitting to the society as a whole were estimated in a prospective intervention study of fitting hearing aids. The study was carried out in the Netherlands, among a representative sample of adult first time hearing aid applicants.

The effects of hearing aid fitting on feelings of satisfaction, the experience of hearing disability and handicap and the psychological well-being of hearingimpaired persons have been described.(Mulrow et al, CD; Stephens \& Meredith, 1991a; Appollonio et al, 1996; Dillon et al, 1997). For use in an economic evaluation however, the effect of hearing aid fitting should be expressed in terms of a change in overall health related quality of life (HRQOL). HRQOL is a concept that consists of several domains, the core of which consists of physical, psychological and social functioning. The Sickness Impact Profile (SIP) and the Medical Outcomes Study Short Form 36 (MOS SF36) are examples of generic HRQOL questionnaires that were used in a hearing-impaired population. The SIP showed some improvement and the MOS SF-36 showed no change after hearing aid fitting (Crandell, 1998). This is not surprising, because the effect of hearing aid fitting to a large extent takes place in the more specific domain of communication function. This domain is not covered in most available questionnaires to assess HRQOL, only the Health Utilities Index (HUI) contains a sensory dimension (Torrance et al, 1996). A disadvantage of the $\mathrm{HUI}$ is that the scores on the hearing, speech and sight dimensions are clustered into the sensory dimension in a way that being both blind and deaf results in the same score as being blind only. This result does not seem valid, as was also recently stated by Cox, et al (2000). In the present study the EQ-5D (EuroQol Group, 1990), a short questionnaire to measure and value HRQOL, was used to assess the effects of hearing aid fitting on generic HRQOL. In order to assess the usefulness of the EQ-5D for this purpose, also social functioning, and indicators of hearing specific HRQOL were measured. Social functioning is an aspect of HRQOL likely to be influenced by hearing impairment (Brazier et al, 1996; Ringdahl \& Grimby, 
2000; Stewart et al, 2000). Auditory disability and handicap and hearing aid satisfaction and use were considered as indicators of hearing specific HRQOL.

In contrast to the extensive literature on the effects of hearing impairment and the fitting of hearing aids, only a limited number of studies have reported on the associated costs. The costs of the hearing aid itself make up the largest part of the costs of hearing aid fitting. The costs of devices for hearing impairment, mainly hearing aids, amounted in 1995 to $€ 50$ million in the Netherlands (Polder et al, 1997). Other costs besides the costs generated by the fitting procedure, could be avoided as a result of a change in HRQOL after hearing aid fitting. The latter type of costs consists mainly of productivity loss and medical consumption. There is evidence that severe hearing impairment leads to productivity losses. In a US study the earnings of severe to profoundly hearing-impaired persons, defined as the inability to detect a sound of 70 decibels averaged across $0.5,1$ and $2 \mathrm{kHz}$., were determined (Mohr et al, 2000). Severely hearing-impaired persons of 65 years and older earned on average $77 \%$ of the earnings of their non hearing impaired counterparts. The present study focuses on moderately hearing impaired persons; it is not known to what extent productivity losses are present in this population. Hearing aid fitting could also lead to savings as a result of a decrease in medical consumption that could be avoided by fitting hearing aids has, to our knowledge, not been investigated yet.

The overall aim of this study was to assess benefits in terms of gain in (aspects of) $\mathrm{HRQOL}$ and possible savings in terms of increased productivity and decreased medical consumption after hearing aid fitting in a population of moderately hearing-impaired first time hearing aid applicants. More specific objectives of the study were: 1) to assess the usefulness of the EQ-5D to determine change in overall HRQOL after hearing aid fitting, 2) to assess change in social functioning after hearing aid fitting, 3) to assess the usefulness of the Amsterdam Inventory to determine change in auditory disability and handicap after hearing aid fitting, 4) to assess the change in productivity at paid and unpaid labour after hearing aid fitting, and 5) to assess the change in medical consumption after hearing aid fitting.

\section{Methods}

\section{Study design}

The study was a prospective intervention study with a baseline measurement and two follow-up measurements. The baseline measurement $\left(T_{0}\right)$ took place directly after receiving the prescription for the hearing aid and obtaining written informed consent. In the Netherlands, for the prescription of a hearing aid hearing-impaired persons are referred to an Ear, Nose, and Throat (ENT) specialist or to an Audiological Centre (AC) by their General 
Practitioner. The actual hearing aid fitting takes place at a hearing aid dispenser. After a trial period in which several hearing aids are tried out, the hearing-impaired person visits the ENT specialist or AC again, for approval of the hearing aid fitted. A hearing aid fitting was approved when, at least, 1) the ear mould was well tolerated and prevented feed-back, 2) speech understanding with the hearing aid was optimised at normal speech levels $(60$ $70 \mathrm{~dB})$ and a 10-15 dB reserve in amplification was still present. The approval entitles the person for a partial reimbursement of the hearing aid. The first follow-up measurement $\left(T_{1}\right)$ took place at this visit (on average 12 weeks after baseline). The second follow up measurement $\left(T_{2}\right)$ took place 25 weeks after baseline. Trained audiology assistants administered all questionnaires in faceto-face interviews, taking place at the ENT clinic or Audiological Centre. At baseline tone and speech audiometry was performed, followed by the questionnaire. At the follow up measurements only the questionnaire was administered. The results of the audiometry are not presented, since they are out of the scope of this paper.

\section{Study population}

The study population consisted of 78 first time hearing aid applicants of 18 years and older who entered the process of hearing aid fitting through the ENT clinic of the Maastricht University Hospital or the Hoensbroeck Audiological Centre (location Venlo). The study population met the following requirements: pure tone audiometry revealed an averaged hearing loss of at least $35 \mathrm{~dB}$ at 1,2 and $4 \mathrm{kHz}$ in the best ear, the hearing loss was due to inner ear pathology without indications of retro cochlear malignancies and there were no contra-indications for hearing aid use (such as draining ears or ear canal pathology). Persons who had had a hearing aid in the past five years and had actually used it for a period longer than six months were not included, as they could not be considered as first-time hearing aid applicants. Persons not mentally capable of answering the questionnaires, not able to come to the hospital, or not able to speak and understand Dutch were not included in the study.

The mean age of the study group was 69 years. Approximately half of the participants was male, and two thirds were married. Most persons had an independent household, and did not live alone. One quarter of the participants had intermediate or higher education. Of the participants only $31 \%$ was of working age (aged below 65 years). The mean age of this subgroup was 55.1 years (sd. 9.3), 10 persons had paid labour, 4 persons were occupationally disabled (not due to hearing impairment), 5 persons had retired early, and 6 persons reported they managed a household. The average number of multi-morbidities was 3.2. The best ear average hearing loss at 1,2 and $4 \mathrm{kHz}$. was $47.4 \mathrm{~dB}$. Almost $80 \%$ was fitted with behind the ear hearing aids and $60 \%$ had binaural fitting. See table 1 . 
Table 1 Characteristics of the study population

\begin{tabular}{|c|c|c|}
\hline \multirow{2}{*}{ Characteristics } & \multicolumn{2}{|c|}{ Study population } \\
\hline & \multicolumn{2}{|c|}{ Age } \\
\hline Mean age in years $(S D)$ & $69.14(11.4)$ & \\
\hline Range & $28-95$ & \\
\hline \multicolumn{3}{|l|}{ Gender } \\
\hline Male & 44 & $56 \%$ \\
\hline \multicolumn{3}{|l|}{ Civil status } \\
\hline Married & 54 & $68 \%$ \\
\hline Widow / widower & 17 & $21 \%$ \\
\hline Not married & 9 & $11 \%$ \\
\hline \multicolumn{3}{|l|}{ Home situation } \\
\hline Alone & 18 & $23 \%$ \\
\hline With other persons in a household & 62 & $77 \%$ \\
\hline \multicolumn{3}{|l|}{ Living situation } \\
\hline Independent household & 76 & $95 \%$ \\
\hline Retirement home/nursing home / religious convent & 4 & $5 \%$ \\
\hline \multicolumn{3}{|l|}{ Education } \\
\hline Primary school & 26 & $33 \%$ \\
\hline Lower education & 32 & $40 \%$ \\
\hline Intermediate education & 16 & $18 \%$ \\
\hline Higher education & 6 & $9 \%$ \\
\hline \multicolumn{3}{|l|}{ Occupational status } \\
\hline Paid employment & 10 & $13 \%$ \\
\hline Occupational disabled & 4 & $5 \%$ \\
\hline Voluntary work & 6 & $8 \%$ \\
\hline Retired & 23 & $28 \%$ \\
\hline Taking care of household & 37 & $46 \%$ \\
\hline \multicolumn{3}{|l|}{ Multi-morbidity } \\
\hline Mean number of reported multi-morbidities (SD) & $3.2(2.0)$ & \\
\hline \multicolumn{3}{|l|}{ Hearing loss (in dB) } \\
\hline Best ear averaged hearing loss at $1,2,4 \mathrm{kHz}$. (SD) & $47.4(9.9)$ & \\
\hline Range & $27-80$ & \\
\hline \multicolumn{3}{|l|}{ Type of hearing aid fitted } \\
\hline Behind-the-ear & 62 & $79 \%$ \\
\hline In-the-ear & 14 & $18 \%$ \\
\hline In-the-canal & 2 & $3 \%$ \\
\hline Monaural/binaural hearing aid & $32 / 48$ & $40 / 60 \%$ \\
\hline
\end{tabular}

\section{Outcome measurement}

The interview consisted of questions concerning effects and costs associated with hearing disability and hearing aid use.

\section{Overall health related quality of life}

Overall quality of life was measured by the EuroQol 5 Dimensions (EuroQol Group, 1990). The EQ-5D is a widely accepted questionnaire to measure generic health related quality of life. The EuroQol consists of five items to describe the different dimensions of overall health state: mobility, self care, daily activities, pain and complaints, and feelings, one item concerned with 
health transition over the past year and a visual analogue scale, presented as a "feeling thermometer" to rate one's own health state. The descriptive items have three possible answers: 'no problems', 'moderate problems', ore 'severe problems'. The EuroQol has successfully been used in an elderly population (Brazier et al, 1996).

Social functioning, an aspect of generic HRQOL, was measured by four items. From the SF36, a questionnaire to measure generic HRQOL, the two items from the social functioning dimension were used (Brazier, 1993). The SF36 items are concerned with the period of 4 weeks preceding the interview. The SF36 is feasible in an elderly population (Brazier et al, 1996). Two other items regarding the quantity of social contacts were added: 1) how many persons visited you during the past 4 weeks, and 2 ) how often did you visit someone during the past 4 weeks.

\section{Subjective auditory disability and handicap}

Subjective hearing disability and handicap are indicators of hearing specific quality of life. The Amsterdam Inventory (Al) was used to measure these concepts. This questionnaire consists of 30 items dealing with a variety of everyday listening situations (Kramer et al, 1995). The Al includes five factors of subjective auditory disability and handicap: 'auditory localisation', 'detection of sounds', 'distinction of sounds', 'intelligibility in noise' and 'intelligibility in quiet'. The factor 'distinction of sounds' consists of eight items; the remaining factors consist of five items. Each item consists of three parts: how often the aspect of hearing disability was experienced ('almost never', 'occasionally', 'frequently', 'almost always'), former hearing performance, and how handicapped he or she feels when experiencing the mentioned situation ('no', 'slightly', 'moderately', 'considerably'). A handicap item is only posed when the participant has rated either 'almost never' or 'occasionally' for the corresponding disability item. In this study only the disability and handicap items were used, resulting in a disability sum score and a handicap sum score per factor. A higher score means more disability or handicap.

\section{Hearing aid satisfaction and use}

One item was used to assess subjective hearing aid satisfaction (answers: very satisfied, moderately satisfied, not satisfied). Two items were used to determine hearing aid use. The first item was used to assess whether the participant used the hearing aid: 'only occasionally', 'some days', 'most of the days', or 'every day'. The second item was associated with the average duration per episode of hearing aid use, possible answers were: 'only for short periods', 'less than half a day', 'more or less half a day', 'the biggest part of the day', or 'all day'. 


\section{Productivity loss}

Absence from paid labour and impediments to paid and unpaid labour were measured to assess productivity loss. For this purpose items from the Health and Labour Questionnaire (van Roijen et al, 1996) were adapted to be more appropriate for the hearing-impaired population in this study since this questionnaire was originally developed for a population suffering from migraine. There were three possible answers to the impediment items: 'hinder due to other health problems', 'hinder (also) due to hearing impairment', 'no hinder due to health problems'.

\section{Medical consumption}

tems concerning the amount of visits to the general practitioner, medical specialist, physiotherapist, or other health care professionals, hours per week home help, the use of a meal service, and the use of medication were used to assess medical consumption. All items concerned the six week period prior to the interview. Medical consumption associated with the hearing aid fitting procedure was not included.

\section{Statistical analysis}

The characteristics of the study population were presented using descriptive statistics. The scores on the descriptive items of the EQ-5D were recoded in a manner that a higher score means less problems. Based on the results of the Amsterdam Inventory, sum scores per factor of hearing disability or handicap were calculated. The distribution of the data was tested for normality. All results, except for loss of productivity, were presented as means (standard deviation) and median. Comparison of baseline scores and the scores after hearing aid fitting was conducted with the paired samples t-test when the data was normally distributed or the Wilcoxon signed ranks test when this was not the case. A p-value smaller than 0.05 was considered to be statistically significant. The scores on the items on loss of productivity before and after hearing aid fitting were presented as frequencies. All analyses were performed using the Statistical Package for the Social Sciences (SPSS).

\section{Results}

\section{Overall health related quality of life}

The only statistically significant change in overall quality of life as measured by the EQ-5D was observed in the feeling dimension at $T_{1}$. The other dimensions, and the feeling thermometer showed no statistically significant change after hearing aid fitting. See Table 2 and Figure 1. 
Table 2 Outcomes of measures of effect before and after hearing aid fitting (mean (SD), median and p-value)

\begin{tabular}{|c|c|c|c|c|c|c|c|c|c|c|c|}
\hline \multirow[b]{2}{*}{ Measure of effect } & \multicolumn{3}{|l|}{$\mathrm{T}_{0}$} & \multicolumn{2}{|l|}{$\mathrm{T}_{1}$} & \multicolumn{5}{|c|}{$\mathrm{T}_{2}$} & \multirow[b]{2}{*}{ P-value } \\
\hline & $\bar{N}$ & Mean (sd) & Median & $\mathrm{N}$ & Mean (sd) & Median & P-value & $\mathrm{N}$ & Mean (sd) & Median & \\
\hline \multicolumn{12}{|c|}{ Quality of life (EuroQol 5 Dimensions) } \\
\hline Mobility & 78 & $2.63(0.49)$ & 3.00 & 77 & $2.68(0.47)$ & 3.00 & 0.225 & 78 & $2.67(0.48)$ & 3.00 & 0.491 \\
\hline Self care & 78 & $2.91(0.29)$ & 3.00 & 77 & $2.94(0.25)$ & 3.00 & 0.705 & 78 & $2.90(0.30)$ & 3.00 & 0.739 \\
\hline Daily Activities & 78 & $2.81(0.43)$ & 3.00 & 77 & $2.78(0.45)$ & 3.00 & 0.439 & 78 & $2.78(0.47)$ & 3.00 & 0.686 \\
\hline Pain and complaints & 78 & $2.53(0.62)$ & 3.00 & 77 & $2.55(0.64)$ & 3.00 & 1.000 & 78 & $2.58(0.59)$ & 3.00 & 0.507 \\
\hline Feeling & 77 & $2.77(0.46)$ & 3.00 & 77 & $2.91(0.33)$ & 3.00 & 0.012 & 78 & $2.86(0.38)$ & 3.00 & 0.071 \\
\hline Health Transition & 78 & $2.01(0.52)$ & 2.00 & 77 & $2.00(0.58)$ & 2.00 & 0.970 & 78 & $2.05(0.55)$ & 2.00 & 0.718 \\
\hline \multicolumn{12}{|l|}{ Social functioning } \\
\hline SF36 Social Dimension $(1-10)$ & 78 & $9.15(1.62)$ & 10.00 & 75 & $9.61(1.24)$ & 10.00 & 0.062 & 78 & $9.69(1.09)$ & 10.00 & 0.008 \\
\hline Visits received last month & 78 & $1.70(0.81)$ & 1.00 & 76 & $1.54(0.68)$ & 1.00 & 0.110 & 78 & $1.64(0.72)$ & 1.50 & 0.561 \\
\hline \multicolumn{11}{|l|}{ Hearing specific health } & 0.507 \\
\hline Hearing specific VAS & 78 & $0.52(0.13)$ & 0.50 & 77 & $0.77(0.12)$ & 0.80 & 0.000 & 80 & $0.78(0.11)$ & 0.80 & 0.000 \\
\hline \multicolumn{12}{|c|}{ Auditory disability (Amsterdam Inventory) } \\
\hline Distinction of sounds $(0-24)$ & 70 & $3.74(4.34)$ & 2.00 & 75 & $2.20(3.41)$ & 1.00 & 0.005 & 64 & $1.72(3.28)$ & 0.00 & 0.002 \\
\hline Intelligibility in noise $(0-15)$ & 75 & $7.67(3.32)$ & 7.00 & 75 & $2.83(2.84)$ & 2.00 & 0.000 & 64 & $2.67(3.87)$ & 2.00 & 0.000 \\
\hline Intelligibility in quiet $(0-15)$ & 72 & $7.17(3.34)$ & 7.00 & 75 & $2.64(2.43)$ & 2.00 & 0.000 & 64 & $2.48(2.64)$ & 2.00 & 0.000 \\
\hline Auditory localization $(0-15)$ & 58 & $5.10(4.15)$ & 5.00 & 74 & $3.01(3.87)$ & 1.00 & 0.001 & 64 & $2.23(3.16)$ & 1.00 & 0.000 \\
\hline Detection of sounds $0-15$ ) & 78 & $4.55(3.04)$ & 4.00 & 75 & $1.40(2.03)$ & 1.00 & 0.000 & 64 & $1.14(2.10)$ & 0.00 & 0.000 \\
\hline \multicolumn{12}{|c|}{ Auditory handicap (Amsterdam Inventory) } \\
\hline Distinction of sounds $(0-24)$ & 1 & 16.00 (n.a.) & n.a & 0 & $\cdot$ & $\cdot$ & $\cdot$ & 0 & $\cdot$ & - & 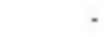 \\
\hline Intelligibility in noise $(0-15)$ & 6 & $8.33(1.86)$ & 9.00 & 1 & 9.00 (n.a.) & n.a & $\cdot$ & 2 & $9.50(0.71)$ & 9.50 & - \\
\hline Intelligibility in quiet $(0-15)$ & 2 & $9.50(0.71)$ & 9.50 & 0 & $\cdot$ & $\cdot$ & $\cdot$ & 1 & 9.00 (n.a.) & n.a & - \\
\hline Auditory localization (0-15) & 5 & $7.20(3.35)$ & 7.00 & 1 & 9.00 (n.a.) & n.a & $\cdot$ & 0 & : & - & - \\
\hline \multicolumn{11}{|l|}{ Hearing aid satisfaction and use } & $\cdot$ \\
\hline Satisfaction $(1-3)$ & & & - & 75 & $2.44(0.70)$ & 3.00 & $\cdot$ & 79 & $2.54(0.59)$ & 3.00 & . \\
\hline Frequency of use $(0-7)$ & & & - & 77 & $6.45(1.36)$ & 7.00 & - & 80 & $6.55(1.10)$ & 7.00 & - \\
\hline Duration of use $(0-14)$ & & & $\cdot$ & 77 & $11.84(3.17)$ & 14.00 & $\cdot$ & 80 & $\begin{array}{r}11.60 \\
(3.37) \\
\end{array}$ & 14.00 & - \\
\hline
\end{tabular}


The mean score on social functioning was already quite high before hearing aid fitting ( 9.15 on a scale from $1-10)$, indicating that the participants did not experience much hinder in social relationships. Nevertheless selfperceived social functioning improved after hearing aid fitting (statistically significant at $\mathrm{T}_{2}$ ). On average more social visits were paid than received. The quantity of social contacts did not change after hearing aid fitting. Table 2 and Figure 1.

Figure 1 Generic health related quality of life (EQ-5D) and social functioning (SF 36) before $\left(T_{0}\right)$ and after hearing aid fitting $\left(T_{1}, T_{2}\right)$, mean and $95 \%$ confidence interval
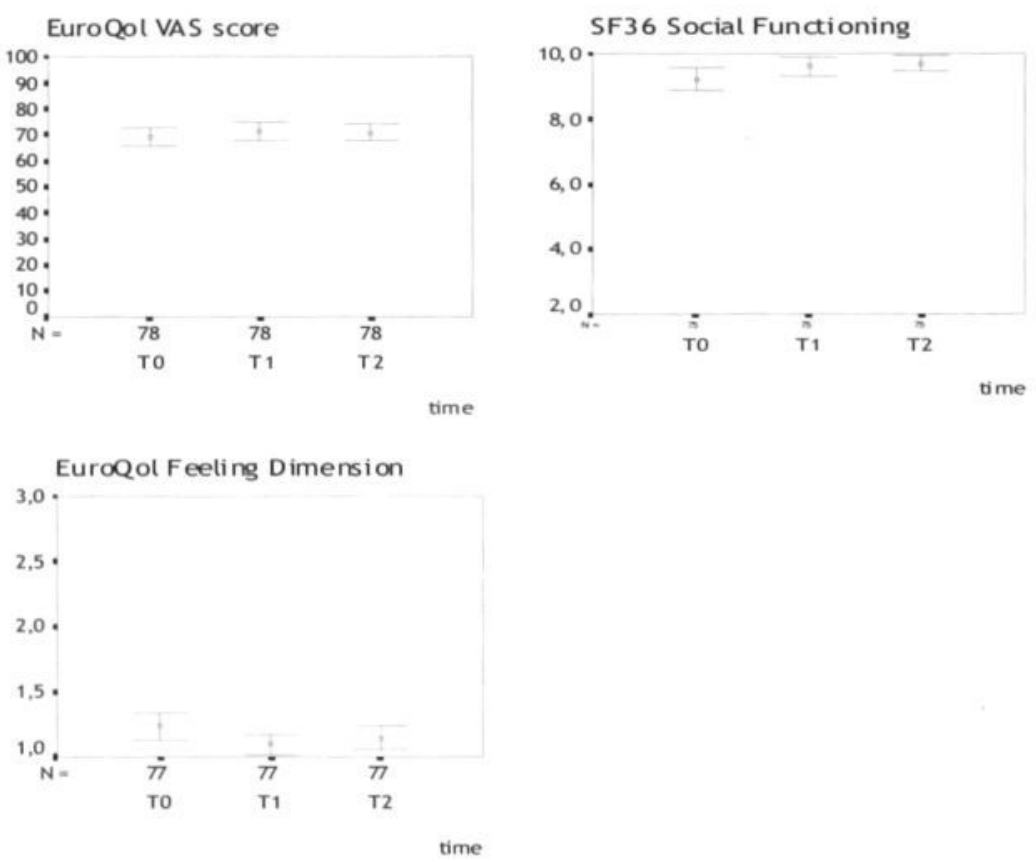

\section{Subjective auditory disability and handicap}

There was a statistically significant improvement in all factors of subjective auditory disability after hearing aid fitting. The median scores of the factors of subjective auditory disability were in the lower quartiles of the scale, indicating mild to moderate disability even before hearing aid fitting. As a result at baseline the hearing handicap part of the questionnaire was only administered to six participants. After hearing aid fitting only two persons filled out the hearing handicap items. Due to these small numbers no change in hearing handicap after hearing aid fitting could be reported. See Table 2 and Figure 2. 
Figure 2 Auditory disability scores before $\left(T_{0}\right)$ and after hearing aid fitting $\left(T_{1}, T_{2}\right)$ per dimension (Amsterdam Inventory) mean and $95 \%$ confidence intervals
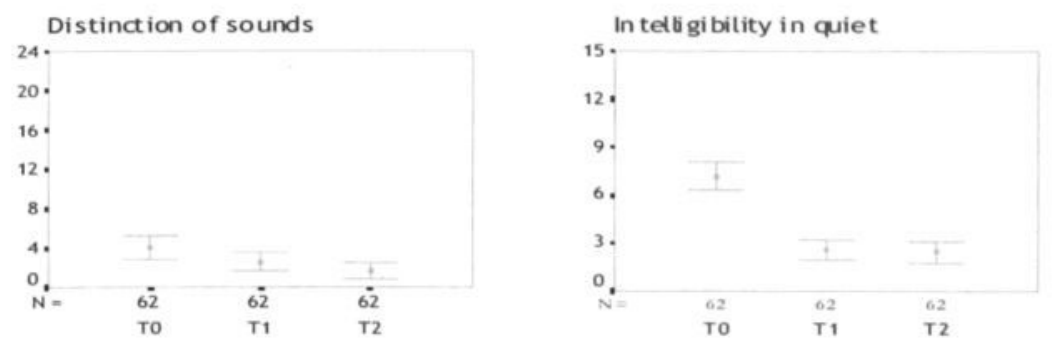

time
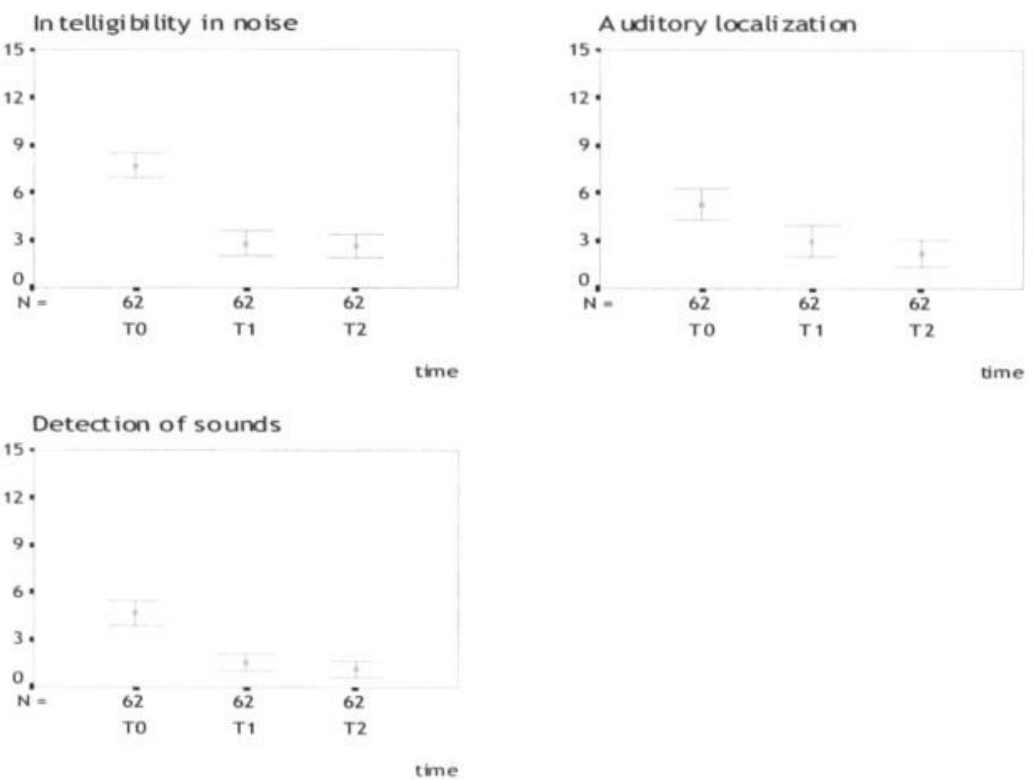

\section{Hearing aid satisfaction and use}

Self reported hearing aid satisfaction was high. The majority of the participants used their hearing aid the whole day. Table 2.

\section{Loss of productivity}

Only 10 participants performed paid labour $(12,5 \%)$. This seems normal after considering the age distribution of a population of adult first time hearing aid applicants. They did not report any absence from work due to hearing impairment or other health problems. At baseline 6 out of the 10 participants with paid labour reported they were in general hindered at work by health problems including hearing impairment. After hearing aid fitting only 2 of 
them reported this. With regard to the more specific items on paid labour, 2 participants reported experiencing problems with concentration at baseline, but not after hearing aid fitting. Prior to hearing aid fitting other problems at paid labour associated with hearing impairment than the ones mentioned in the items were reported by 2 participants. These problems were associated with attending group meetings and having consultations with employees. These problems were no longer reported after hearing aid fitting. Productivity at unpaid labour was frequently influenced by other health problems beside hearing impairment. Only six participants reported that unpaid labour was influenced by their hearing impairment. They mainly reported that they were hindered doing club and volunteer work. This did not change after hearing aid fitting. Table 3.

Table 3 Loss of productivity at paid and unpaid labour and medical consumption due to health problems before and after hearing aid fitting

(HI: hearing impairment, mdn: median)

\begin{tabular}{|c|c|c|c|c|c|c|c|c|}
\hline \multirow[b]{2}{*}{ Paid labour } & \multicolumn{4}{|c|}{$\mathrm{T}_{0}$} & \multicolumn{4}{|c|}{$\mathrm{T}_{2}$} \\
\hline & \multicolumn{3}{|c|}{$\begin{array}{r}\mathrm{N} \text { Yes Yes, (also) } \\
\text { due to } \mathrm{HI}\end{array}$} & No & \multicolumn{3}{|c|}{$\begin{array}{r}\mathrm{N} \text { Yes Yes, (also) } \\
\text { due to } \mathrm{HI}\end{array}$} & No \\
\hline Absence form work & 10 & 0 & $\overline{0}$ & 10 & 10 & $\overline{0}$ & $\overline{0}$ & $\overline{10}$ \\
\hline Hindered by health problems & 10 & 0 & 6 & 4 & 10 & 0 & 2 & 8 \\
\hline Problems concentrating & 10 & 1 & 2 & 7 & 10 & 0 & 0 & 10 \\
\hline Difficulty making decisions & 10 & 1 & 0 & 9 & 10 & 0 & 0 & 10 \\
\hline Secluded myself & 10 & 0 & 0 & 10 & 10 & 1 & 0 & 9 \\
\hline Others took over work & 10 & 1 & 0 & 9 & 10 & 1 & 0 & 9 \\
\hline Other problems at work & 10 & 1 & 2 & 7 & 10 & 0 & 0 & 10 \\
\hline Unpaid labour & \multicolumn{3}{|c|}{$\begin{array}{r}\mathrm{N} \text { Yes Yes, (also) } \\
\text { due to } \mathrm{HI}\end{array}$} & No & \multicolumn{3}{|c|}{$\begin{array}{r}\mathrm{N} \text { Yes Yes, (also) } \\
\text { due to } \mathrm{HI}\end{array}$} & No \\
\hline Others took over household tasks & 76 & 20 & 1 & 55 & 79 & 20 & 0 & 59 \\
\hline Hinde & 66 & 19 & 1 & 46 & 69 & 31 & 2 & 36 \\
\hline Hindered doing volunteer work & 44 & 9 & 5 & 30 & 45 & 10 & 6 & 29 \\
\hline Hindered in contact with (grand)children & 52 & 13 & 1 & 38 & 48 & 8 & 3 & 37 \\
\hline Hindered studying & 12 & 1 & 1 & 10 & 9 & 0 & 0 & 9 \\
\hline Hindered in other activities & 80 & 10 & 2 & 68 & 80 & 5 & 0 & 75 \\
\hline \multicolumn{9}{|l|}{ Medical consumption' } \\
\hline General practitioner $^{2}$ & 60 & & $.05(1.36)$ & 2.00 & 36 & & $67(0.96)^{3}$ & 1.00 \\
\hline Medical specialist ${ }^{2}$ & 71 & & $.24(2.49)$ & 2.00 & 32 & & $34(0.60)^{4}$ & 1.00 \\
\hline Physiotherapist $^{2}$ & 11 & & $.55(9.25)$ & 12.00 & 5 & & $.00(6.40)$ & 8.00 \\
\hline Other health care professionals & 63 & & $.50(2.89)$ & 1.00 & 33 & & $.67(4.81)$ & 2.00 \\
\hline Number of medications per day & 55 & & $.20(1.19)$ & 2.00 & 52 & & $.37(1.40)$ & 2.00 \\
\hline Hours home help per week & 15 & & $.57(1.53)$ & 3.00 & 13 & & $.81(1.60)$ & 3.00 \\
\hline Meal service & 7 & & - & - & 6 & & - & \\
\hline
\end{tabular}

'Medical consumption not associated with the hearing aid fitting procedure. ${ }^{2}$ Number of contacts over the past 6 weeks. ${ }^{3} \mathrm{p}$-value $=0.017$ (Wilcoxon signed ranks test). ${ }^{4} \mathrm{p}$-value $=0.012$ (Wilcoxon signed ranks test). 


\section{Medical consumption}

A large proportion of the participants had contacts with their GP (75\%), or one or more medical specialists (88\%). The participants used on average 2 to 3 medications. Professional home help was used by $19 \%$ of the participants. Only a small number of the participants received treatment from a physiotherapist or another (para)medical professional $(8 \%)$, or used a meal service $(9 \%)$. Both the number of persons that had had a consultation and the number of consultations per person with the GP and the medical specialist decreased after hearing aid fitting, after subtracting consultations associated with the hearing aid fitting procedure. Other measured aspects of medical consumption did not change after hearing aid fitting. Table 3.

\section{Conclusion and discussion}

The HRQOL of first time hearing aid applicants, as measured by the EQ-5D did not change after hearing aid fitting, except for a small improvement in the feeling dimension. Social functioning, as an aspect of generic HRQOL, did improve after hearing aid fitting, the quantity of social contacts did however not change. In contrast, the indicators of hearing specific HRQOL, auditory disability and handicap and hearing aid satisfaction and use, revealed substantial benefit after hearing aid fitting in this population of first time applicants. Although the EQ-5D was assessable in this population of elderly hearing-impaired persons, it could be concluded that the EQ-5D was not wellsuited to evaluate the effect of hearing aids on generic HRQOL. The EQ-5D could be useful to obtain a general description of this patient group for comparison towards other population groups.

The disability part of the Al proved to be sensitive to change in hearing disability after hearing aid fitting. Due to floor effects in the sum scores on the five dimensions, the hearing handicap part of the questionnaire was administered to only a small number of participants ( 6 persons). To further increase the responsiveness of the Al to evaluate hearing aid fitting in a population of moderately hearing-impaired individuals, the disability questions could in future be rephrased to minimize floor effects. To increase the response on the handicap questions, they could be administered regardless of the answer on the corresponding disability question. Overall, it could be concluded that the Al was suited to evaluate the effects of hearing aid fitting on hearing disability and handicap in a population of first time hearing aid applicants. The questionnaire seems however less well-suited for use in populations with mild hearing loss.

A substantial proportion of the participants reported problems at unpaid labour. These problems were mostly due to other health problems, and not 
due to hearing impairment. This does not seem counterintuitive when considering their age and morbidity status.

Ten participants $(12.5 \%)$ had paid labour, which seems representative for first time hearing aid applicants in the Netherlands, where labour participation in the age group 60 to 64 years old is 15\% (website Dutch Central Bureau of Statistics, www.cbs.nl). This is comparable to the rest of western Europe, but much smaller than in, for instance, Japan. Due to the small number of persons with paid labour in our study the conclusions concerning the amount of productivity loss among moderately hearing-impaired persons which could be avoided by fitting hearing aids should be interpreted with some caution. Nevertheless this study offers some indications regarding the quantity and origins of these productivity losses. Among first time hearing aid applicants absence from work due to hearing related problems does not seem to be a factor, since non of the participants reported sick leaf before or after hearing aid fitting. Of the persons with paid labour, 60\% (6 persons) reported hearing related problems in the work situation before hearing aid fitting. After hearing aid fitting only $20 \%$ ( 2 persons) reported these problems. This could indicate that hearing aids improve functioning at work for at least some moderately hearing-impaired persons. The past decade in the Netherlands labour participation in elderly age groups has increased, mainly because the labour participation of women has doubled. In countries where larger proportions of elderly people have paid work, and especially after the age of 65, the productivity losses (mainly due to loss of efficiency at work) are expected to be larger as would be the effect of intervention. For a better quantification of possible productivity savings after hearing aid fitting, a questionnaire covering specific problems of hearing-impaired persons with paid labour should be developed.

Medical consumption remained stable after hearing aid fitting. This result could be biased because persons with multiple health problems tend to cluster their contacts with medical specialists in order to save time and travel expenses. It is possible that, in the present study, the participants, out of convenience, visited other medical specialists on the same day they visited the ENT specialist in the process of hearing aid fitting, causing a clustering of medical consumption at baseline.

Overall, this study showed that hearing aid fitting in a population of moderately hearing-impaired individuals relieved problems in paid labour, but did not seem to affect unpaid labour. Medical consumption remained relatively stable over a period of 25 weeks after first time hearing aid fitting. The Amsterdam Inventory proved to be a useful questionnaire to assess the effects on hearing disability, as an indicator of hearing specific HRQOL. The effects of hearing aid fitting on generic HRQOL could not be determined with the EQ-5D, while hearing aid fitting did lead to an improvement in at least one aspect of generic HRQOL; namely social functioning. 


\section{Chapter 3}

Development of a questionnaire to measure hearing-related health state preferences framed in an overall health perspective 
Joore MA, Brunenberg DEM, Zank H, van der Stel H, Anteunis LJC, Boas GM, Peters HJM. The development of a questionnaire to measure hearing related health states framed in an overall health perspective. International Journal of Technology Assessment in Health Care, 2002; 18(3): 528-539. 


\section{Introduction}

This paper presents the development and use of a preference based instrument to evaluate generic health state: the Audiological Disabilities Preference Index (ADPI). Hearing impairment is a very common disorder, especially in elderly persons. In the Netherlands it affects up to $25 \%$ of the people aged over 55 years and more than $60 \%$ of the people older than 80 years (Chorus et al, 1995). In an ageing population, the number of hearingimpaired persons is likely to grow in the future decades. Several studies pointed out that hearing impairment is associated with social isolation, cognitive dysfunction, reduced self-reliance, loss of independence and depression (Appollonio et al, 1996; Jerger et al, 1995; Mulrow et al, 1990). In most cases a hearing aid is the only option for rehabilitation. In the light of the growing number of hearing-impaired persons and the increasing technological possibilities and price of hearing aids there is need for an economic evaluation of hearing aids. The effects of hearing aid fitting on health state should be determined with a measure that is both preferencebased and generic. A preference-based questionnaire provides the combination of scores on the items that leads to the highest overall health outcome. This is important in decisions regarding resource allocation. Moreover, in order to determine the cost-effectiveness of hearing aids relative to other health care interventions, the effect of hearing aids should be assessed with a questionnaire that is generic, but yet sensitive enough to detect relevant changes in health state after hearing aid fitting. Existing measures do not meet these requirements. The development of the ADPI addresses this gap.

The only generic questionnaires used to evaluate hearing aids are the Sickness Impact Profile and the Medical Outcomes Study Short Form 36 (Crandell, 1998). The SIP showed some improvement and the MOS SF-36 showed no change after hearing aid fitting. The MOS SF-36 is still in an experimental phase $^{4}$, and therefore not a first choice for a generic preference based measure. The widely accepted preference-based generic health state questionnaires, such as the Euroqol 5 Dimensions (EQ-5D; EuroQol Group, 1990), the Health Utility Index (HUI; Torrance et al, 1996) and the Quality of Well Being Scale (Kaplan \& Anderson, 1988), also seem less well suited to detect change in health state after hearing aid fitting for the following reasons. First, these questionnaires are rather general, and consequently less sensitive towards relatively small and specific changes in overall health state. Second, these questionnaires focus heavily on the physical dimension of health status, which is not likely to be influenced by hearing aid fitting. The $\mathrm{HUI}$ does contain a sensory dimension, but the scores on the hearing, speech and sight dimensions are clustered into the overall sensory dimension in a way that being both blind and deaf results in the same preference score as being blind only. As recently also stated by Cox, et $\mathrm{al}^{6}$ this result does not seem valid. Third, the presence of multi-morbidity could lead to a re-scaling of the 
impact of hearing impairment on the overall health state. The disutility of multiple disorders is not simply the sum of the disutilities of each disorder taken separately (Cox et al, 2000). The impact of multi-morbidity on overall health state could also fluctuate over time, for instance due to seasonal influences, and therefore bias the results of longitudinal studies.

To overcome the problems associated with the use of generic measures to assess hearing aid effect there is a number of specific descriptive questionnaires available, such as the Hearing Handicap Inventory for the Elderly (Ventry \& Weinstein, 1982), the Profile of Hearing Aid Benefit (Cox \& Rivera, 1992), the abbreviated version of the latter (Cox \& Alexander, 1995), the Hearing Aid Performance Inventory (Schum, 1993), the Amsterdam Inventory for Auditory Disability and Handicap (Kramer et al, 1995), and the Client Oriented Scale of Improvement (Dillon et al, 1997). These questionnaires are without doubt sensitive to changes after hearing aid fitting, but not suited to assess gain in health state for use in economic evaluations because the outcomes are not preference based, do not provide a single index, and are not generic. The ADPI was developed to provide preferences of health states associated with hearing impairment, that could be framed in overall health in order to make comparisons with other conditions. The results of the ADPI would be useful to quantify and interpret preferences for outcomes after the rehabilitation of hearing impairment, and to conduct cost-effectiveness analysis of the rehabilitative options for hearing impairment.

The overall hypothesis tested in this study was whether the ADPI was a suitable measure to evaluate the effect of hearing aid fitting on hearing specific and on generic health state. This hypothesis was investigated in an intervention study of hearing aid fitting in hearing-impaired adults. The objectives were to 1) gain experience with the use of a preference based questionnaire in an elderly hearing-impaired population, 2) to assess gain in health state preference after hearing aid fitting, 3 ) to evaluate the reliability of the ADPI using hypothetical marker states, and 4) to compare the results of the ADPI with the EQ-5D.

\section{Methods}

\section{Development of the ADPI}

The ADPI consists of a description of the hearing specific health state, the valuation of the hearing specific health state on a visual analogue scale and the transformation from the hearing specific scale to an overall health state scale. 
In the ADPI the health state under investigation was subjective hearing disability. The Amsterdam Inventory, a questionnaire on subjective hearing disability developed by Kramer et al (1995), was used to obtain descriptions of the domains of subjective hearing disability. This questionnaire was chosen from the available specific questionnaires for the following reasons. To our knowledge the Amsterdam Inventory was the only questionnaire on subjective hearing disability in which different dimensions of hearing disability and handicap had been identified by factor analysis. Furthermore, a European questionnaire seemed the most appropriate for this study, since communication and public activities are likely to differ across cultures. Another reason to use this questionnaire was the availability of a validated Dutch version. The five factors from the Amsterdam Inventory ("auditory localisation", "detection of sounds", "distinction of sounds", "intelligibility in noise", and "intelligibility in quiet"), had substantial correlations with performance measures of auditory disability such as hearing threshold level, speech reception in quiet and speech reception in noise. ${ }^{16}$ The factor distinction of sounds consisted of eight questions; the remaining factors consisted of five questions. For each subjective hearing disability factor, the question with the highest loading was used in the hearing health state description. Since the Amsterdam Inventory has proven to be a valid measure of subjective auditory disability it was assumed that the items used in the health state description were valid markers of the concept of subjective auditory disability and handicap. Every question had three possible answers: no problems, moderate problems and severe problems. The main reason to choose for a three-point scale was to limit the number of possible hearing specific health states to a maximum of 243 health states (three options, 5 factors: $3^{5}=243$ ).

\section{Hearing specific health state valuation}

As the ADPI was designed for use in an elderly hearing-impaired population, the visual analogue scale, being the least difficult method of preference determination, seemed most suitable for health state preference measurement. Because the described health state concerned hearing, the end points of the specific visual analogue scale were formulated as "deaf" and "perfect sense of hearing" instead of worst and best imaginable health state. The respondents valued their own level of subjective hearing disability on this visual analogue scale, which resulted in hearing specific health state preferences. Two hypotheses regarding the construct validity of the specific health state valuation were formulated. A low correlation between the hearing related health state preference and hearing loss was predicted. Hearing loss was defined as the best ear pure tone average hearing loss (BEPTA) at 1, 2 and $4 \mathrm{kHz}$ and was assessed by pure tone audiometry. The weak relationship between audiologically detected hearing loss (impairment) 
and hearing disability has been reported (Bess et al, 1991; Mulrow et al, 1990). The correlations between reported degree of satisfaction with the hearing aid and the change in hearing related health state preference at the two follow up measurements was predicted to be moderate.

\section{Framing the hearing specific health state preferences in overall health}

Since the end points of the hearing specific visual analogue scale ("deaf" and "perfect sense of hearing") are also points on the overall health state scale (ranging from "worst imaginable health state" to "best imaginable health state"), there is a relation between both scales. The valuations of the end points of the specific visual analogue scale were used as reference points in the positive linear transformation of the hearing specific health state preference to the overall health state scale. Hereby the hearing specific health state preferences were framed in the concept of overall health. This has been recommended by Gold et al (1996). The transformation of the hearing related health state preference to the overall health state scale was performed in two ways. In the first transformation the assumption was made that the health state "perfect sense of hearing" on the hearing specific scale was equal to the "best imaginable health state" on the overall health state scale (e.g. equal to 1). All health problems except those associated with hearing (multi-morbidity) were discounted for. To derive overall health state preferences without the presence of multi-morbidity the formula 1 was used ("P" is "preference"):

$P_{\text {Transformed Health State }}=P_{\text {Hearing Related Health State }}\left[1-P_{\text {Deaf }}\right]+P_{\text {Deaf }}$

Since hearing impairment is a condition most commonly in elderly persons, who are likely to suffer from multi-morbidity, the situation in the first transformation seemed inadequate. It seemed more realistic to assign a value to the "perfect sense of hearing" health state equal to the maximum health state a hearing-impaired population would be able to reach when the hearing impairment would be fully corrected. In the second transformation the health state "perfect sense of hearing" on the specific scale was assumed equal to the overall health state preference of an age-matched population without hearing related health problems. Formula 2 for the transformation from the hearing specific scale to the overall health state scale, when taking the presence of multi-morbidity into account was as follows ("P" is "preference"):

(2)

$P_{\text {Transformed Health State }}=P_{\text {Hearing Related Health State }}\left[P_{\text {No Hearing Related Health Problem }} \cdot P_{\text {Deaf }}\right]+P_{\text {Deaf }}$ 


\section{Hypothetical marker states}

The valuation of "deaf" on the overall health state scale was determined by asking the participants in the before-after hearing aid fitting study to value "deaf" on a visual analogue scale ranging from zero is "worst imaginable health state" to 1 is "best imaginable health state". To determine the testretest reliability of the valuation of the hypothetical health state "deaf", the participants of the present study were asked to value "deaf" on the visual analogue scale at all three measurement occasions. For each person the mean valuation of "deaf" over all three measurements was used in the transformation. Because of the possibility that the hearing aid intervention would cause a shift in the perception of "deaf" among participants, some additional hypothetical marker states were added to the questionnaire. The participants were asked to value the following hypothetical marker states: "mild asthma" (the use of medication is necessary, but an attack of tightness of the chest occurs seldom), "severe heart failure" (little physical activity leads to severe complaints, such as tightness in the chest, chest pain and fear of dying) and "blind" (not able to see anything). The marker states served as anchor points for mild ("mild asthma") and more severe ("severe heart failure" and "blind") health states. It was assumed that when the respondents attached values to the hypothetical marker states that would not differ too much from valuations found in the literature the respondents would also be able to attach a value to their own hearing related health state. The value of "mild asthma" was expected to lie between 0.80 and 0.90 (Mittmann et al, 1999), that of "severe heart failure" between 0.30 and 0.40 and "blind" between 0.40 and 0.50 (Gold et al, 1998). Overall it was hypothesized that respondents would attach the lowest valuations to the marker state "severe heart failure", more or less the same valuations to the marker states "deaf" and "blind" and the highest valuations to the marker state "mild asthma".

The valuation of the health state "perfect sense of hearing" was assumed to be equal to the overall health state preference of a population without hearing-related problems. This value was determined in a cross-sectional study.

\section{Prospective evaluation study}

\section{Study design}

The study was an prospective evaluation study with a baseline measurement and two follow-up measurements. The baseline measurement took place directly after receiving the hearing aid prescription and obtaining written informed consent. The intervention consisted of the process of hearing aid fitting, following normal procedure in the Netherlands. The first follow up measurement $\left(T_{1}\right)$ took place when a satisfactory hearing aid was fitted by the hearing aid dispenser, and the second follow up measurement $\left(T_{2}\right)$ was scheduled 4 months after baseline. Trained audiology assistants conducted 
audiometry and administered the ADPI, the EQ-5D, questions on hearing aid satisfaction and a series of demographic questions in face-to-face interviews, taking place at the ENT clinic or Audiology Centre.

\section{Study sample}

Patients were eligible for the study if they: 1 ) were aged 18 years or older, 2) lived in the Netherlands, 3) received a prescription for a hearing aid at the Ear, Nose, and Throat (ENT) clinic of the Maastricht University Hospital or the Hoensbroeck Audiology Centre, and 4) had not used a hearing aid for the past five years. In the Netherlands persons entitled to a hearing aid prescription meet the following requirements: pure tone audiometry with an averaged hearing loss of at least $35 \mathrm{~dB}$ at 1,2 and $4 \mathrm{kHz}$ in the best ear, hearing loss is due to inner ear pathology without indications of retro-cochlear malignancies and there are no contra-indications for hearing aid use (such as draining ears or ear canal pathology). Persons not mentally capable of answering the questionnaires, not able to come to the hospital, or not able to speak and understand Dutch were not included in the study either.

\section{EuroQol 5 Dimensions}

The EuroQol 5 Dimensions (EQ-5D) is a short comprehensive measure to evaluate the effect of health care interventions on the health state. It consists of two parts; the first part consists of five questions describing health state, the second part is presented as the EQ-5D feeling thermometer: a visual analogue scale.

The following a priori hypotheses about the size of the gain in health state preference after hearing aid fitting measured with the EQ-5D visual analogue scale and the correlation with the change in health state as measured with the ADPI were formulated. The gain in health state as measured by the EQ-5D was expected to be small. Correlation between hearing related health state preference and the EQ-5D visual analogue score was predicted to be low.

The valuation of the "perfect sense of hearing" health state was based on the results of a cross-sectional study in a GP practice carried out by the SIHI Study Group (1999). The non hearing disabled part of the study population was identified by asking the question "How is your sense of hearing?" (answering options: poor, moderate, good). Persons who answered "good", were considered to be not hearing disabled. Hereafter, pure tone audiometry was performed, information on demographic variables was collected and the EQ$5 \mathrm{D}$ was administered. The mean score on the EQ-5D of the non-hearing disabled subgroup was considered as an estimation of the "perfect sense of hearing" health state. A total of 245 persons of 55 years and older were included. 


\section{Statistical analysis}

The scores on the EQ-5D were recoded so that a higher score means better functioning. Comparison of means was conducted with the paired samples ttest or the Wilcoxon signed ranks test. The stability of the marker states was assessed using Pearson correlations and intraclass correlation coefficients (ICC). The strength of the relationship between the hearing related health state preference and the EQ-5D, hearing loss and hearing aid satisfaction was assessed by Pearson correlations. A p-value smaller than 0.05 was considered to be statistically significant. All analyses were performed using the Statistical Package for the Social Sciences (SPSS).

\section{Results}

\section{Description of the study populations}

From February 1998 to March 1999126 patients were enrolled in the study (28\% attended the University Hospital and $72 \%$ attended the Audiological Centre). $\mathrm{T}_{1}$ took place on average at 12 weeks after baseline (median 11 weeks). Although some range in the duration of the first follow up period was inherent to the design, the average duration of the follow up period was longer than the anticipated 6 weeks. Therefore $T_{2}$, scheduled at 4 months after baseline, was rescheduled for some patients to be at least 6 weeks after $T_{1} . T_{2}$ took place on average at 25 weeks after baseline (median 24 weeks, range 30 weeks). To test whether the range in duration of follow up influenced the results, Pearson correlations between the duration of the follow up (in number of weeks) and the change in hearing specific health state (VAS-score) of the corresponding period were calculated. The correlation between the duration of the first follow up period and the change in hearing specific VAS score in that period was low, $-0.226(p=0.027)$. The correlations between the duration of follow up and the change in specific VAS score from $T_{1}$ to $T_{2}$ (correlation coefficient $0.048, p=0.690$ ), and from baseline to $T_{2}$ (correlation coefficient $-0.056, \mathrm{p}=0.634$ ) were close to zero. Altogether, duration of follow up did not seem to affect the results on the specific VAS.

After baseline 28 patients left the study. The largest part left the study because they decided not to be fitted with a hearing aid (14 persons), 7 persons were lost to follow up, 5 persons left the study on their own request, one persons was ill at the time of the measurement, and one person deceased. After $T_{1}$ another 20 persons left the study. Of these 3 decided not to keep their hearing aid, 1 person deceased, 1 person missed the appointment for $\mathrm{T}_{2}$ due to illness, 9 persons left the study on their own request and 6 persons were lost to follow-up. Overall the persons who left the study were somewhat younger and had somewhat better hearing. A total of 78 
persons completed the third and final measurement. There was a large range in age among the participants: the youngest was 29 years and the oldest 96 years old, and the mean age was 69.14 years. The mean hearing loss was $47.37 \mathrm{~dB}$ at 1,2 and $4 \mathrm{kHz}$ in the best ear. There were slightly more male participants. Multi-morbidity was rather common; only 7 persons reported no multi-morbidity, 41 persons presented $1-3$ morbidities and 30 persons more than 3 morbidities besides hearing impairment. Most of the persons were fitted with behind-the-ear hearing aids $(\mathrm{N}=62)$, in-the-ear hearing aids were fitted in 14 cases and only two persons were fitted with an in-the-canal hearing aid.

Of the 245 persons who were interviewed at the GP practice to determine the value of the overall health state of the age-matched group without hearing related problems, 90 persons valued their hearing as "good". The mean age of this group was 71.67 years (SD 8.65, median 72 ), which was comparable to the mean age in the intervention study. Mean averaged hearing loss of the best ear at $1,2,4, \mathrm{kHz}$ was $27 \mathrm{~dB}$ (SD 11.85, median $25 \mathrm{~dB}$, range $62 \mathrm{~dB}$ ).

\section{ADPI results}

\section{Gain in hearing specific health state}

After hearing aid fitting, the mean scores on the first five questions, addressing aspects of hearing related health states, showed a statistically significant reduction. The largest improvements were found in "detection of sounds" and "intelligibility in quiet", the smallest improvement in "intelligibility in noise". Prior to hearing aid fitting the average value for the hearing specific health state was 0.51 points. At $T_{1}$ and $T_{2}$ the scores were almost equal: respectively 0.77 and 0.78 points. The improvement compared to baseline was approximately $27 \%$ and statistically significant, p-value < 0.0005 . Change in hearing related health state from baseline to $T_{2}$ and hearing loss (BEPTA) were not correlated $(r=-0.066)$. The correlation between gain in hearing related health state and reported degree of satisfaction with the hearing aid at the second follow up measurement was higher $(r=0.389, p<$ $0.01)$. Table 1.

\section{Framing the hearing specific health state preferences in overall health}

The average value of the health state "deaf" over all three measurements was 0.30 , in the formulas the average value of "deaf" per person was used. In the cross-sectional study the mean score on the EQ-5D visual analogue scale of the group without hearing related problems (the valuation of the "perfect sense of hearing" health state) was $0.73(s d=0.16$, median 0.75$)$.

When using formula 1 (transformation in absence of multi-morbidity) the mean hearing specific health state preference at baseline $(0.51)$ corresponded 
with a mean health state preference of 0.66 . When formula 2 (transformation with the presence of multi-morbidity) was used, 0.51 corresponded with a mean health state preference of 0.52 . The hearing specific health state preference at $T_{1}(0.77)$ corresponded with health state preferences of 0.85 (in absence of multi-morbidity) and 0.64 (with multi-morbidity). At $T_{2}$ the scores were almost the same. The paired difference between baseline and $T_{1}$ was $19 \%$ (in absence of multi-morbidity) and $12 \%$ (in presence of multi-morbidity). Both paired differences were statistically significant $(p=0.000)$. The paired differences from baseline to $T_{2}$ were similar. See Table 1 .

Table 1 ADPI results

\begin{tabular}{|c|c|c|c|c|c|c|c|c|c|}
\hline & \multirow[b]{2}{*}{$\mathrm{N}$} & \multicolumn{2}{|l|}{$\overline{T_{0}}$} & \multicolumn{3}{|l|}{$\overline{T_{1}}$} & \multicolumn{3}{|l|}{$\overline{T_{2}}$} \\
\hline & & Mean & Sd & Mean & Sd & p-value ${ }^{4}$ & Mean & Sd & p-value ${ }^{4}$ \\
\hline \multicolumn{10}{|l|}{$\overline{\text { Description }}$} \\
\hline Detection of sounds & 78 & 1.99 & 0.44 & 2.92 & 0.27 & 0.000 & 2.88 & 0.36 & 0.000 \\
\hline Intelligibility in quiet & 78 & 1.91 & 0.40 & 2.87 & 0.34 & 0.000 & 2.94 & 0.25 & 0.000 \\
\hline Intelligibility in noise & 78 & 1.95 & 0.39 & 2.51 & 0.68 & 0.000 & 2.35 & 0.63 & 0.000 \\
\hline Auditory localisation & 78 & 2.15 & 0.55 & 2.62 & 0.55 & 0.000 & 2.66 & 0.56 & 0.000 \\
\hline \multirow[t]{2}{*}{ Distinction of sounds } & 78 & 2.38 & 0.57 & 2.84 & 0.46 & 0.000 & 2.87 & 0.34 & 0.000 \\
\hline & $\mathrm{N}$ & $\overline{\text { Mean }}$ & Sd & Mean & Sd & $\begin{array}{l}\text { Paired } \\
\text { Difference }\end{array}$ & Mean & Sd & $\begin{array}{l}\text { Paired } \\
\text { Difference }\end{array}$ \\
\hline \multicolumn{10}{|l|}{$\overline{\text { Preferences }}$} \\
\hline Hearing related VAS & $76^{2}$ & 0.51 & 0.13 & 0.77 & 0.11 & $0.26^{5}$ & 0.78 & 0.11 & $0.27^{5}$ \\
\hline Transformed VAS Formula 1 & $73^{3}$ & 0.66 & 0.13 & 0.85 & 0.09 & $0.19^{5}$ & 0.85 & 0.07 & $0.19^{5}$ \\
\hline Transformed VAS Formula 2 & $73^{3}$ & 0.52 & 0.10 & 0.64 & 0.06 & $0.12^{5}$ & 0.64 & 0.05 & $0.12^{5}$ \\
\hline
\end{tabular}

${ }^{1}$ Minimum is 1 and maximum is $3 ;{ }^{2}$ Two persons did not complete the condition specific scale at $\mathrm{T}_{1} ;{ }^{3}$ Five persons did not value the health state "deaf" all three measurements; ${ }^{4}$ Wilcoxon Signed Ranks Test; ${ }^{5}$ Paired difference statistically significant at the 0.000 level (Paired Samples T-Test)

\section{The marker states in the ADPI}

Some participants found it difficult to attach values to the hypothetical marker states, which led to some missing values. A total of 68 respondents valued all marker states at $T_{0}, T_{1}$ and $T_{2}$. At baseline the mean valuation of the marker state "deaf" was 0.29 points with a standard deviation of 0.20 . The same question was asked at $T_{1}$ and $T_{2}$ and the valuations were respectively 0.33 (sd. 0.22 ) and 0.29 (sd. 0.17 ). The differences were not statistically significant. The valuations of "mild asthma" at baseline and the two follow ups were $0.62,0.67$ and 0.67 , respectively. The valuation at baseline was lower than the valuation at follow up, but this was not statistically significant. The valuations of "severe heart failure" $(0.19,0.17$ and 0.19 , respectively) and "blind" $(0.17,0.17$ and 0.14 respectively) did not differ statistically significantly either. 
Table 2 Marker state results (mean (sd), Pearson correlation coefficients, and Intraclass correlation coefficients

\begin{tabular}{|c|c|c|c|c|c|c|c|c|c|c|c|c|}
\hline & \multicolumn{3}{|c|}{ Deaf } & \multicolumn{3}{|c|}{$\begin{array}{c}\text { Mild } \\
\text { Asthma } \\
\end{array}$} & \multicolumn{3}{|c|}{$\begin{array}{c}\text { Severe } \\
\text { Heart Failure }\end{array}$} & \multicolumn{3}{|c|}{ Blind } \\
\hline & $\mathrm{N}$ & Mean & Sd & $\mathrm{N}$ & Mean & Sd & $\mathrm{N}$ & Mean & Sd & $\mathrm{N}$ & Mean & Sd \\
\hline$\overline{T_{0}}$ & 77 & 0.29 & 0.20 & 77 & 0.62 & 0.18 & 77 & 0.19 & 0.20 & 77 & 0.17 & 0.21 \\
\hline $\mathrm{T}_{1}$ & 71 & 0.33 & 0.22 & 72 & 0.67 & 0.15 & 70 & 0.17 & 0.18 & 72 & 0.17 & 0.24 \\
\hline \multirow[t]{2}{*}{$T_{2}$} & 72 & 0.29 & 0.17 & 73 & 0.67 & 0.12 & 72 & 0.19 & 0.20 & 73 & 0.14 & 0.21 \\
\hline & $\mathrm{N}$ & $R^{T}$ & $p$-value & $\mathrm{N}$ & $R^{1}$ & $\mathrm{p}$-value & $\mathrm{N}$ & $\mathrm{R}^{\top}$ & p-value & $\mathrm{N}$ & $\overline{R^{\prime}}$ & p-value \\
\hline$T_{0}-T_{1}$ & 72 & .235 & 0.047 & 71 & .235 & 0.048 & 70 & .144 & 0.233 & 72 & .103 & 0.388 \\
\hline$T_{0}-T_{2}{ }^{1}$ & 73 & .237 & 0.005 & 72 & .120 & 0.317 & 72 & .364 & 0.002 & 73 & .367 & 0.001 \\
\hline \multirow[t]{2}{*}{$\mathrm{T}_{1} \cdot \mathrm{T}_{2}{ }^{1}$} & 70 & .408 & 0.000 & 68 & .225 & 0.065 & 67 & .498 & 0.000 & 70 & .561 & 0.000 \\
\hline & $\mathrm{N}$ & $\mathrm{ICC}^{2}$ & $p$-value & $\mathrm{N}$ & $\mathrm{ICC}^{2}$ & $p$-value & $\mathrm{N}$ & $\mathrm{ICC}^{2}$ & p-value & $\mathrm{N}$ & $\mathrm{ICC}^{2}$ & $\mathrm{p}$-value \\
\hline $\mathrm{T}_{0}-\mathrm{T}_{1}-\mathrm{T}_{2}$ & 70 & .570 & 0.000 & 68 & .434 & 0.003 & 67 & .594 & 0.000 & 70 & .606 & 0.000 \\
\hline
\end{tabular}

${ }^{1}$ Pearson correlation coefficients; ${ }^{2}$ Average measure intraclass correlation coefficients

The stability of the marker states was assessed using Pearson correlation coefficients and the average intraclass correlation coefficient (ICC). Both the Pearson correlation coefficients and the ICCs were low to moderate, which was indicative of a large variation in individual scores. The marker state "mild asthma" had lower Pearson correlation coefficients and ICC's than the other marker states. The marker state "mild asthma" had, as expected, the highest valuation, but the valuations were not as high as had been assumed (between 0.62 and 0.67 rather than between 0.80 and 0.90 ). The valuations of the marker state "severe heart failure" (between 0.17 and 0.19 rather than between 0.30 and 0.40 ) and "blind" (between 0.14 and 0.17 rather than between 0.40 and 0.50 ) were also lower than assumed. Table 2. All respondents attached the highest valuation at "mild asthma", and 35 respondents attached the lowest valuation at "severe heart failure". "Blind" was valued as the worst marker state by 27 respondents, and "deaf" by 6 respondents.

\section{EQ-5D results}

The scores on the first five questions of the EQ-5D regarding the dimensions of overall health showed only little change over the three measurements. Only the feeling dimension improved statistically significantly from baseline to $T_{1}$. The results on the visual analogue scale of the EQ-5D showed slight improvement after the hearing aid fitting (paired differences 0.02). These improvements were however not statistically significant (table 3 ). The correlation between change in hearing related health state and change on the EQ-5D visual analogue was -0.039 . 


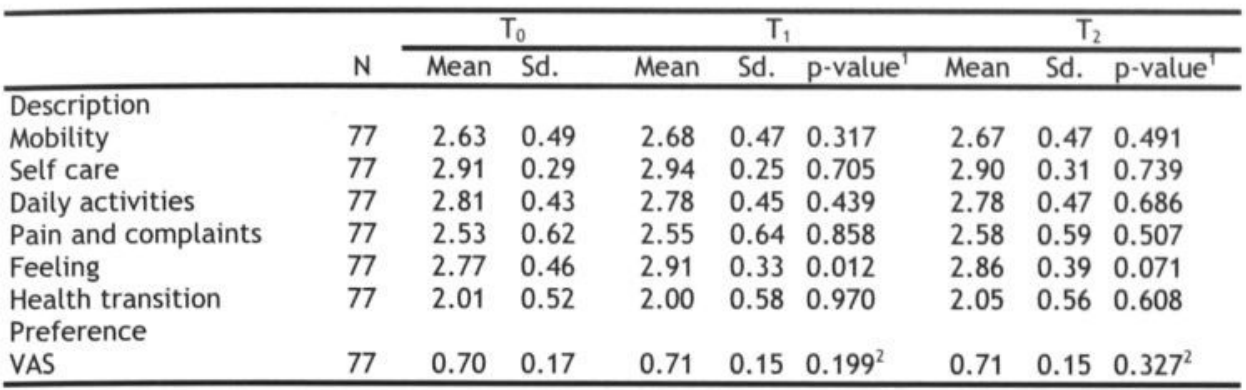

'Wilcoxon Signed Ranks test; ${ }^{2}$ Paired Samples T-Test

\section{Conclusion and discussion}

The aim of this study was to develop a preference-based questionnaire to determine health state preferences associated with hearing disabilities. The ADPI proved to be practical to use, even in an elderly hearing-impaired population, considering its shortness and the low number of missing values. In the intervention study, gain in health state preference after hearing aid fitting was assessed. All aspects of subjective hearing disability showed a significant improvement after hearing aid fitting. It seemed plausible that the largest improvement was found in the aspects "detection of sounds" and "intelligibility in quiet", and the smallest improvement in "intelligibility in noise", since hearing aids are more effective in situations with little background noise. The hearing specific visual analogue scale of the ADPI showed an improvement of $27 \%$ after hearing aid fitting. As expected, correlation of hearing specific health state with hearing loss was low, while correlation with reported degree of hearing aid satisfaction was higher. This indicates that the construct validity of the ADPI was satisfactory. The equivalent of the gain on the hearing specific scale on the generic scale was 0.12 . Under the influence of multi-morbidity the gain on the generic scale decreased with 0.07 (from 0.19 to 0.12 ). In general, scores on the ADPI showed that hearing aid fitting was effective in solving hearing related problems, and that the scale was sensitive to this change.

The reliability of the ADPI was investigated using the valuations of the hypothetical marker states. The mean valuations of the marker states were similar, and the ranking of the marker states was in concordance with expectation. The large individual variation of the valuations of the hypothetical marker states found in this study was consistent with other studies (Bennett et al, 1997; Torrance, 1986). The valuations of the marker states were all considerably lower than had been expected based on 
literature. This could indicate that the values respondents attached to their own hearing related health state were also quite low. A possible explanation could be found in the fact that respondents had only recently admitted to themselves, and their family and friends, that they were hearing-impaired and in need of a hearing aid. As a result they might have increased their perception of the relative seriousness of health states related to hearing problems. This hypothesis could however not be supported by the results of other studies.

The transformed health state outcomes of the ADPI were quite sensitive towards the valuations of the health states that marked the endpoints of the hearing-specific scale. Therefore, a careful choice of the population used for the valuation of the endpoints seemed important. A major advantage of the transformation is that the influence of multi-morbidity on change in generic health state is revealed and held constant during the period of intervention. The underlying assumption was that no interaction between the impact of hearing impairment and the impact of other health problems on overall health state preferences was present. This assumption is questionable, and further research is necessary to investigate the relation between the specific health problem under investigation and other health problems that may be present. As expected the EQ-5D did not show a statistically significant effect of hearing aid fitting on generic health state. Only the question regarding "feelings" showed improvement after hearing aid fitting (statistically significant at $T_{1}$ ). The correlation between the score on the hearing specific visual analogue scale of the ADPI and the score on the EQ-5D visual analogue scale was, as expected, low.

\section{Policy implications}

The merits of condition-specific preference-based instruments relative to descriptive ones have been recognized by other authors as well, and this has led to the development of preference-based instruments such as the McKnee for patients undergoing total knee replacement Bennett et al, 1997), and the Rhinitis Symptom Index and the Asthma Symptom Index (Revicki et al, 1998a; Revicki et al, 1998b). The outcomes of specific preference-based questionnaires can be used in cost-effectiveness analyses that provide information for resource allocation decisions within patient groups.

The lack of sensitivity of the existing generic preference based instruments could become a larger problem in the future, as it is likely that in the future CEA will be more frequently performed for medical interventions that lead to relatively small changes in quality of life and no change in the duration of life. Not being able to detect small effects of these interventions in particularly elderly persons can lead to biases in cost-effectiveness ratios, and therefore in underestimating the cost-effectiveness of interventions for these substantial patient groups. 
Three features of the ADPI are innovative. First, since the aspects of subjective hearing disability are associated with technical aspects of hearing aid performance, the relative contribution of each of these aspects to the (change in) hearing specific health state could indicate the relative importance of certain features of hearing aids for hearing aid users. This information is useful for clinical decision models about hearing aid fitting, and research and development of hearing aid technologies. The allocation of the weights per aspect can be achieved by using the method of egalitarian evaluation (Peters \& Zank, 1999). A paper concerning the outcomes of this allocation for the population described in the present study is in preparation. Second, the ADPI provides specific health state preferences as well as specific preferences framed in overall health. The advantage of this method is that change in health state is measured on a scale that is most suited for the purpose of the study, but also interpretable on a generic scale. The method of framing specific health state preferences in overall health could be applied to other specific health problems as well. Further research needs to be done to determine whether 'framed' health state preferences are suited for mutual comparison when different health problems are concerned and hence different end-points of the specific VAS are used. Third, the descriptive part of the ADPI could also be useful as a taxonomic health state description in population surveys to determine population preferences for hearing related health states.

In summary, the ADPI is a feasible preference based measure to obtain direct preferences for hearing related health states, framed in overall health. These health state preferences are needed for clinical decision making and economic evaluation studies about rehabilitative options for audiological disabilities. The complex relation between specific and generic quality of life, further complicated by the presence of multi-morbidity, should however be an area of further research. 



\section{Chapter 4}

Response shift in the measurement of quality of life after hearing aid fitting in hearing-impaired adults 
Joore MA, Potjewijd J, Timmerman AA, Anteunis LJC. Response shift in the measurement of quality of life in hearing impaired adults after hearing aid fitting. Quality of Life Research. 2002; 11: 299-307. 


\section{Introduction}

Hearing disability is one of the most common chronic health problems in western society, especially among the elderly. In the Netherlands $25 \%$ of the people aged over 55 years are hearing disabled (Chorus et al, 1995). In elderly persons, hearing impairment is in most cases caused by presbyacusis: a gradually progressive bilateral sensorineural hearing loss, in which the highest frequencies are affected first and the lower follow gradually (Weinstein, 1994). It has been shown that hearing disability is associated with: social isolation, cognitive dysfunction, loss of independence, and a loss of overall quality of life (Mulrow et al, 1990; Cacciatore et al, 1999; Bess et al, 1991; Bess et al, 1989). Hearing aids may provide protection against these adverse effects of hearing loss (Mulrow et al, 1990). Since hearing aids do not intend to cure hearing loss, but rather to increase the well being of the hearing disabled person, from an economic perspective the multidimensional construct of quality of life (QOL) seems the most appropriate outcome parameter to evaluate the effects of hearing aid fitting.

Change in perceived $\mathrm{QOL}$ is usually measured using questionnaires that are administered several times during a certain period, for example in hearing disabled persons before hearing aid fitting and 3 months afterwards. When using such a before-after design it is presumed that the meaning of for instance 'having a perfect QOL' stays the same during the whole study period. More theoretically, it is assumed that a person's self-evaluation of a target construct (such as QOL) remains stable. This may however not be true (Schwartz \& Sprangers, 1999; Allison et al, 1997). It has been shown that the meaning of one's self-evaluation of a target construct may change; this phenomenon is called response shift (Schwartz \& Sprangers, 1999). Response shift is founded in research on organizational change (Golembiewski et al, 1976) and education (Howard et al, 1979), but it may occur in any field where self-reports are required. Schwartz and Sprangers (1999) defined response shift as: the idea that an individual may undergo changes in: (a) internal standards of measurement; (b) values; or (c) conceptualisation of a target construct (like QOL). The occurrence of response-shift has been reported in a few studies handling about severe chronic illnesses, such as cancer (Bernhard et al, 1999; Sprangers, 1996; Breetveld \& van Dam, 1991) and end-stage renal disease (Adang, et al, 1998; Kiebert et al, 1994) but to our knowledge a response-shift related to the measurement of self-reported hearing disability and rehabilitation has not yet been described.

In this study quality of life changes after fitting hearing aids in hearing impaired persons served as a setting in order to study response shift in a relatively mild health condition. Hearing impairment seems very well suited for this purpose since there are some indications that processes causing response shift are present in this patient group. Many elderly persons are reluctant to confront the reality of their hearing handicap, and try to hide the 
fact they might need a hearing aid (Jerger et al, 1995). In concordance with this, Hallam et al (1996) found indications for the presence of coping styles like minimization of hearing loss. It was also found that elderly persons generally under-rate their hearing disability in self-report measures (Lutman, 1991).

The main objective of this study was to investigate whether response shift in the measurement of $\mathrm{QOL}$ occurred in hearing-impaired adults after being fitted with hearing aids for the first time. This paper describes the study of the component of response shift caused by changes in internal standards: scale recalibration. The concept of change in internal standards of measurement, or scale recalibration, was first introduced by Howard et al (1979). Based on personality and experience persons have a perception of their functioning, and thus an idea of what answering categories like 'some problems' and 'severe problems' mean to them. New experiences can lead to a change in the perception of their functioning. Hearing disabled persons, for example, may think they can follow a conversation in a group meeting quite well, while after being fitted with a hearing aid they may realize that earlier without a hearing aid they only understood half the conversation. The occurrence of scale recalibration was examined by a then-test. The then-test is an extension of the conventional before-after design with a retrospective baseline (the then-test), which is obtained at the same time as the after treatment test: the post-test (Howard et al, 1979). Because the then-test is completed at the same time as the post-test, both results have the same internal standard of measurement.

\section{Methods}

\section{Study design}

This research was part of a study to assess the cost-effectiveness of hearing aid fitting. The design was an prospective intervention study with a pre-test $\left(T_{0}\right)$, and a post-test and a then-test $\left(T_{1}\right)$. $T_{0}$ took place directly after receiving the prescription for the hearing aid and obtaining written informed consent. The intervention consisted of the process of hearing aid fitting, as it is usual in the Netherlands. After this process was completed and had resulted in a satisfactory hearing aid fitting $T_{1}$ took place. The post-test and then-test were administered at this time, on average 12 weeks after the pre-test.

\section{Study population}

The study population consisted of hearing-impaired persons of 18 years and older who attended the Ear, Nose, and Throat (ENT) clinic of the University 
Hospital Maastricht or the Hoensbroeck Audiological Centre, and received a prescription for a hearing aid for the first time. The persons who received a prescription for a hearing aid met the following requirements: 1) pure tone audiometry revealed an averaged hearing loss of at least $35 \mathrm{~dB}$ at 1, 2 and 4 $\mathrm{kHz}$ at the best ear, 2) the hearing loss was due to inner ear pathology and 3) there were no contra-indications for hearing aid use (such as draining ears or ear canal pathology). Persons with the following characteristics were not included in the study: 1) indications of retrocochlear malignancies, 2) rapid progression of hearing impairment 3 ) hearing aid re-applicant, 4) not mentally capable of answering the questionnaires 5 ) not able to come to the hospital, or 6) not able to speak and understand the Dutch language.

\section{Outcome measurement}

At $T_{0}$ pure tone and speech audiometry were performed, followed by an interview; the pre-test. At $T_{1}$ only the interview took place. The interview consisted of questions concerning 1 ) overall quality of life, 2) hearing related quality of life, and 3) demographic variables. Trained audiology assistants administered all questionnaires in face-to-face interviews, taking place at the ENT clinic or Audiological Centre.

Overall QOL was measured by the EuroQol 5 Dimensions (EQ-5D), a widely accepted questionnaire to measure generic QOL (EuroQOl Group, 1990). The EQ-5D consists of five questions to describe the dimensions of one's health state: 'mobility', 'self care', 'daily activities', 'pain and complaints' and 'feelings', and one question concerned with health transition over the past year. The last part consists of a VAS, ranging from $0=$ 'worst imaginable health state' to 100 = 'best imaginable health state', used to rate one's own QOL.

Hearing related QOL was measured using the Audiological Disabilities Preference Index (ADPI; Joore et al, 2002). The is partly based on items from the Amsterdam Inventory; a questionnaire on subjective auditory disability and handicap developed by Kramer, et al (1995). The ADPI includes five items, covering five factors of auditory disability: 'auditory localisation', 'detection of sounds', 'distinction of sounds', 'intelligibility in noise' and 'intelligibility in quiet'. Each item has three possible answers: 'no problems', 'moderate problems' and 'severe problems'. The ADPI further consists of a horizontal visual analogue scale (VAS) of 10 centimetres length, ranging from zero $=$ 'deaf' to $100=$ 'perfect sense of hearing' (referred to as: 'Hearing VAS'). Respondents were asked to rate the perception of their own hearing related QOL on the line. All items in the ADPI, the five questions on factors of hearing disability and the 'Hearing VAS', were used as then-test items. As recommended by Schwartz \& Sprangers (1999) for validation purposes thentest items were included where response shift was less likely to occur. The items and 'feeling thermometer' from the EQ-5D were used as control items. 
Regarding the content of the items of the EQ-5D and the crudeness of the answering categories, it did not seem likely that this questionnaire, as other generic $\mathrm{QOL}$ questionnaires, would be sensitive to change in $\mathrm{QOL}$ after hearing aid fitting (Cox et al, 2000). First the post-test items of the ADPI were administered. Then, the respondents were asked to think back to the situation before hearing aid fitting, and answer the then-test items of the ADPI accordingly. The same procedure was then repeated for the EQ-5D items. It was decided to first administer all hearing specific questions, followed by the generic questions, because this was thought to be less confusing for the (elderly) respondents than 'mixing' generic and specific items.

\section{Hypotheses}

It was expected that hearing aid fitting would lead to an improvement of the hearing related $\mathrm{QOL}$ of the hearing-impaired persons. This improvement in hearing related $\mathrm{QOL}$ might lead to a response shift effect. When, as a result of hearing aid fitting, the hearing-impaired persons adapt to a higher level of hearing related $\mathrm{QOL}$, it could be expected that there would be an decrease in their reported level of hearing related $\mathrm{QOL}$ before hearing aid fitting. In this situation the post-test scores of the 'Hearing VAS' and the items from the ADPI were expected to be higher then the pre-test scores, and therefore the conventional change was expected to be positive (conventional change: posttest minus pre-test). And furthermore, the then-test scores were expected to be lower than the pre-test scores, and therefore the then-test change (posttest minus then-test) was expected to be larger than the conventional change. The response shift effect (then-test minus pre-test) was expected to be negative. Regarding the control items from the EQ-5D it was thought that the items regarding the physical dimensions of health ('mobility' and 'self care') would not be influenced at all by hearing aid fitting, and therefore no response shift would occur in these items. With respect to the other items of the EQ-5D it was expected that both the conventional change and the thentest change would be very small, if at all present, and hence that no or only a very small response shift effect would occur.

\section{Statistical analysis}

Demographic variables were shown by means of descriptive statistics. From the raw scores per patient the following new variables were computed: 'conventional change', 'then test change' and 'response shift'. The conventional change was computed by subtracting the pre-test score from the post-test score. The then-test change was computed by subtracting the thentest score from the post-test score. The response shift was computed by subtracting the pre-test from the then-test. The distribution of the data was tested for normality. All results were presented as means (standard deviation). Comparisons were conducted with the Wilcoxon signed ranks test, 
or the paired samples t-test (only when the data was normally distributed). Because of the large number of tests, it was decided to indicate statistically significant results only if the $p$-value was smaller than 0.005 . The analyses were performed with the SPSS 10.0 statistical software package.

\section{Results}

\section{Characteristics of the study population}

In the period from February 1998 to March 1999126 patients were enrolled in the study. After $T_{0}$ a total of 28 persons left the study for the following reasons: 14 persons decided not to be fitted with a hearing aid, 7 persons were lost to follow up because they could not be contacted on their home address to make an appointment for $T_{1}, 5$ persons left the study on their own request, mostly because they were not willing to travel to the hospital to fill out the questionnaire, 1 person missed $T_{1}$ due to illness and 1 person deceased before $T_{1}$ could take place.

The study population consisted of the remaining 98 persons. The mean age was 67 years (sd 12 years, median 69 years). Slightly more subjects were male $(\mathrm{N}=53)$. Most persons were living together with another person $(\mathrm{N}=79)$, of whom most persons were married $(\mathrm{N}=70)$. Only 4 persons lived in a retirement home. The largest proportion had lower education $(\mathrm{N}=70)$ and only a small proportion had higher education $(\mathrm{N}=13)$. The majority of persons reported to take care of the household $(\mathrm{N}=56)$, or to be retired $(\mathrm{N}=26)$. The mean number of reported multi-morbidities was 3 (sd 2). The mean averaged hearing loss of the best ear measured at 1,2 and $4 \mathrm{kHz}$ was $46 \mathrm{~dB}$ (sd 10). Most persons were fitted with behind-the-ear hearing aids (79 persons). See table 1.

\section{Then-test items}

The results for the items on subjective hearing disability and handicap are presented in Table 2. Depending on the item a maximum of 11 persons did not experience the situation mentioned in the item, and hence could not answer it at $T_{0}$ or $T_{1}$. As expected all items showed a negative response shift (all statistically significant, $\mathrm{p}<0.001$, Wilcoxon Signed Ranks Test). The conventional change was statistically significant for the items on 'intelligibility in quiet' and 'sound detection' ( $p$-value $<0.001$, Wilcoxon Signed Ranks test). The items on 'intelligibility in noise', 'sound distinction' and 'auditory localization' showed no statistically significant conventional change. For each item the improvement found with the then-test was larger than using the conventional approach. The then-test changes were all statistically significant $(p<0.000$, Wilcoxon Signed Ranks Test), this in contrast with the conventional changes. With respect to the 'Hearing VAS' 2 persons had missing values. No response shift effect was observed $(-2.63, \mathrm{p}$ - 
value 0.066 , Paired Samples T-Test). The mean score at the pre-test was 51.63, and at the post-test the mean score was 77.66. The average improvement from the conventional perspective (post-test minus pre-test) was 26.09 (p-value $<0.001$, Paired Samples T-Test). See Table 2.

Table 1 Characteristics of the study population

\begin{tabular}{|c|c|c|c|}
\hline \multicolumn{4}{|l|}{ Demographic variables } \\
\hline$\overline{\mathrm{N}}$ & 98 & Education & \\
\hline Age & & primary school & 33 (34\%) \\
\hline mean (sd) & $67(12)$ & lower education & $38(39 \%)$ \\
\hline range & $28 \cdot 95$ & Intermediate education & $14(14 \%)$ \\
\hline Gender & & higher education & $13(13 \%)$ \\
\hline male (\%) & $53(54 \%)$ & Occupational status & \\
\hline Civil status & & paid employment & $6(6 \%)$ \\
\hline married & 70 (71\%) & occupational disabled & $4(4 \%)$ \\
\hline widow/widower & $17(18 \%)$ & voluntary work & $6(6 \%)$ \\
\hline not married & $11(11 \%)$ & retired & $26(27 \%)$ \\
\hline Home situation & & taking care of household & $56(57 \%)$ \\
\hline living alone & $19(19 \%)$ & Hearing loss (average at $1,2,4 \mathrm{kHz}$ ) & \\
\hline Living situation & & mean $\mathrm{dB}(\mathrm{sd})$ & $46(10)$ \\
\hline independent household & $94(96 \%)$ & range & $30-80$ \\
\hline retirement home & $6(4 \%)$ & Type of hearing aid & \\
\hline Multi morbidity & & behind-the-ear & 79 (81\%) \\
\hline Mean number of morbidities (sd) & $3(2)$ & in-the-ear & $15(15 \%)$ \\
\hline & & in-the-canal & $4(4 \%)$ \\
\hline
\end{tabular}

\section{Control items}

The results for the control items are presented in Table 2 . With regard to the items of the EQ-5D 2 persons had one or more missing values. As expected, none of the response shift effects in the EQ-5D items were statistically significant (all p-values $>0.005$, Wilcoxon Signed Ranks Test). Overall, only small changes were observed in the results of the EQ-5D items. Only with regard to the 'feeling' item the conventional change was statistically significant (p-values 0.001, Wilcoxon Signed Ranks Test). The conventional changes of the other control items were not statistically significant (all pvalues $>0.005$, Wilcoxon Signed Ranks Test). One person did not complete the EQ-5D VAS. The mean pre-test score of generic QOL on this VAS was 69, and the mean post-test score was 71. The conventional change was 2 (not statistically significant, p-value 0.064 , Paired T-Test). The mean then-test score was equal to the pre-test score: 69 , and hence no statistically significant response shift occurred ( $p$-value 0.701 , Paired T-Test). 
Table 2 Conventional change scores ( $T_{1}$ minus $\left.T_{0}\right)$, Then-test change scores $\left(T_{1}\right.$ minus Then-test score), and Response shift scores (Then-test minus $\mathrm{T}_{0}$ )

\begin{tabular}{|c|c|c|c|c|c|c|c|c|c|}
\hline \multirow[b]{2}{*}{ Items } & \multirow{2}{*}{$\begin{array}{c}\mathrm{T}_{0} \\
\mathrm{~N} \text { mean }(\mathrm{sd})\end{array}$} & Then-test & $\mathrm{T}_{1}$ & \multicolumn{2}{|c|}{$\begin{array}{c}\text { Conventional } \\
\text { change }\end{array}$} & \multicolumn{2}{|c|}{$\begin{array}{l}\text { Then-test } \\
\text { change }\end{array}$} & \multicolumn{2}{|c|}{$\begin{array}{l}\text { Response } \\
\text { shift }\end{array}$} \\
\hline & & $\mathrm{N}$ mean $(\mathrm{sd})$ & $\mathrm{N}$ mean $(\mathrm{sd})$ & mean & $\begin{array}{c}\mathrm{p}- \\
\text { value }\end{array}$ & mean & $\begin{array}{c}\mathrm{p}- \\
\text { value }\end{array}$ & mean & $\begin{array}{c}\mathrm{p}^{-} \\
\text {value }\end{array}$ \\
\hline$\overline{\mathrm{ADPI}}$ & & & & & & & & & \\
\hline $\begin{array}{l}\text { Sound } \\
\text { distinction }{ }^{4} \\
\text { Intelligibility }\end{array}$ & $932.83(.48)$ & $962.40(.72)$ & 96 & 0.00 & 0.983 & 0.44 & 0.000 & -0.45 & 0.000 \\
\hline $\begin{array}{l}\text { in quiet }{ }^{4} \\
\text { Intelligibility }\end{array}$ & $972.24(.64)$ & $971.47(.66)$ & $962.90(.31)$ & 0.65 & 0.000 & 1.43 & 0.000 & -0.76 & 0.000 \\
\hline $\begin{array}{l}\text { in noise } \\
\text { Auditory }\end{array}$ & $972.34(.66)$ & $961.64(.63)$ & $872.48(.66)$ & 0.20 & 0.021 & 0.90 & 0.000 & -0.71 & 0.000 \\
\hline $\begin{array}{l}\text { localization }{ }^{4} \\
\text { Sound }\end{array}$ & $912.48(.64)$ & $881.95(.43)$ & $872.52(.59)$ & 0.02 & 0.762 & 0.54 & 0.000 & -0.46 & 0.000 \\
\hline det & 982.62 & 961 & 962. & 0.30 & 0.000 & 1.21 & 0.000 & -0.91 & 0.000 \\
\hline VAS & 980. & 970. & 960.78 & 0.26 & 0.000 & 0.29 & 0.000 & -0.03 & 0.066 \\
\hline & & & & & & & & & \\
\hline Mobility ${ }^{4}$ & $981.35(.48)$ & 971.31 & $971.30(.46)$ & -0.05 & 0.297 & -0.01 & 0.782 & -0.04 & 0.394 \\
\hline $\begin{array}{l}\text { Self care }{ }^{4} \\
\text { Daily }\end{array}$ & 3107 & 971 & 971.05 & -0.01 & 0.705 & -0.02 & 0.414 & 0.01 & 0.655 \\
\hline activities ${ }^{4}$ & $981.18(.41)$ & $971.22(.46)$ & $971.21(.43)$ & 0.03 & 0.513 & -0.01 & 0.782 & 0.04 & 0.317 \\
\hline complai & 981.45 ( & 971. & 971.43 & -0.01 & 1.000 & 0.01 & 0.840 & -0.02 & 0.886 \\
\hline Feelings ${ }^{4}$ & $971.29(.52)$ & $971.23(.51)$ & 971.10 ( & -0.18 & 0.001 & -0.12 & 0.001 & -0.05 & 0.394 \\
\hline $\operatorname{VAS}^{3}$ & $980.69(.16)$ & $970.69(.14)$ & $970.71(.14)$ & 2.22 & 0.064 & 1.86 & 0.071 & 0.04 & 0.701 \\
\hline
\end{tabular}

${ }^{1}$ Scores on the dimensions range from 1 to 3, a higher score is less problems, ${ }^{2}$ Scores on the dimensions range from 1 to 3 , a higher score on the dimensions is more problems, ${ }^{3}$ Paired T. Test, "Wilcoxon Signed Ranks Test.

\section{Conclusion and discussion}

\section{Did response shift occur?}

The scores of the items from the ADPI all showed a statistically significant improvement when using the then-test approach (this in contrast with the conventional approach), and in each item score a negative and statistically significant response shift occurred. These results confirmed the hypothesis that when the hearing-impaired persons adapt to a lower level of hearing disability and handicap as a result of hearing aid fitting they perceived their self-reported level of hearing disability and handicap before hearing aid fitting as more serious. Regarding the 'Hearing VAS' as expected the mean pre-test score was smaller than the mean post-test score. The observed response shift was however not statistically significant, and therefore did not confirm the hypothesis. The absence of response shift effect in the 'Hearing VAS' as opposed to the relatively large response shift effects in the items from the ADPI does on first sight not correspond with the opinion that in 
theory the more generic the concept being measured, the greater the likelihood that response shift would occur (Wilson, 1999). In theory this is certainly true: the larger the variety in determinants of a concept the greater the susceptibility to recalibration. On the other hand, a specific item might trigger a person more strongly to remember and relive an earlier situation than a more generic item. This could have been the case in this study, especially taking into account the old age of the respondents. Another factor that could have been of influence is the difference in response technique between the specific items (three point scale) and the hearing related quality of life question (VAS). It is possible that the elderly respondents found it easier to respond to an ordinal than to a cardinal scale, resulting in more valid answers on the specific items. In 4 out of 5 of the control items of the EQ-5D no change was observed. Only the conventional change and the then-test change in the feeling dimension were statistically significant. This is in concordance with the hypotheses, and the evidence that fitting hearing aids influences psychological well being ${ }^{3}$. As expected, none of the response shift effects in the control items were statistically significant. These results indicated that response shift indeed took place in the measurement of hearing related $\mathrm{QOL}$ after hearing aid fitting.

\section{Possible sources of bias}

There is some question about the influence of memory problems on the results of the then-test (recall bias). In the case of first time hearing aid users a memory problem could be present taking into account the old age of this group of respondents, although respondents who clearly suffered from cognitive problems were not included in the study. On the other hand, the respondents were asked to think back to a relatively recent situation (3 months ago) they are likely to have experienced for many years, because hearing impairment is a slowly progressive condition and persons often wait a long time to seek help. Moreover, the respondents are still in the position to experience the situation without a hearing aid when they do not wear it. This makes the presence of a memory problem less likely.

Another type of bias could be caused by the participants' wish to think positively of the intervention they had undergone. When the participant deliberately gives unjust positive answers this is called 'faking good' bias, if the participant is not deliberately trying to deceive it is called 'social desirability' bias (Streiner \& Norman, 1995). Both types of bias could have been introduced in this study. First, since some of the participants had spend a considerable amount to the contribution of their hearing aid, they could have had the inclination to justify for that by making their condition more serious. Second, when becoming a hearing aid user the participants admitted their hearing impairment not only to themselves, but also to the rest of the world. Knowing that the prevailing social attitude towards hearing impairment is characterised by mistrust, and the association with old age and mental 
disorders (Gilhome Herbst, 1983), starting hearing aid users might search for justification of their choice. Therefore it could be possible that the participants afterwards increased their pre-treatment level of disability and handicap to justify hearing aid fitting towards themselves, their family members, and perhaps even towards the interviewer. On the other hand, the participants of the study were included after they had indicated they were prepared to enter the process of hearing aid fitting; knowing that this would cost them a certain amount money, and knowing that this would label them as being hearing-impaired. Therefore it seems more likely that if the factors that could have caused 'faking good' and 'social desirability' bias were present, it would have been during the period before help-seeking. This is supported by the finding that hearing-impaired persons who seek help report more hearing disability than persons who do not seek help, even when controlled for the degree of hearing impairment (Swan \& Gatehouse, 1990). A more methodological factor that could have introduced 'faking good' or 'social desirability' bias could have been the use of face-to-face interviews as method of data-collection. Regarding the old age of the participants the nonresponse rates were expected to be much higher when the collection had been otherwise. It could be stated that 'faking good' or 'social desirability' bias were at least not the only factors causing the present response shift effect. Overall, the results of this study reveal the presence of response shift caused by scale recalibration after hearing aid fitting in hearing disabled persons, meaning that after hearing aid fitting they perceive their condition to have been worse than they did before the intervention.

\section{Implications for the care for hearing disabled persons}

A conclusion of this study is, that hearing-impaired individuals motivated to start using hearing aids under-rate their amount of self-reported hearing disability and handicap. In general this phenomenon is normal and even desirable: fortunately most persons, in time and to a certain extent, learn to cope or adapt to their physical problems (Wilson, 1999). Wilson (1999) even stated that persons who lack these mechanisms are somatized or hypochondriacal. In the situation of hearing impairment there are however two reasons why this phenomenon might be less beneficial. First, hearing disabled persons can be characterized as late or even non help-seekers. In the Netherlands only $40 \%$ of the hearing disabled persons contact their GP and only $20 \%$ of the hearing disabled persons are fitted with hearing aids (Duijvestijn et al, 1999). This could have negative consequences because at a later age handling hearing aids, especially the more sophisticated ones, becomes more difficult (Stephens \& Meredith, 1991b). Second, the stigma of hearing loss and hearing aids in society might influence coping behaviour, which might in this case be called neglect. If this would be the case there is a task for health care workers to distinguish between normal adaptive psychological mechanisms and neglect concerning health related behaviour, in 
order to prevent a compromised $\mathrm{QOL}$ as a result of the postponement of hearing rehabilitation until a very late age.

\section{Implications for research}

Hearing disability as present in this study population is a relatively mild condition when compared to cancer and end-stage renal disease, in which response shift has been observed earlier (berhard et al, 1999; Sprangers, 1996; Breetveld \& van Dam, 1991; Adang et al, 1998; Kiebert et al, 1994). Therefore this study showed that response shift does not only occur in study populations with severe, life-threatening diseases who undergo major treatments.

This study mainly intended to demonstrate the presence of response shift. Response shift in different groups of hearing disabled persons (for instance help-seekers and non-help-seekers), the origin and magnitude of factors initiating response shift, and the consequences of response shift in the measurement of hearing aid benefit should form an area of further research. Furthermore, the occurrence of response shift in $\mathrm{QOL}$ ratings over time could have large implications for the estimation of the effectiveness of medical interventions and for the use of these estimations in cost-effectiveness analyses. After a successful treatment the then-test change is likely to be larger than the conventional change, meaning that the conventional change could be an underestimation of the effectiveness of the treatment. In terms of QOL however, some authors (Adang et al, 1998; Wilson, 1999). argued that psychological adaptation is a welcome capacity of human beings, and that then-test changes do no justice to this capacity. 


\section{Chapter 5}

The influence of experience on health state valuation 
Joore MA, Potjewijd J, Anteunis LJC. The influence of illness experience on health state valuation. Submitted. 


\section{Introduction}

Health status assessment is a cognitive task, it requires thinking and the processing of information about past and current circumstances (Barofsky, 2000). Furthermore, the valuation of a health state may be driven by factors other than the perceived burden of the illness, such as prognosis or public opinion (Ustun et al, 1999). Therefore different (groups of) persons may perceive and process the same information in varying ways, and thus giving different health state valuations. This has been confirmed by empirical evidence: as reviewed by de Wit (2000), a majority of studies concludes that valuations for health states differ among groups.

This study focuses on the influence of illness experience on health state valuations. Illness experience has been suggested as a major contributing factor to between-group differences (Dolan, 1996; Badia et al, 1998; Kind \& Dolan, 1995). Since health state valuations are used as measure of effect in the economic evaluation of health care interventions, it is important to recognize and understand diversity in preferences, not only between patients and nonpatients, but also among subgroups in the general population (Sculpher \& Gafni, 2001). The objective of this study was to contribute to a better understanding of the influence of different forms of illness experience on the valuation of health states, and its consequences for the determination of the effectiveness of medical interventions.

Current poor health experience generally seems to lead to higher health state valuations (de Wit et al, 2000). This has been referred to as 'valuation shift' (Dolan, 1996). It has been suggested that because of higher patient scores, gain in health state would then be potentially higher from a population perspective than from a patient perspective (Gold et al, 1996). This would however only hold true in the presence of a ceiling effect. Furthermore the influence of illness experience may be different for specific health states: persons who value their own health as 'poor', assign higher values to severe health states, but lower values to mild health states than persons who value their own health as 'good' (de Wit, 2000; Kind \& Dolan, 1995; Badia et al, 1996). This results in a narrowing of the health continuum, referred to as 'valuation compression'. A possible explanation for both 'valuation shift' and 'valuation compression' could be a change in internal standards of measurement: illness experience might alter a person's perception of sickness and health. The anchor points on the health continuum vary for persons according to their illness experience. The distinction between persons with and without illness experience is an ambiguous one. Dolan (1999) suggested a framework to classify different degrees of experience along three axes: type of experience (personal or other), time since illness (current illness or past illness) and period of illness (long term or short term). In this definition experience ranges from the maximum personal experience of a current patient with a long history of illness, to minimal experience in a healthy 
member of the public without illness history or further knowledge of illness or persons with illness. It is clear that persons are very heterogeneous with regard to illness experience on this continuum. Physicians for instance may be more comparable to patients than to less informed members of the public. Also, patients with a recent experience of mild illness may be less experienced than members of the public with a long experience of severe disability in their family.

In this study hearing impairment served as a setting in order to investigate between-group differences for valuations of health states before and after intervention (in this study hearing aid fitting), whether these between-group differences affect gain in health state after intervention, and 'valuation compression'. Hearing impairment is a very common disorder, especially among elderly persons (Chorus et al, 1995). It is associated with social isolation, cognitive dysfunction, reduced self-reliance, loss of independence and depression (Appollonio et al, 1996; Jerger et al, 1995; Mulrow et al, 1990). In most cases a hearing aid (HA) is the only option for rehabilitation. Valuations for both hearing related and generic health states were obtained in four groups of individuals: hearing-impaired patients in the process of hearing aid fitting, persons with medical knowledge of hearing impairment, persons with medical knowledge of visual impairment, and persons without illness experience or medical knowledge.

We formulated the following hypotheses:

Hypothesis 1: Valuations of health states before and after hearing aid fitting obtained from persons with $\mathrm{HI}$ experience are higher than valuations for the same health states obtained from persons without $\mathrm{HI}$ experience.

Hypothesis 2: Gain in health state after hearing aid fitting is higher in persons without $\mathrm{HI}$ experience than in persons with $\mathrm{HI}$ experience.

Hypothesis 3: Valuations of the bottom anchor point of a specific VAS obtained from persons with experience with that particular illness are higher than valuations obtained from persons without that illness experience.

Hypothesis 4: Persons experienced with illness use a smaller proportion of the VAS than persons without illness experience (valuation compression).

\section{Methods}

\section{Design and study population}

The study consisted of two protocols: 1) a prospective intervention study of fitting hearing aids in hearing-impaired adults, and 2) a survey study. The prospective cohort study consisted of a baseline measurement $\left(T_{0}\right)$ before the fitting of hearing aids, and a follow-up measurement when the hearing aid fitting was approved by the ENT specialist or audiologist after a trial period. 
The study population in the prospective intervention study consisted of adult first time hearing aid users each having an averaged hearing loss of at least 35 $\mathrm{dB}$ at 1,2 and $4 \mathrm{kHz}$ in their best ear. The patients entered the study after receiving a prescription for a hearing aid. Exclusion criteria were indications of retro-cochlear malignancies, and contra-indications for hearing aid use (such as draining ears or ear canal pathology). In the period from February 1998 to March 1999, 126 patients were enrolled in the study. We will refer to this group as Patient Group.

The study population of the survey consisted of employees of the Finance department (Finance group), the ear, nose and throat (ENT group) department, and the Ophthalmology department (Ophthalmology group) of the university hospital Maastricht. We recruited 26 persons of each department. Persons were not included if they were hearing-impaired (defined as a pure tone averaged hearing loss of at least $35 \mathrm{~dB}$ at 1,2 and 4 $\mathrm{kHz})$. The ENT group served as an example of persons with medical knowledge of hearing impairment and hearing aid fitting, the Ophthalmology group as an example of persons with medical knowledge of visual impairment, and the Finance group as an example of persons without illness experience or medical knowledge.

\section{Data collection}

All measurements in both study protocols took place at the university hospital Maastricht and the Audiological Centre Hoensbroeck (location Venlo) and consisted of pure tone audiometry and a face to face interview. The interview included a series of visual analogue scales (VAS). The first VAS ranged from ' 0 ' is 'deaf' to ' 100 ' is 'perfect sense of hearing', and was used to determine valuations of hearing related health states before and after hearing aid fitting (this VAS will be referred to as 'specific VAS'). The Patient group completed the specific VAS with respect to their actual hearing related health state before and after hearing aid fitting. The Population group, ENT group and Ophthalmology group valued case descriptions of the patients hearing specific health state before and after hearing aid fitting. The case descriptions were based on the patient scores on a questionnaire to measure hearing handicap and disability, the Amsterdam Inventory (Kramer, 1996). This questionnaire consists of five factors: intelligibility in quiet, intelligibility in noise, auditory localization, distinction of sounds and detection of sounds. The questionnaire was administered before and after hearing aid fitting, at the same time the patients completed the 'specific VAS'. See Table 1 for case descriptions. In all groups the subjects were subsequently asked to value the following generic hypothetical health states on VAS from ' 0 ' is 'worst imaginable health state' to ' 100 ' is 'best imaginable health state': 'mild asthma', 'blind', 'severe heart failure', and 'deaf'. 
Table 1 Case descriptions of health states before and after hearing aid fitting

\begin{tabular}{|c|c|c|}
\hline Factor & Situation before hearing aid fitting & Situation after hearing aid fitting \\
\hline Hearing aid & I don't wear a hearing aid & I wear a hearing aid \\
\hline Intelligibility in quiet & $\begin{array}{l}\text { I can hear the birds singing outside } \\
\text { reasonably well }\end{array}$ & $\begin{array}{c}\text { I can hear the birds singing outside } \\
\text { very well }\end{array}$ \\
\hline Intelligibility in noise & $\begin{array}{c}\text { I can understand the newsreader } \\
\text { on the radio at normal volume } \\
\text { with difficulty }\end{array}$ & $\begin{array}{c}\text { I can understand the newsreader on } \\
\text { the radio at normal volume } \\
\text { very well }\end{array}$ \\
\hline Auditory localization & $\begin{array}{c}\text { I carry on a conversation with } \\
\text { someone during a crowded meeting } \\
\text { with difficulty }\end{array}$ & $\begin{array}{l}\text { I can carry on a conversation with } \\
\text { someone during a crowded meeting } \\
\text { reasonably well. }\end{array}$ \\
\hline Distinction of sounds & $\begin{array}{c}\text { Most of the times I look in the right } \\
\text { direction when somebody calls on } \\
\text { the street }\end{array}$ & $\begin{array}{c}\text { I always look in the right } \\
\text { direction when somebody calls on } \\
\text { the street }\end{array}$ \\
\hline Detection of sounds & $\begin{array}{l}\text { I can hear rhythm in music or songs } \\
\text { reasonably well }\end{array}$ & $\begin{array}{c}\text { I can hear rhythm in music or songs } \\
\text { very well }\end{array}$ \\
\hline
\end{tabular}

\section{Analysis}

Descriptives on the characteristics of all subjects were obtained. The valuations of the (descriptions of the) health states before and after hearing aid fitting were used to examine between-group differences (hypothesis 1). The valuation of 'deaf' was used to examine the differential use of the bottom anchor point of the specific VAS (hypothesis 2). 'Blind' was added as a control item. 'Mild asthma' served as an example of a mild health state, and 'severe heart failure' as an example of a severe health state. The difference between the valuations of 'asthma' and 'heart' was used to test 'valuation compression' (hypothesis 3). The VAS scores were tested for normality and for equality of error variances. The between group comparisons were done using the Kruskal-Wallis test, since most VAS scores were not normally distributed. When a group effect was found (a p-value smaller than 0.05 indicated statistical significance), the differences were further explored using MannWhitney $U$ tests. Because of the large number of pairwise comparisons, for the Mann-Whitney $U$ tests a p-value of 0.005 was chosen as cut off point for statistical significance. Analysis of variance was used to investigate the possible influence of education level, gender and age. A p-value smaller than 0.05 indicated statistical significance. If differences existed among the means, the Bonferroni multiple comparison procedure was used to determine which means differed. All analyses were performed with the SPSS statistical software package. 


\section{Results}

\section{Description of the study populations}

Descriptive statistics of the characteristics of the subjects are presented in Table 2. In the Patient group a total of 126 persons completed the baseline measurement. The follow up measurement was completed by 98 persons. Patients left the study for the following reasons: not fitted with a hearing aid $(n=14)$, lost to follow up $(n=7)$, left study on own request $(n=5)$, illness of patient $(n=1)$, patient deceased $(n=1)$. Both in the sample before and after hearing aid fitting age ranged from 28 to 95 years and the mean age was 67 years (sd 12 years). In the sample before hearing aid fitting slightly more subjects were male (57\%), and after hearing aid fitting slightly less (41\%). Most persons had a lower education level: in the group before hearing aid fitting $68 \%$ and in the subgroup after hearing aid fitting $72 \%$. The best ear pure tone average (BEPTA) hearing loss had a mean of $46 \mathrm{~dB}$. Most persons were fitted with behind-the-ear hearing aids $(81 \%)$. The average number of multimorbidities reported was 3 , indicating relatively poor health. In the survey the mean age of the Finance group was 36 years (sd 8 years), the majority was male $(69 \%)$, most persons had intermediate level education (58\%), and hearing loss was very small (BEPTA $5 \mathrm{~dB}$ ). The Ophthalmology group and the ENT group were very similar with respect to age (mean age 37 and 34 years, respectively), gender ( $31 \%$ males in both groups) education (most persons had higher level education) and hearing loss (BEPTA $4 \mathrm{~dB}$ and $0 \mathrm{~dB}$, respectively). The Ophthalmology group and the ENT group had relatively less male employees and a higher education level than the Finance group.

Table 2 Characteristics of the study populations

\begin{tabular}{|c|c|c|c|c|c|}
\hline \multirow[b]{3}{*}{ Characteristics } & \multicolumn{3}{|c|}{$\begin{array}{c}\text { Experience with } \\
\text { hearing impairment }\end{array}$} & \multicolumn{2}{|c|}{$\begin{array}{l}\text { No experience with } \\
\text { hearing impairment }\end{array}$} \\
\hline & \multicolumn{2}{|c|}{ Patient group } & \multirow{2}{*}{$\begin{array}{l}\text { ENT } \\
\text { group }\end{array}$} & \multirow{2}{*}{$\begin{array}{l}\text { Finance } \\
\text { group }\end{array}$} & \multirow{2}{*}{$\begin{array}{l}\text { Ophthalmology } \\
\text { Group }\end{array}$} \\
\hline & Before HA & After HA & & & \\
\hline$\overline{\mathrm{N}}$ & 126 & 98 & 26 & 26 & 26 \\
\hline Age (sd) & $67(12)$ & $67(12)$ & $34(9)$ & $36(8)$ & $37(11)$ \\
\hline Male & $72(57 \%)$ & $40(41 \%)$ & $8(31 \%)$ & $18(69 \%)$ & $8(31 \%)$ \\
\hline Lower education & $86(68 \%)$ & 71 (72\%) & $3(12 \%)$ & $1(4 \%)$ & $4(15 \%)$ \\
\hline Intermediate education & $26(21 \%)$ & $14(14 \%)$ & $6(23 \%)$ & $15(58 \%)$ & $4(15 \%)$ \\
\hline Higher education & $14(11 \%)$ & 13 (13\%) & $17(65 \%)$ & $10(38 \%)$ & $18(70 \%)$ \\
\hline BEPTA' (sd) & $46(11)$ & $46(10)$ & $0(8)$ & $5(7)$ & $4(10)$ \\
\hline Behind-the-ear hearing aid & - & $79(81 \%)$ & 0 & 0 & 0 \\
\hline In-the-ear hearing aid & - & 15 (15\%) & 0 & 0 & 0 \\
\hline In-the-canal hearing aid & - & $4(4 \%)$ & 0 & 0 & 0 \\
\hline
\end{tabular}

${ }^{1}$ BEPTA $=$ Best Ear Pure Tone Average Hearing Loss at 1,2 and $4 \mathrm{kHz}$ 


\section{Between-group difference in valuations}

Two persons in the Patient group did not complete the specific VAS. The VAS scores are presented in Table 3. The valuations of the health state before and after HA fitting were statistically significantly different between the four groups. Multiple comparisons revealed that valuation of the health state before HA fitting from the ENT group was higher than the valuations of the other groups, including the Patient group. With regard to the health state after HA fitting the valuation from the ENT group was significantly higher than the valuation form the Patient group, but not higher than the valuations obtained in the groups without experience with hearing impairment. The gain in health state did not differ statistically significantly between the groups. These results indicate that the valuations of the health state before and after hearing aid fitting differed among the groups. The observed difference between the valuations for those health states did however similar not differ between the groups.

\section{Differential use of the anchor point of the VAS}

Two persons in the patient group did not complete the valuations of 'deaf' and 'blind'. Surprisingly the lowest valuations of 'deaf' were found in the two groups with experience with hearing impairment $(0.31)$, and the highest valuation in the Ophthalmology group $(0.43)$. The valuations did however not differ statistically significantly between the groups. In contrast the valuations of the control item 'blind' did differ between the groups. As expected the valuation was the highest in the VI group $(0.34)$. The lowest valuation was found in the Patient group (0.20). Pairwise comparison revealed that this difference was statistically significant (Table 3 ).

\section{Valuation compression}

One person in the Patient group did not complete the valuations of 'asthma' and 'heart'. The valuations for 'asthma' varied from 0.46 in the HI group to 0.67 in the Patient group. The valuations differed statistically significantly between the groups. Pairwise comparisons revealed that the valuation from the Patient group was higher than the valuations of the other groups. The valuation of the severe marker state 'heart' ranged from 0.19 in the Patient group to 0.24 in the ENT group. The valuations did not differ statistically significantly between the groups. The mean difference between the valuations for 'asthma' and 'heart' differed statistically significantly between the groups. Counter to what we had hypothesized the Patient group used the largest proportion of the VAS $(0.49)$. The ENT group used the smallest proportion $(0.21)$. Pairwise comparison revealed that the Patient group and the ENT group differed statistically significantly (Table 3 ). 
Table 3 Health state valuations from the Patient group, ENT group, Finance group and Ophthalmology group

\begin{tabular}{|c|c|c|c|c|c|c|c|c|c|}
\hline & \multicolumn{4}{|c|}{$\begin{array}{c}\text { Experience with } \\
\text { hearing impairment }\end{array}$} & \multicolumn{4}{|c|}{$\begin{array}{l}\text { No experience with } \\
\text { hearing impairment }\end{array}$} & \multirow[b]{2}{*}{$\begin{array}{c}\text { Kruskall- } \\
\text { Wallis Test } \\
\text { p-value }\end{array}$} \\
\hline & $\overline{m d n}$ & $\begin{array}{l}\text { Patient } \\
\text { group } \\
\text { mean (sd) }\end{array}$ & mdn & $\begin{array}{l}\text { ENT } \\
\text { group } \\
\text { mean (sd) }\end{array}$ & & $\begin{array}{l}\text { Finance } \\
\text { group } \\
\text { mean (sd) }\end{array}$ & $\begin{array}{l}\text { Oph } \\
\text { mdn }\end{array}$ & $\begin{array}{l}\text { thalmology } \\
\text { group } \\
\text { mean (sd) }\end{array}$ & \\
\hline \multicolumn{10}{|l|}{ Specific VAS } \\
\hline Before $\mathrm{HA}^{1}$ & 0.50 & $0.53(0.13)$ & 0.63 & $0.64(0.12)$ & 0.50 & $0.52(0.14)$ & 0.50 & $0.49(0.18)$ & 0.001 \\
\hline After $\mathrm{HA}^{2}$ & 0.80 & $0.78(0.11)$ & 0.85 & $0.86(0.09)$ & 0.83 & $0.82(0.11)$ & 0.80 & $0.78(0.17)$ & 0.004 \\
\hline Change & 0.23 & $0.26(0.18)$ & 0.22 & $0.22(0.11)$ & 0.25 & $0.30(0.14)$ & 0.28 & $0.29(0.15)$ & 0.231 \\
\hline \multicolumn{10}{|l|}{ Generic VAS } \\
\hline Deaf & 0.30 & $0.31(0.21)$ & 0.30 & $0.31(0.17)$ & 0.30 & $0.33(0.16)$ & 0.40 & $0.43(0.22)$ & 0.095 \\
\hline Blind ${ }^{3}$ & 0.10 & $0.20(0.24)$ & 0.30 & $0.31(0.22)$ & 0.20 & $0.23(0.19)$ & 0.30 & $0.34(0.24)$ & 0.002 \\
\hline Asthma $^{4}$ & 0.70 & $0.63(0.20)$ & 0.53 & $0.53(0.18)$ & 0.60 & $0.54(0.19)$ & 0.60 & $0.58(0.17)$ & 0.003 \\
\hline Heart failure & 0.20 & $0.19(0.19)$ & 0.20 & $0.24(0.17)$ & 0.20 & $0.21(0.17)$ & 0.20 & $0.22(0.15)$ & 0.283 \\
\hline $\begin{array}{l}\text { Asthma- } \\
\text { heart failure }\end{array}$ & 0.50 & $0.44(0.27)$ & 0.30 & $0.29(0.21)$ & 0.35 & $0.33(0.21)$ & 0.38 & $0.36(0.20)$ & 0.002 \\
\hline
\end{tabular}

'Valuation from the ENT group is statistically significantly different from the valuations of the other groups (Mann-Whitney $U$ Test, $p<.005) ;{ }^{2}$ Difference between ENT group and Patient group is statistically significantly (Mann-Whitney $U$ Test, $p<.005$ ); ${ }^{3}$ Difference between Ophthalmology group and Patient group is statistically significantly different (Mann-Whitney $U$ Test, $\mathrm{p}<.005) ;{ }^{4}$ Difference between Patient group and ENT group is statistically significantly (Mann-Whitney $U$ Test, $\mathrm{p}<.005$ ).

\section{Controlling for the effects of age, gender and education}

After having assured that the assumption of equality of variances was not threatened (Levene Test), analysis of variance showed no statistically significant effect of gender or education level on the valuation of health states (see Table 4). Also none of the interactions between gender, education level, age and group were statistically significant. Age alone did influence some of the valuations: the 'health state after hearing aid fitting', 'asthma' and the difference between the valuations for 'asthma' and 'heart failure'.

After adjusting for age, the between-group effect on the valuation of the 'health state after hearing aid fitting' changed, and was no longer statistically significant. When corrected for age the mean valuation for this health state in the Patient group stayed more or less the same, but the valuations in the other groups dropped. It was found that in the Patient Group higher age was negatively correlated with the valuation for the health state after hearing aid fitting (Figure 1).

Age also influenced the valuation of 'asthma'. In the nonpatient groups the mean difference between the valuation for 'asthma' and 'heart failure', e.g. the proportion of the VAS used for valuation, became even smaller when 
adjusted for age. This suggest that higher age is positively correlated with the part of the VAS used to give valuations for mild and severe health states. This is graphically illustrated in Figure 2.

Table 4 Health state valuations (mean, se) from the Patient group, ENT group, Finance group and Ophthalmology group (adjusted for age when appropriate)

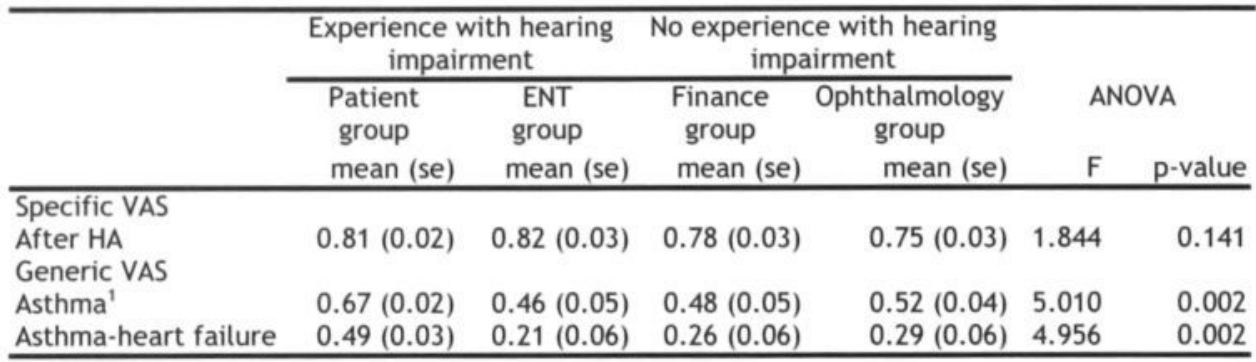

'Valuation from Patient group is statistically significantly different from the valuations of the other groups (Bonferroni).

\section{Conclusion and discussion}

\section{Were between-group differences present?}

The valuations of the health states before and after HA fitting differed between the groups. After adjusting for age the between-group effect on the valuation of the 'health state after hearing aid fitting' was however no longer statistically significant. In the Patient group higher age was correlated with a lower valuation for the health state after HA fitting, confirming the findings of Lamden et al (1995) were age was inversely related to perceived improvement in social, emotional and communicative functioning after hearing aid fitting.

It was hypothesized that the valuations of the health states before and after HA fitting obtained in persons with experience with hearing impairment would be higher than in persons without this kind of experience. With respect to the persons with medical knowledge of hearing impairment (the ENT group) the results confirmed this hypothesis. The relatively high valuation (higher even than in the Patient group) of the 'health state before hearing aid fitting' in the ENT group could be the result of their experience with satisfied hearing aid users. Their knowledge of and belief in a satisfactory intervention for hearing impairment could have positively influenced their perception of both health states. The valuations obtained in the Patient group were however not higher than the valuations obtained in both groups without experience with hearing impairment (Finance group and Ophthalmology group). A possible 
explanation could be that the patients had a lower perception of their hearing related health state due to the fact that they were currently seeking help for it. It is known that hearing-impaired persons who seek help report more hearing disability than persons who do not seek help, even when controlled for the degree of hearing impairment (Swan \& Gatehouse, 1990).

Figure 1 Valuations for 'before hearing aid fitting' and 'after hearing aid fitting' (unadjusted and adjusted for age)
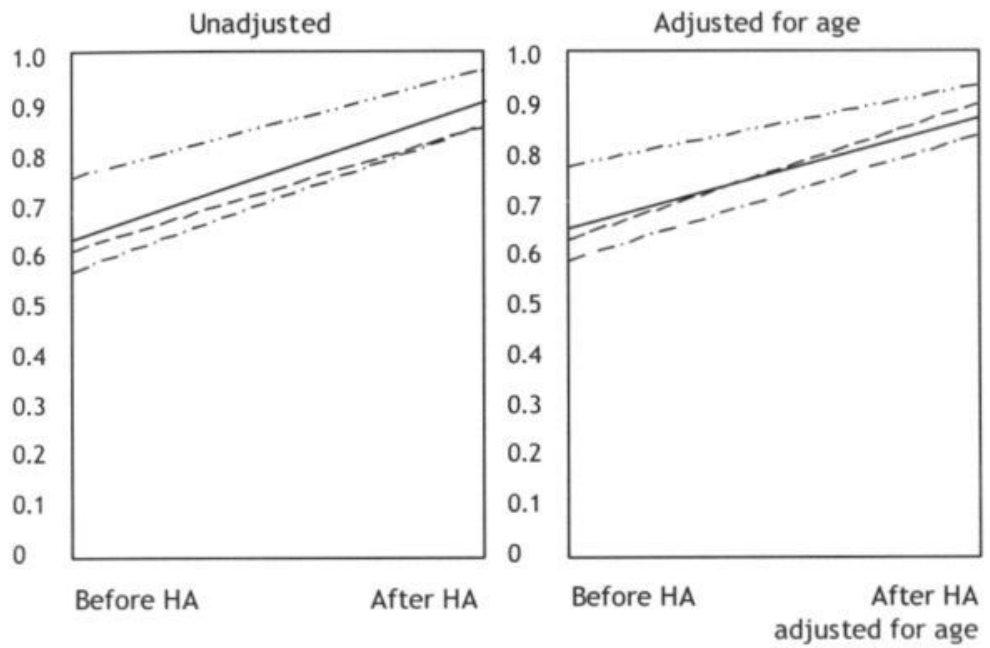

Patients

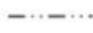

ENT

Finance

Ophthalmology

Figure 2 Valuations for 'heart failure' and 'asthma' (unadjusted and adjusted for age)
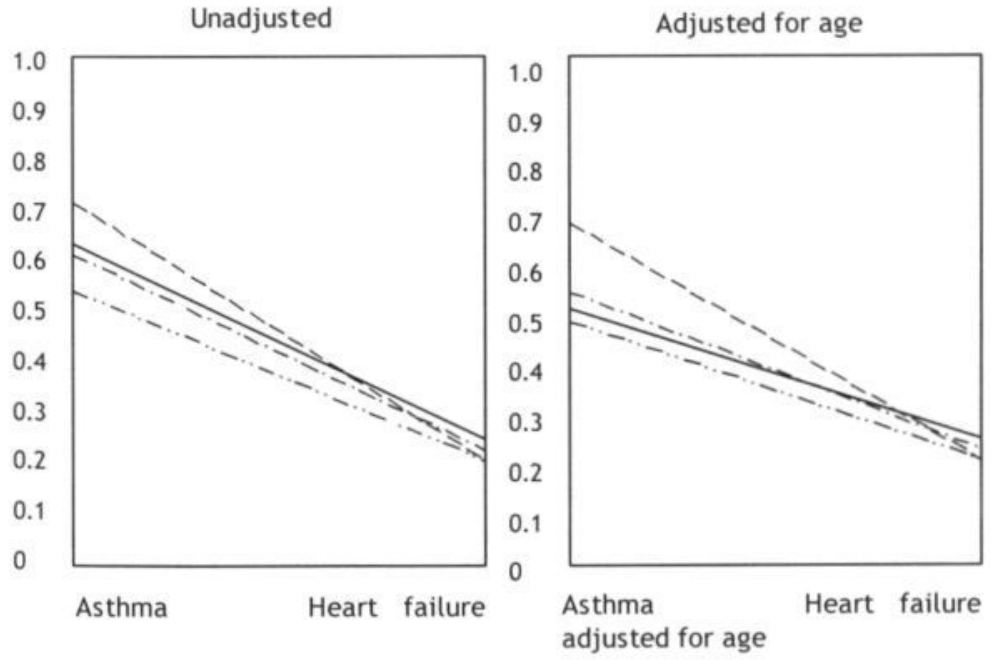

Patients

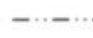

ENT

Finance

Ophthalmology 


\section{Did between-group differences affect gain in health state?}

The difference between the groups in gain in health state valuation after hearing aid fitting was not statistically significant. This indicates that the between-group differences only affected the positions of the valuations of the health states before and after hearing aid fitting on the VAS, but not the difference between the two valuations.

This is not in concordance with earlier findings that gain from population perspective is usually larger than gain based on patient values (Gold et al, 1996).

\section{Did differential use of the bottom anchor point of the specific VAS occur?}

The valuations of 'deaf' were not higher in the groups with $\mathrm{HI}$ experience, but were equal among the groups. This results indicates that the valuation shift observed in the valuations for the health states before and after HA fitting was not due to a differential use of the bottom anchor point of the specific VAS. In contrast to the valuation of 'deaf', the valuation of 'blind' was higher in the Ophthalmology group, and differed among the groups. Possibly, the ordering of the questions was of influence on the valuation of 'deaf'. The ENT group valued 'blind' equally high as the Ophthalmology group. It is likely that the subjects made a ranking decision when valuating 'deaf' after 'blind'. There seems to be some consensus that 'blind' is more serious than 'deaf', see Gold et al (1998) for instance. It is possible that the ENT group was reluctant to assign a higher value to 'deaf' than to 'blind', resulting in equal values for 'blind' and 'deaf', and thus a relatively low valuation for 'deaf'. These results indicate that illness experience might also influence the ranking of health states.

\section{Did valuation compression occur?}

The hypothesis that persons personally experienced with illness would use a smaller proportion of the VAS than persons without illness experience could be fully rejected in this study. It were the patients who used the largest part of the VAS to give valuations to the mild and severe health states. Since the valuations for 'heart' were equal among the groups, this was largely because the patients had higher valuations for the mild health state. Which is not in concordance with earlier findings that patients give lower valuations for better health states (de Wit, 2000; Kind \& Dolan, 1995; Badia et al, 1996). The valuations for 'asthma' in the nonpatient groups were very similar, indicating that illness experience through medical knowledge as opposed to personal experienced illness did not influence the proportion of the VAS used to value health states. 


\section{Overall conclusion}

From the results of this study it was confirmed that illness experience, both personally as otherwise, influences the valuation of health states. Not only the valuations of health states, but also the ranking of health states seemed to be altered by illness experience. The results did not confirm that gain in health state after hearing aid fitting was larger from nonpatient perspective than based on patient values. With regard to valuation compression there was some indication that the influence of experience on health state valuations may be less straight forward than presumed, in contrast to earlier findings, it was observed that patient group on average used a larger part of the VAS than the nonpatient groups. 


\section{Chapter 6}

The cost-effectiveness of hearing aid fitting in the Netherlands 
Joore MA, van der Stel H, Peters HJM, Boas GM, Anteunis LJC. The costeffectiveness of hearing aid fitting in the Netherlands. Archives of Otolaryngology Head and Neck Surgery. In review process. 


\section{Introduction}

Hearing impairment is a very common condition, of which the onset is tightly coupled with ageing. When defined as an average pure tone hearing loss of the best ear of $35 \mathrm{~dB}$ or more at $1,2,4 \mathrm{kHz}$, hearing impairment was found in $75 \%$ of the population aged over 80 years (Abutan et al, 1993). As the prevalence of hearing impairment increases rapidly with age, hearing impairment will be one of the most prevalent health problems in societies with ageing populations. Hearing impairment has been associated with emotional, social and communication dysfunction (Mulrow et al, 1990).

Even so, there is only little information about the economic consequences of hearing impairment to society. In the United States the lifetime costs of profound to severe hearing loss (defined as hearing thresholds of $70 \mathrm{~dB}$ or more averaged across the frequencies $0.5,1$ and $2 \mathrm{kHz}$ ) when the onset is above 60 years of age were estimated to be on average 43,000 United States dollars (US\$) (Mohr et al, 2000). It has been shown that the use of hearing aids improves the social, emotional and communication functions and reduces depression (Mulrow et al, 1990). Although in most cases of sensorineural hearing impairment a hearing aid is the only option for rehabilitation, only a few studies calculated both costs and effects associated with hearing aid fitting (Tonning et al, 1995; Brickley et al, 1996, Parving et al, 1997; Yueh et al, 2001). None of these studies focused on the societal costs and effects of fitting hearing aids, and no study performed a cost-effectiveness analysis.

The objective of this study was to determine the cost-effectiveness of fitting hearing aids in adult hearing-impaired persons compared to not fitting hearing aids, in the Netherlands. All costs are in Euro's (1 Euro is 1.08 US\$, 1998 conversion rate). The results from a prospective study of hearing aid fitting in first time users were combined with observational data in order to obtain a realistic view of the economic impact of hearing aid fitting on society. All data were incorporated in a simulated cohort model of hearing disability in the population. The study results in two cost-effectiveness ratios for hearing aid fitting: costs per quality adjusted life year (QALY) and costs per hearing related quality adjusted life year (Hearing-QALY). The latter is a combined measure of effect, based on life-expectancy and on hearing specific quality of life.

\section{Methods}

\section{Model of hearing aid fitting}

The assessment of the costs and effects of hearing aid fitting in persons with hearing complaints, by its very nature requires the use of a dynamic modelling approach. People have hearing complaints, may undergo the process of 
hearing aid fitting, may become better or worse, may in time re-apply for hearing aids or not, and so on.

Figure 1 A model of hearing aid fitting in the Netherlands

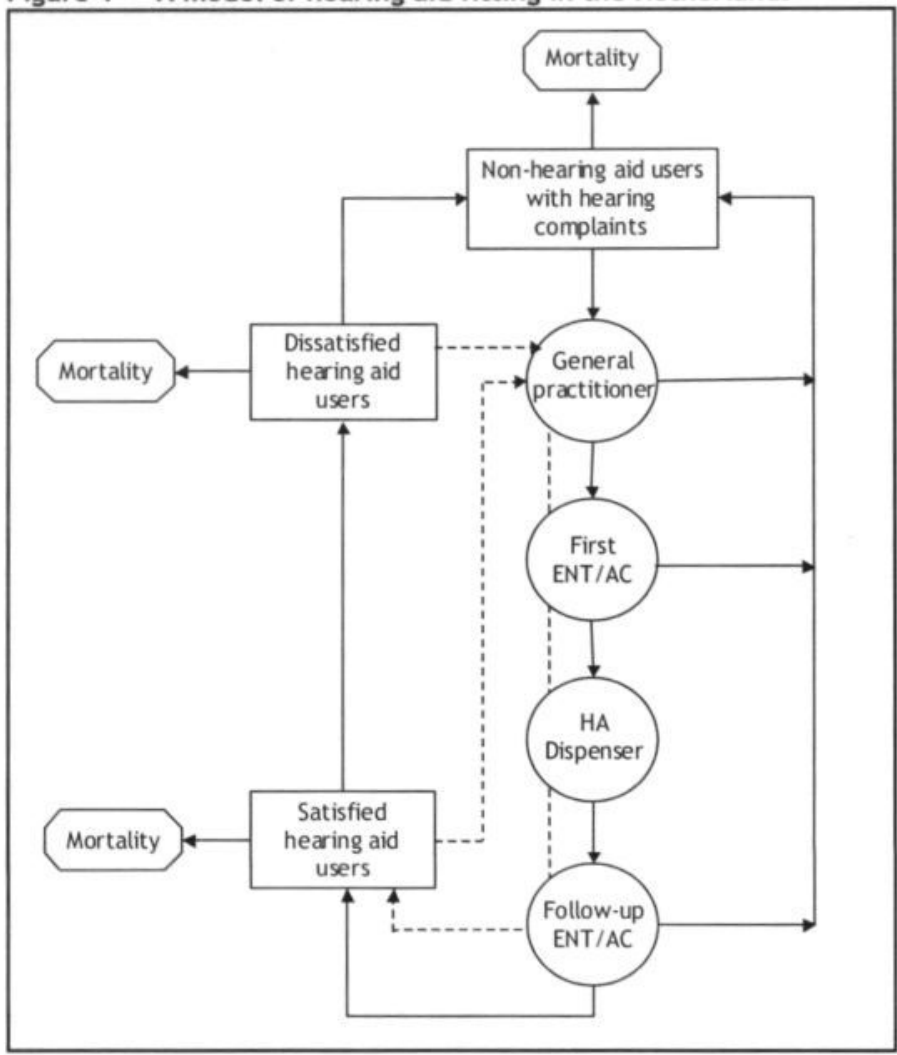

In a dynamic model the population is divided over different health states, and over time persons move from one health state to another according to certain transition probabilities that can be assessed empirically. These models are often referred to as state transition models or Markov models. Markov models are particularly useful when modelling decision problems involving ongoing risk (Sonnenberg \& Beck, 1993). We used cohort simulation to evaluate the model: a fixed number of persons per age group were followed during their lifetime. The cohort ceased to exist when all members of the cohort group had died. The model ran with steps of one year: during the year persons moved between the different health states, resulting in a new distribution of persons over the health states on the first day of the next year. The starting year of the model was 1995, while mortality figures were based on data from the Central Bureau of Statistics (CBS) of that year. Both future costs and future benefits were discounted to their present value by a rate of $5 \%$. Boas et al (2001) describe the technical and methodological merits of dynamic 
modelling in the case of hearing aid fitting more extensively. The model distinguishes between three different health states: persons with hearing complaints without a hearing aid ("non hearing aid users with hearing complaints"), persons with hearing complaints who are satisfied with their hearing aid ("satisfied hearing aid users"), and persons with hearing complaints who are dissatisfied with their hearing aid ("dissatisfied hearing aid users"), see the rectangular boxes in figure 1. From these health states persons can enter the diagnostics and treatment phase (circular boxes, figure 1). In the Netherlands all patients must first consult their GP for referral to either an Ear Nose and Throat (ENT) specialist or an Audiological Centre (AC). Only ENT-specialists and audiologists are entitled to prescribe hearing aids. ACs offer multidisciplinary specialised help for the more serious or complicated cases. The actual hearing aid fitting takes place at a hearing aid dispenser. Once a satisfying hearing aid is fitted the patient returns to the ENT-specialist or AC for approval of the hearing aid fitted. The approval entitles the patient to (partial) reimbursement of the hearing aid.

\section{Quality of life assessment and cost/QALY calculation}

A prospective intervention study of hearing aid fitting was carried out at the Ear Nose and Throat (ENT) clinic of the university hospital Maastricht in collaboration with the Hoensbroeck Audiology Centre. The medical ethics committee of the university hospital Maastricht approved of the study. Hearing-impaired persons of 18 years and older were asked to enter the study when they received a prescription for a hearing aid from their ENT specialist or audiologist. Immediately after their written informed consent the baseline measurement took place. This measurement consisted of pure tone audiometry and a questionnaire. Afterwards a hearing aid dispenser performed the hearing aid fitting. When, after the trial period a satisfying hearing aid was fitted the person visited the ENT specialist or audiologist again, and the hearing aid fitting was evaluated and eventually approved. The follow up measurement was scheduled at 4 months after baseline at the ENT clinic or audiology centre. From February 1998 to March 1999126 hearingimpaired persons entered the study. Of them $28 \%$ attended the University Hospital and $72 \%$ the audiology centre. A total of 48 persons left the study for the following reasons: no hearing aid fitted $(N=17)$, deceased $(N=2)$, illness $(N=2)$, own request $(N=15)$, lost to follow up $(N=12)$. Finally 78 persons completed the third and final measurement. The mean age of the persons who completed the study was 69.1 years (range 29 to 96 years). The mean hearing loss was $47.4 \mathrm{~dB}$ at 1,2 and $4 \mathrm{kHz}$ in the best ear. The persons who left the study were somewhat younger (65.5 years), and had somewhat better hearing $(43.5 \mathrm{~dB})$ than the persons who completed the study. Approximately half of the participants was male ( 42 persons, $53.8 \%$ ) and 52 persons were married $(66.7 \%)$. Most persons were fitted with a hearing aid behind the ear (79\%), the remaining persons were fitted with an in-the-ear hearing aid (18\%), and only 2 persons (2.6\%) were fitted with an in-the-canal hearing aid. 
In order to measure change in overall health related quality of life the EuroQol 5 Dimensions (EQ-5D) was used (EuroQol Group, 1990). This generic measure consists of five questions concerned with the dimensions of overall health status ('mobility', 'self care', 'daily activities', 'pain and complaints', and 'feeling'), a question about health transition and a visual analogue scale (VAS). The answers on the VAS can be interpreted as patient scores. Dolan (1995) developed an algorithm to calculate population utilities from the patient data. It was perceived that the sensitivity of the EQ-5D, as for virtually all generic measures, to detect changes in health related quality of life after hearing aid fitting would be sub optimal. Therefore the effect of hearing aid fitting was also measured using a hearing specific scale: a VAS ranging from ' 0 ' is 'deaf' to ' 1 ' is 'perfect sense of hearing'. This hearing specific VAS is part of a newly developed multi-attribute questionnaire (the Audiological Disabilities Preference Index; ADPI) to measure the effect of interventions for hearing impairment and disability on specific quality of life (Joore et al, 2002b; Zank et al, 2002). The ADPI also provides a method to frame the directly obtained hearing specific health state preferences in an overall health perspective, taking into account the presence of multimorbidity. This method is described in Joore et al (2002b).

It was assumed that only satisfied hearing aid users would experience gain in quality of life as a result of hearing aid fitting. The total amount of QALYs gained was computed by counting the total number of satisfied users in a certain year, multiplying by the change in the population utility estimate from the EQ-5D, and adding over the total life expectancy. Age specific cost/QALY ratio's were calculated by dividing the total amount of costs by the total amount of QALYs gained generated in the specific age category. To calculate the overall cost/QALY ratio the distribution of persons over the age categories should match the distribution of persons eligible for a hearing aid (persons with hearing complaints) at population level. Otherwise the average cost/QALY ratio might not be representative at population level, and thus not suited for decision making (Baltussen et al, 1996). Therefore the number of persons in each age group reflected the age specific prevalence of hearing complaints. Then, the overall cost/QALY outcome was calculated by dividing the sum of costs by the sum of QALYs. In the calculation of the costs/HearingQALY the gain on the hearing specific VAS was used.

\section{Probabilities}

Non hearing aid users with hearing complaints

Of the Dutch population circa $11.4 \%$ has hearing complaints defined as 'having some difficulties' or 'being unable' to follow a conversation in a group of 3 persons or more (CBS, 1994). Of the population with hearing complaints, approximately $20 \%$ is fitted with hearing aids (Duijvestijn et al, 1999). Based on an epidemiological field study (Chorus et al, 1995) the population with 
hearing complaints but without hearing aids was for both sexes subdivided in five-years age groups. From this it was calculated that $4.04 \%$ of the population aged from 15 to 60 years and $32.43 \%$ of the population aged over 60 years have hearing complaints, but no hearing aid. Of the population with hearing complaints younger than 60 years $67 \%$ was male, as opposed to $50 \%$ in the general population under 60 years. Annually approximately 132,000 nonhearing aid users of 15 years and older contact their GP with hearing complaints for the first time (incidence of 9.2 patients per 1000 patients, in: Chorus et al, 1995). Based on age specific incidence data it was calculated that the average transition probability to contact the GP from the population of non-hearing aid users with hearing complaints was $4.28 \%$ for persons aged between 15 and 60 years and $16.44 \%$ for persons aged over 60 years (Chorus, 1995). See Table 1.

\section{Diagnostics and treatment phase}

Of the persons who visit the GP with hearing problems $45 \%$ are not referred to an ENT specialist or AC (Abutan et al, 1993). When referred to the ENTspecialist or AC, $75 \%$ received a prescription for a hearing aid (Duijvestijn et al, 1999). Eventually, somewhat over $7 \%$ of all hearing aid trials ended without the purchase of a hearing aid (Streukens \& Leenen, 1996). The probabilities to first see the GP and eventually have a hearing aid fitted are the same for men and women (Duijvestijn et al, 1999). It was assumed that all hearing aid re-applicants (both satisfied and dissatisfied) would go through all treatment stages and end up with a new satisfyingly fitted hearing aid (dotted lines in figure 1). Table 1

\section{Satisfied and dissatisfied hearing aid users}

All persons who were first fitted with hearing aids entered the satisfied hearing aid users population, since it was assumed that if the person was not satisfied with the hearing aid fitting, no hearing aid would be purchased. It was found that $11 \%$ of all hearing aid users develop a dissatisfied attitude towards the hearing aid, expressed in an (ir)regular use of the hearing aid for less than four hours per day (Chorus et al, 1995). Since this phenomenon seemed more prevalent in elderly persons (Kapteyn et al, 1995), it was assumed that of the inflow to the dissatisfied hearing aid users population the proportion of persons aged between 15 and 60 years was 10\%, versus $90 \%$ persons of 60 years and older. This resulted in transition probabilities of 6.08 and 12.16 respectively. Based on the study of Grootveld et al (1989) it was calculated that annually $12 \%$ from the dissatisfied hearing aid users were transferred to the non-hearing aid users population, because they no longer used their hearing aid. The average replacement time of the persons in the satisfied hearing aid users population was calculated by correcting the annual number of hearing aids sold for 1 ) the proportion of hearing aids sold to first time hearing aid users, and 2) mortality in the population of satisfied hearing 
aid users. It was assumed that the average replacement time of irregularly used hearing aids was approximately double the replacement time of satisfied hearing aid users. See Table 1.

\section{Mortality}

All populations were adjusted for mortality annually. Mortality rates were specific for age (five-years age groups) and gender.

\section{Costs}

In this study costs were considered from a societal point of view. Societal costs consist of the extra health care and non-health care costs (regardless of who pays for them) decreased by savings resulting from the possible gain in productivity related to the intervention. The direct health care costs included in the study were associated with: consultations (general practitioner, ear nose and throat specialist, audiology centre), diagnostics (audiometry), hearing aid fitting, hearing aid instrument, hearing aid use (batteries, repair). Direct non health care costs such as time costs and costs of travel associated with the hearing aid fitting and hearing aid use were not quantified. Possible savings in terms of increased productivity were assessed in the prospective study of first time hearing aid fitting. The most recent price information was from 1998, so all costs were based on the 1998 price level. On July first 1998 1.0 Euro was 1.08 US\$. Table 1 provides a summary of all cost input.

\section{GP consultation}

In 1998 the costs per GP consultation were on average $€ 16.26$ (Ooostenbrink et al, 2000). Only the costs of the GP consultations related to the referral to the ENT specialist or audiological centre were counted. This number was estimated at 1.5 consultations per person, the costs of GP consultations related to hearing aid fitting were $€ 24.40$.

\section{ENT clinic}

In the Netherlands $85 \%$ of all hearing aid fittings was performed through an ENT clinic. The costs per ENT consultation were in 1998 on average $€ 28.26$ (low estimate, non-university hospital) (Oostenbrink et al, 2000). During the process of hearing aid fitting the ENT-specialist was visited twice: for diagnosing the hearing impairment and prescribing a hearing aid, and later for the approval of the hearing aid fitted. At both consultations in the ENT-clinic tone and speech audiometry was performed to diagnose hearing impairment and evaluate the hearing aid fitted. The costs of the audiometry were based on weighted averages of the tariffs for voluntary and compulsory insurance. In 1998 the costs for tone audiometry were $€ 29.55$ and the costs for speech audiometry were $€ 63.65$. The total costs of the ENT clinic amount to $€ 242.92$ 
per successful hearing aid fitting ( $€ 121.46$ per consultation). It was assumed that after a negative trial at the hearing aid dispenser only $50 \%$ of the persons would consult the ENT specialist afterwards, and that at this consultation no audiometry would be performed. The costs of the follow up at the ENT clinic after a negative trial amount to $€ 28.26$.

\section{Audiology Centre}

Of all hearing aid fittings $15 \%$ is performed at an audiology centre. The tariff for the audiology centre was $€ 216$ in 1998. For this amount audiometry, and when indicated an extensive counselling and rehabilitation program is performed.

\section{Hearing aid dispenser}

It was assumed that every person who receives a prescription shows at a dispenser. The costs of a negative trial at the hearing aid dispenser were estimated to amount to the dispensers fee in the price of a hearing aid (39\%) (Ziekenfondsraad, 1994).

\section{Hearing aid}

In the Netherlands a market study of the average purchase costs of a hearing aid found an average price of a hearing aid of $€ 636.00$ in 1995 (Mot \& Meulenbeek, 1997). This price was corrected for price differences from 1995 to 1998 using the Dutch health care price index figures (Oostenbrink et al, 2000 ), resulting in an average price of $€ 671.00$ in 1998. According to the market study of the Dutch Association of Hearing Aid Dispensers 25\% of all sales are binaural fittings (Streukens \& Leenen, 1996), in which case the costs are doubled. Costs resulting from the use of hearing aids were costs of batteries and repair. Based on the average daily hearing aid use in satisfied and dissatisfied users (Verlare, 1985) and the costs of hearing aid batteries (website NVVS: www.nvvs.nl), the yearly costs of batteries were estimated at $€ 34.30$ for satisfied users and $€ 10.04$ for dissatisfied users. At average behind-the-ear hearing aids were repaired 1.2 times per 5 years and in-theear hearing aids 1.9 times per 5 years. The average costs per repair were estimated at $€ 68.1$ (Streukens \& Leenen, 1996). Based on the ratio of behindthe-ear versus in-the-ear hearing aids (75:25), the average yearly repair costs per hearing aid were estimated at $€ 18.75$.

\section{Productivity loss}

Only 10 persons in the prospective hearing aid fitting study performed paid labour (12,5\%). This seemed normal after considering the age distribution of a population of adult first time hearing aid applicants. They did not report any absence from work due to hearing impairment or due to other health 
problems (Joore et al, 2002a). Based on these results, in this population of moderately hearing-impaired first time hearing aid users, there are no productivity losses due to not being fitted with hearing aids. And thus, there are no savings resulting from possible gain in productivity after hearing aid fitting.

\section{Analysis}

The characteristics of the study population were presented using descriptive statistics. The results on the EQ-5D (VAS and the population utility estimate) and the hearing specific VAS were presented as mean +/- standard deviation. The comparison of the scores before and after hearing aid fitting on the EQ-5D and the hearing VAS was conducted with the paired samples t-test when normally distributed, or the Wilcoxon Signed Ranks Test when not normally distributed. The $95 \% \mathrm{Cl}$ of the change in EQ-5D population utility estimate, and the change in Hearing-VAS score, together with the highest and lowest estimates of the costs were used to construct cost-effectiveness confidence boxes on the cost-effectiveness plane to present the confidence limits of the estimates of the cost/QALY outcome and the cost/Hearing-QALY outcome. The cost-effectiveness plane is a coordinate system with the incremental costs on the $y$-axis and the incremental effects on the $x$-axis, and is often used to show the outcomes of cost-effectiveness studies (Briggs \& Fenn, 1998). The four quadrants represent the four possible outcomes of incremental costs and health effects of a new health intervention. Univariate sensitivity analysis was performed in order to test the robustness of the cost/QALY outcomes for variation in single model input parameters.

\section{Results}

\section{Quality of life and cost outcomes}

The average scores on the hearing-VAS showed a substantial and highly statistically significant improvement after hearing aid fitting $(0.27,95 \% \mathrm{Cl}$ $0.22-0.30, p<0.001$, Paired T-Test), while both the result on the EQ-5D VAS (patient preferences) and the EQ-5D population utility estimate showed only a small and non statistically significant gain in quality of life $(0.02$ and 0.03 respectively). When the result on the hearing-VAS was framed in an overall health perspective the improvement was $0.12(95 \% \mathrm{Cl} 0.10-0.14, \mathrm{p}<0.001$ Paired T-Test). The average costs of hearing aid fitting in a population of persons with hearing complaints amount to $€ 781$ (base case estimate, discounted). Of this amount $60 \%$ is spent on hearing aids, $16 \%$ on hearing aid batteries and repair, and $14 \%$ are direct health care costs. Based on the highest and lowest estimates for all cost parameters, the average incremental costs range between $€ 1.197$, and $€ 490$. 


\begin{tabular}{lcc}
\hline Parameter & $\begin{array}{c}\text { Base case } \\
\text { estimate }\end{array}$ & $\begin{array}{c}\text { Range of } \\
\text { estimate Source }\end{array}$ \\
\hline
\end{tabular}

Non hearing aid users with hearing complaints

Annual probability to visit GP for hearing complaints (<60yr) Annual probability to visit GP for hearing complaints ( $\geq 60 \mathrm{yr}$ )

Diagnostics and treatment phase

Annual probability to be referred by GP

Annual probability to receive prescription for a hearing aid

Annual probability of negative trial at dispenser

Hearing aid users

Annual probability to become dissatisfied HA user ( $<60 \mathrm{yr}$ )

Annual probability to become dissatisfied HA user ( $\geq 60 \mathrm{yr}$ )

Annual probability to become a non HA user

Hearing aid replacement time satisfied $\mathrm{HA}$ user

Hearing aid replacement time dissatisfied $\mathrm{HA}$ user

Mortality

Annual age and gender specific mortality

Gain in generic quality of life

Patient score on the EQ-5D VAS $(95 \% \mathrm{CI})$

Population utility estimate EQ-5D $(95 \% \mathrm{CI})$

Gain in hearing specific quality of life

Patient score on hearing specific VAS $(95 \% \mathrm{CI})$

Patient score on hearing specific VAS framed in an overall

health perspective $(95 \% \mathrm{CI})$

\section{Costs}

GP consultation

ENT-clinic first consultation

ENT-clinic follow up consultation after successful trial

ENT-clinic follow up consultation after negative trial

Audiology Centre

Ratio hearing aid fittings through ENT clinic/AC

Hearing aid

Proportion binaural fittings

Hearing aid dispenser negative trial (per hearing aid)

Hearing aid battery costs for satisfied HA users

Hearing aid battery costs dissatisfied HA users

Hearing aid repair costs satisfied HA users

Hearing aid repair costs dissatisfied HA users

Savings as a result of reduced productivity loss

$\begin{array}{rrr}4.3 \% & 2.1 \%-8.6 \% & 1 \\ 16.4 \% & 8.2 \%-32.9 \% & 1\end{array}$

$54.5 \%$

$75.0 \%$

$7.4 \%$

$40 \%-70 \%$

$62.5 \%-87.5 \%$

$3.7 \%-11 \%$

2

3

3

$\begin{array}{rrr}6.1 \% & 0 \%-12 \% & 1,4 \\ 12.2 \% & 12 \%-24 \% & 1,4 \\ 12.0 \% & \cdot & 4 \\ 8.2 \text { yrs } & 4.1-12.4 \text { yrs } & \text { EO } \\ 5.0 \text { yrs } & 7.5-22.5 \text { yrs } & \text { EO }\end{array}$

5 yrs categories

CBS

0.02

$-0.02 \cdot 0.05$

TS

0.03

$-0.03 \cdot 0.08$

TS

0.27

$0.22 \cdot 0.31$

TS

0.12

$0.10-0.14$

EO: expert opinion; TS: this study.

${ }^{1}$ Chorus et al, 1995; ${ }^{2}$ Abutan et al, $1993 ;{ }^{3}$ Streukens et al, $1996 ;{ }^{4}$ Grootveld et al, 1989; ${ }^{5}$ Joore et al, 2002b; ${ }^{6}$ Oostenbrink et al, 2000; ${ }^{7}$ Mot, 1997; ${ }^{8}$ Sick Fund, 1994; ${ }^{9}$ Consumers information on www.NVVS.nl; ${ }^{10}$ Verlare, 1985; "Information from personal communication with the Dutch association of hearing aid dispensers (NVAB). 


\section{Cost / QALY outcomes}

Based on the average outcome of the EQ-5D population utility estimate (mean utility gain 0.03 ) as a result of hearing aid fitting in the total population with hearing complaints per person on average 0.05 QALYs are gained. The cost/QALY outcome ranges from $€ 11,984$ in the youngest to $€ 34,902$ in the oldest age group. The increase with age is due to increasing mortality during the life span of a hearing aid in elderly age groups. As a result the outcomes are also slightly less beneficiary for male as compared to female hearing aid users in the age groups above 50 years. The average cost/QALY outcome amounts to $€ 15,807 /$ QALY. This outcome is considered as base case estimate. 23,745/QALY).

Figure 2 Age-specific cost-effectiveness ratios for hearing aid fitting based on gain in health state assessed by EQ-5D (population and patient estimate) and hearing-VAS (specific score and framed in an overall health perspective)

Cost-effectiveness

ratio

60.000

50.000

40.000

30.000

20.000

10.000

0

$15-19 \quad 20-24 \quad 25-29 \quad 30-34 \quad 35-39 \quad 40-44 \quad 45-49 \quad 50-54 \quad 55-59 \quad 60-64 \quad 65-69$ 70-74 75-79 80-84 85-89 90-94 95-99

- 0.03 gain EQ-5D population utility estimate

age

- 0.02 gain EQ-5D patient estimate

- 0.27 gain hearing-VAS

-0.12 gain hearing-VAS framed in overall health perspective

When using the patient scores on the EQ-5D VAS, per person on average 0.03 QALYs are gained. The cost/QALY outcome ranges from $€ 17,996$ in the age group 15-19 years to $€ 52,502$ in persons aged 95-99 years. Based on the average gain in hearing related quality of life 0.44 Hearing-QALYs are gained. The costs/Hearing-QALY ranges from $€ 1,333$ in the youngest ages to $€ 3,889$ in the oldest age-group. The overall costs/Hearing-QALY amount to $€ 1,759$. When using average gain in hearing related quality of life framed in overall health of 0.12 the outcome across all age-groups amounts to $€ 3.952 / \mathrm{QALY}$ (range from $€ 2.996$ to $€ 8.726 /$ QALY) . See Figure 2 for a graphical illustration. 


\section{Results on the cost-effectiveness plane}

The lower and upper limit of the $95 \% \mathrm{Cl}$ of the average incremental population utility $(-0.03$ and 0.08$)$ combined with the highest and lowest incremental cost estimates result in a worst and best case scenario. The cost/QALY in the worst case scenario amount to $€ 24.239$ per QALY lost, and the cost/QALY in the best case scenario amount to $€ 3.718$ per QALY gained.

Based on these outcomes a confidence box was constructed around the base case cost/QALY outcome. The highest and lowest incremental cost estimates together with the lower and upper boundaries of the gain in hearing related quality of life, are used to construct a confidence box for the cost/HearingQALY outcome (see Figure 3). In the worst case scenario in this hearing specific perspective the costs are $€ 3,305$ per Hearing-QALY gained, and in the best case scenario the costs are $€ 959$ per Hearing-QALY gained.

Figure 3 Confidence boxes on the cost-effectiveness plane representing the worst and best case outcomes using the $95 \% \mathrm{Cl}$ of the population utility estimate (E; left figure) and of the hearing VAS score (right figure), and the range in cost outcomes (C)
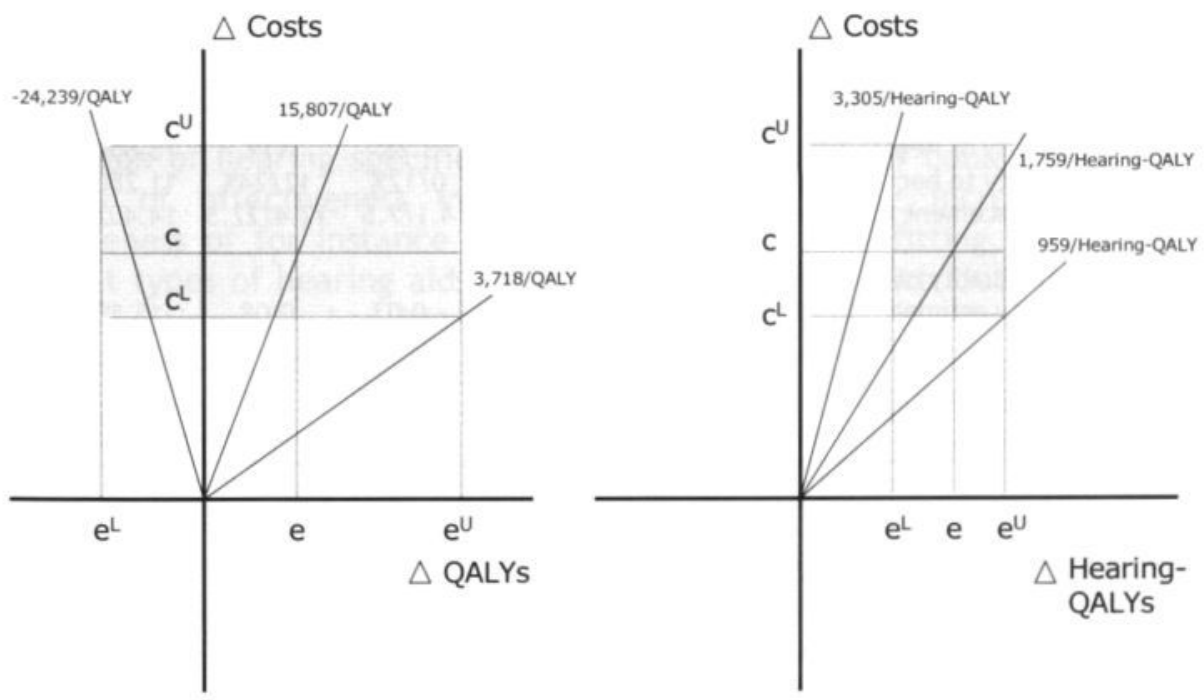

\section{Sensitivity analysis}

The base case outcome ( $€$ 15,807/QALY based on the average incremental population utility of 0.03 ) is used as input in the univariate sensitivity analysis. Change in quality of life has by far the most impact on the cost/QALY outcome. Varying the utility gain between -0.03 and 0.08 the cost/QALY ranges from $€-15,807$ to $€ 5,936$. When the price per hearing aid is varied between $€ 350$ and $€ 1,000$, the cost/QALY outcome varies between $€$ 
11,209 and $€ 20,575$. When the proportion stereo fitting is changed from the base case estimate of $25 \%$ to $10 \%$ and $50 \%$, the outcome changes from $€$ $14,560 / Q A L Y$ to $€ 17.948 / Q A L Y$. When the replacement time of a hearing aid is halved and doubled the outcome varies between $€ 14,402$ and $€ 20,175$ per QALY. Amongst the transition parameters in the sensitivity analysis, becoming a dissatisfied hearing aid user has the largest impact on the outcome. When the chance to become dissatisfied is halved and doubled, the outcome varies between $€ 11,280$ and $€ 20,283$ per QALY. The other transition parameters in the sensitivity analysis have only little effect on the cost/QALY outcome. See Table 2.

Table 2 Outcomes univariate sensitivity analysis; base case $€ 15,807$

\begin{tabular}{|c|c|c|c|}
\hline \multirow[b]{2}{*}{ Parameter } & \multicolumn{2}{|c|}{ Range of estimate } & \multirow{2}{*}{$\begin{array}{c}\text { Range } \\
\text { Cost/QALY } \\
€\end{array}$} \\
\hline & low & high & \\
\hline $\begin{array}{l}\text { Non hearing aid users with hearing complaints } \\
\text { Annual probability to visit GP for hearing complaints } \\
\text { ( }<60 \text { yrs } / \geq 60 \text { yrs) }\end{array}$ & $2.1 / 8.2 \%$ & $8.6 / 32.9 \%$ & $15,909 \cdot 15,720$ \\
\hline Diagnostics and treatment phase & & & \\
\hline $\begin{array}{l}\text { Annual probability to be referred by GP } \\
\text { Annual probability to receive prescription for HA } \\
\text { Annual probability of negative trial at dispenser } \\
\text { Annual probability to become dissatisfied ( }<60 / \geq 60 \mathrm{yrs} \text { ) } \\
\text { Hearing aid replacement time (satisfied/dissatisfied) }\end{array}$ & $\begin{array}{l}40 \% \\
62.5 \% \\
3.7 \% \\
0 / 12 \% \\
4.1 / 7.5\end{array}$ & $\begin{array}{c}70 \% \\
87.5 \% \\
11 \% \\
12 / 24 \% \\
12.4 / 22.5\end{array}$ & $\begin{array}{l}15,691-16,039 \\
15,565-16,197 \\
15,652-16,017 \\
11,280-20,283 \\
14,402-20,175\end{array}$ \\
\hline $\begin{array}{l}\text { Gain in generic quality of life } \\
\text { Population utility estimate EQ-5D }(95 \% \mathrm{CI})\end{array}$ & -0.03 & 0.08 & $-15.807-5,936$ \\
\hline $\begin{array}{l}\text { Costs } \\
\text { Proportion binaural fittings } \\
\text { Hearing aid }\end{array}$ & $\begin{array}{rl} & 10 \% \\
€ & 350 \\
\end{array}$ & $\begin{array}{rl} & 50 \% \\
€ & 1,000 \\
\end{array}$ & $\begin{array}{l}14,560-17,948 \\
11,209-20,575\end{array}$ \\
\hline
\end{tabular}

\section{Conclusion and discussion}

Given the base case estimate of input parameters, hearing aid fitting costs society between $€ 11,997 /$ QLY in the youngest age group, and $€$ $35,001 /$ QALY in the oldest age group. The average outcome across all ages is $€ 15,807 /$ QALY. Laupacis et al (1992) found that the reimbursement of interventions costing below CAN\$20,000 per QALY was generally never questioned (CAN\$ 20,000 $\cong € 16,000$ ). The base case estimate of $€$ 15,807 QALY for fitting hearing aids is around CAN\$20,000 per QALY, and based on this outcome fitting hearing aids could be considered as a costeffective health care intervention. Since the $95 \% \mathrm{Cl}$ of the change in quality of life after hearing aid fitting as measured by the EQ-5D included zero, the effect of hearing aid fitting on generic quality of life could not be determined 
unambiguously. As a result, the confidence box around the cost/QALY outcome (Figure 3 ) clearly shows that the conclusion that fitting hearing aids is more cost-effective than not fitting hearing aids remains uncertain.

The improvement on the Hearing-VAS was in contrast substantial and statistically significant. The effectiveness of hearing aids improving hearing related quality of life was hereby confirmed. These observations could indicate that the EQ-5D lacked sensitivity for the purpose of this study. Even though this seems highly likely, no study has been able to demonstrate an effect of hearing aid fitting on generic quality of life using a measure suitable for use in CEA (Bess, 2000; Yueh et al, 1999). Other prominent generic health status measures besides the EQ-5D, like the Short Form Health Survey 36 (SF36) and the Health Utilities Index (HUI) Mark II, would also suffer from limitations for this purpose. The SF36 contains very few items that could be influenced by the psychological, social and emotional consequences of hearing impairment (Cox et al, 2000). According to the HUl Mark II scoring formula, being both deaf and blind generates the same amount of disutility as being only deaf or only blind, which is a counterintuitive outcome (Cox et al, 2000). Overall, there is need for health status measures suited for the evaluation of the effect of interventions for sensory disabilities, such as hearing aids, on generic quality of life.

The hearing specific VAS was used to determine the weights for the calculation of hearing specific QALYs. This type of QALY could be useful as measure of effectiveness in studies determining the incremental costeffectiveness of for instance binaural versus monaural fitting, and amongst different types of hearing aids. For this purpose a multiattribute preferencebased questionnaire has been developed around the hearing specific VAS (Zank et al, 2002; Joore et al, 2002b).

The cost-effectiveness of an intervention is only one criterion for inclusion in the basic package of social insurance. The necessity of treatment for the individual and the severity of the disease are also criteria for the inclusion of an intervention in the basic package (Rutten \& van Busschbach, 2001). Hearing impairment is often trivialized as a normal aspect of ageing and associated with stigmatised conditions such as mental disorders (Gilhome Herbst, 1983). This could lead to a lower perception of the severity of hearing impairment and the necessity of hearing aid fitting than in reality might be the case. Perhaps this has played a role in the decrease of the reimbursement for hearing aids in the Netherlands over the last years. With the advancing technological possibilities of hearing aids and the related increase of the price of hearing aids the amount of reimbursement might become a barrier to seek treatment for hearing-impaired persons.

The sensitivity analysis showed highly robust outcomes with respect to the major cost and transition parameters. The parameter that most substantially 
influenced the base case estimate was the change in quality of life. The only other parameters that influenced the cost/QALY outcome were the costs of the hearing aid, and the probability to become a dissatisfied hearing aid user. In the sensitivity analysis it was assumed that the price of the hearing aid would not influence the gain in health related quality of life. In real life more expensive (for instance digital) hearing aids might lead to a larger gain in health related quality of life. In future research the possible extra benefits of more expensive hearing aids, or binaural fitting, should be identified in terms of the incremental cost-effectiveness in well defined patient categories. The probability to become a dissatisfied hearing aid user also influenced the outcome quite substantially. Therefore, changes in hearing aid fitting policy that would increase the probability to become a dissatisfied hearing aid user would considerably increase the amount of cost/QALY for hearing aid fitting. For instance, screening for hearing impairment in order to fit more hearingimpaired persons with hearing aids could lead to an increase in the probability to become a dissatisfied user when the detected cases are not really motivated to start using hearing aids. Cutting down on the professional quality and quantity of support for hearing aid users might have a similar effect. On the other hand extra counselling programmes to keep hearing aid users motivated are likely to improve the cost-effectiveness of hearing aid fitting. 
Chapter 7

Conclusions and discussion 



\section{Introduction}

The starting point of this thesis was to perform an economic evaluation of hearing aid fitting, with special attention to the measurement of the effects of hearing aid fitting on (generic) health state. In this chapter the main findings of this thesis are presented, and some methodological issues of the studies underlying this thesis are discussed. Policy implications of the findings are addressed, and some areas of further research are identified.

\section{Main findings}

\section{Societal effects of hearing aid fitting}

Chapter 2 describes the effects of hearing aid fitting on generic health related quality of life (HRQOL), on medical consumption and on productivity loss.

The effects of hearing aid fitting on generic HRQOL were not statistically significant (as assessed with the EQ-5D), while hearing aid fitting did lead to an improvement in at least one aspect of generic HRQOL; namely social functioning (as measured with the SF36). Medical consumption remained relatively stable over a period of 25 weeks after first time hearing aid fitting. The effects of hearing aid fitting on hearing disability and handicap were substantial. It was shown that in a population of first time hearing aid applicants no absence from paid work took place as a result of hearing impairment. Naturally, these results only apply to the small subset of hearingimpaired persons who are motivated to start using hearing aids. In this population hearing aid fitting did relieve problems in paid labour, but did not seem to affect problems in unpaid labour. The small proportion of first time hearing aid users with paid labour in this study $(12.5 \%, \mathrm{~N}=10)$ prevented the quantification of possible savings as a result of improved efficiency at work.

\section{Measuring hearing related health state preferences}

The newly developed Audiological Disabilities Preference Index (ADPI) proved to be a useful instrument in the measurement of change in hearing related health state after hearing aid fitting. Both the construct validity and the reliability of the ADPI were assessed, and was found to be satisfactory.

After hearing aid fitting subjective hearing disability was diminished in every aspect. Since the aspects of subjective hearing disability are associated with technical aspects of hearing aid performance, the relative contribution of each of these aspects to the (change in) hearing specific health state indicates the relative importance of certain features of hearing aids for hearing aid users. This information is useful for clinical decision models about hearing aid fitting, and research and development of hearing aid technologies. In the Chapter 4 of this thesis the descriptive part of the ADPI is used as a 
taxonomic health state description to determine preferences for hearing related health states in other populations.

The hearing specific visual analogue scale of the ADPI showed an improvement of $27 \%$ after hearing aid fitting. The equivalent of the gain on the hearing specific scale on the generic scale was 0.12 . Under the influence of multimorbidity the gain on the generic scale changed from 0.19 to 0.12 . The advantage of the proposed method of framing specific health state preferences in overall health is that change in health state is measured on a scale that is most suited for the purpose of the study, and is also interpretable on a generic scale.

In summary, the ADPI is a feasible preference based measure to obtain direct preferences for hearing related health states, framed in overall health. These health state preferences are needed for clinical decision making and economic evaluation studies about rehabilitative options for audiological disabilities.

\section{Response shift in the measurement of quality of life}

Response shift was observed in the measurement of quality of life after hearing aid fitting. Hearing disability as present in this study population is a relatively mild condition when compared to cancer and end-stage renal disease, in Wric'n response s'nift 'has 'been observed earlier (Bernhard et al, 1999; Adang et al, 1998; Kiebert et al, 1994; Sprangers, 1996; Breetveld \& van Dam, 1991). Therefore this study showed that response shift does not only occur in study populations with severe, life-threatening diseases who undergo major treatments.

In theory, the more generic the concept being measured, the greater the likelihood that response shift will occur, as the larger the variety in determinants of a concept the greater the susceptibility to recalibration (Wilson, 1999). The absence of response shift effect in the hearing specific VAS as opposed to the relatively large response shift effects in the items in the descriptive part of the ADPI is on first sight not in concordance with this theory. On the other hand, a specific item might trigger a person more strongly to remember and relive an earlier situation than a more generic item. This could have been the case in this study, especially taking into account the old age of the respondents. Another factor that could have been of influence is the difference in response technique between the specific items (three point scale) and the hearing related quality of life question (VAS). It is possible that the elderly respondents found it easier to respond to an ordinal than to a cardinal scale, resulting in more valid answers on the specific items. 


\section{The influence of experience on health state valuation}

In Chapter 5 the influence of different forms of illness experience on the valuation of health states, and its consequences for the determination of the effectiveness of hearing aid fitting was investigated. Valuations for both hearing related and generic health states were obtained in four groups of individuals: hearing-impaired patients in the process of hearing aid fitting, persons with medical knowledge of hearing impairment, persons with medical knowledge of visual impairment, and persons without illness experience or medical knowledge.

From the results of this study it was confirmed that illness experience, both personally and through medical knowledge, influences the valuation of health states ('valuation shift'). More specifically it was found that, not only the valuations of health states, but also the ranking of health states seemed to be altered by illness experience. The direction of the influence of experience on health state valuations may however be less straight forward than presumed. First, instead of valuation compression, it was found that the patients stretched out the scale, as compared to the nonpatient groups. Second, gain in health state after hearing aid fitting was not larger from nonpatient perspective than based on patient values.

\section{The cost-effectiveness of hearing aid fitting}

Given the base estimate of input parameters, hearing aid fitting costs society between $€ 11,997 /$ QALY in the youngest age group, and $€ 35,001 /$ QLY in the oldest age group. The average outcome across all ages is $€ 15,807 / \mathrm{QALY}$. Laupacis et al (1992) found that the reimbursement of interventions costing below CAN\$ 20,000 per QALY was generally never questioned (CAN\$ 20,000 $€ 16,000$ ). The base case estimate of $€ 15,807 \wedge Q A L Y$ for fitting hearing aids is around CAN\$20,000 per QALY, and based on this outcome fitting hearing aids could be considered as a cost-effective health care intervention.

Since the effect of hearing aid fitting on generic quality of life, as measured with the EQ-5D was not statistically significant, the conclusion that fitting hearing aids is more cost-effective than not fitting hearing aids remains uncertain. The improvement on the hearing specific VAS was however substantial and statistically significant. So, the effectiveness of hearing aids improving hearing related quality of life was confirmed. This could indicate that the EQ-5D lacked sensitivity for the purpose of this study. Even though this seems highly likely, it is a fact that no study has been able to demonstrate an effect of hearing aid fitting on generic quality of life using a measure suitable for use in CEA (Bess, 2000; Yueh et al, 1999). Until then, the cost-effectiveness of hearing aid fitting can not be determined unambiguously. This emphasizes the need for measures suitable for the evaluation of the effects of interventions for sensory disabilities, such as fitting hearing aids, on generic quality of life. 


\section{Methodological issues}

\section{Design of the study}

The study to evaluate the effects of first time hearing aid fitting had an observational design. Especially when the change in effect is subtle, in an observational design the effect can easily be missed, or unjustly be found, due to bias caused by uncontrolled determinants (Bouter \& van Dongen, 1995). In this study the effect of hearing aid fitting on hearing specific outcome parameters was expected, and proved to be, substantial. Therefore it seems unlikely that the conclusions based on these results are faulty. The effect of hearing aid fitting on more generic parameters (such as generic quality of life), was however indeed subtle. It is possible that the design of this study lacked the strength to reliably assess subtle effects of hearing aid fitting. These results should therefore be handled with caution.

\section{Study population}

The study population was recruited amongst adult persons who had received a prescription for a hearing aid at the university hospital Maastricht and the Audiology Centre Hoensbroeck (location Venlo). This implies that both persons who are fitted with hearing aids through the ENT clinic, and persons who are fitted through an Audiology Centre were included in the study. Since the university hospital Maastricht is besides an academic centre and teaching hospital also the only hospital in the region, we believe the patients recruited through the ENT clinic are representative for all Dutch first time hearing aid users who attend an ENT clinic.

The size of the study population was too small to draw conclusions concerning subgroups of this population (like persons with paid labour and persons consuming a particular kind of medical care, Chapter 2), and conclusions concerning small effects (like the effect on generic quality of life, Chapter 2). These conclusions should therefore be handled with caution.

\section{Measures of effect and data collection}

The generic measures used to assess to effects of hearing aid fitting on generic quality of life are proven valid and reliable, also in an elderly population (Brazier, 1993; Brazier et al, 1996; EuroQol Group, 1990). These questionnaires were expected to be less sensitive to the effects of hearing aid fitting, but this would hold for virtually all generic quality of life measures. This has also been argued by Cox et al (2000). The EQ-5D population utility outcome (Dolan, 1995) was used as a measure of effect in the costeffectiveness analysis. This outcome reflects the population's TTO score for the patient scores on the descriptive part of the EQ-5D. This procedure of transforming patient scores to SG or TTO preferences has been recommended by several authors because in many situations the SG or TTO are not practical 
(Torrance et al, 2001; Krabbe et al, 1997). This would certainly apply to this study in an elderly hearing-impaired patient group. The questionnaire to measure hearing disability and handicap (Amsterdam Inventory), has been validated in a population similar to our study population (Kramer et al, 1995). The Health and Labour Questionnaire (van Roijen et al, 1996), was adapted for use in this hearing-impaired population. The items to assess medical consumption and hearing aid satisfaction and use were formulated for this study.

The ADPI was especially designed for this study. Both the construct validity and the reliability of the ADPI were assessed, and proved to be satisfactory (Chapter 3 ). In the ADPI the VAS is used to elicitate preferences. VAS scores are not utilities, and therefore according to theory not fit for use in cost= utility analysis. Some authors have even argued whether VAS provide values (Bleichrodt \& Johannesson, 1997). VAS scores also seem prone to biases like end-aversion bias and context bias (Torrance et al, 2001). Since in this elderly hearing-impaired population both the SG and the TTO seemed not feasible, the VAS was used despite its shortcomings. The general assumption underlying the transformed health state outcomes of the ADPI is that no interaction between the impact of hearing impairment and the impact of other health problems on overall health state preferences is present. This assumption is questionable, and further research needs to be done to explore the relation between multiple health problems.

All data were collected in face to face interviews, which was the appropriate way of data collection taking into account the average age of the study population. To avoid miscommunication due to hearing problems the participants received a copy to read the questions while the interview took place.

\section{Modelling in cost-effectiveness analyses}

In determining the cost-effectiveness of hearing aid fitting it was most efficient to combine available aggregate data with empirical data on the effects of hearing aid fitting, by applying a modelling approach. Some of the assumptions in the model are based on expert opinion, since no other data source was available. This is one of the weaknesses of the methodology of every modelling study: a model is only as strong as the data it is based on. We believe we correctly handled this shortcoming by performing a sensitivity analysis. The sensitivity shows that the model is robust for most parameters, including the ones based on expert opinion. A major advantage of a modelling approach is that it allows decision makers to explore the implications of an intervention in different ways and under different conditions (Russell, 1999). 


\section{Policy implications}

Reluctance to confront the reality of hearing handicap, hiding the fact a hearing aid may be needed (Jerger et al, 1995), and minimization of hearing loss (Hallam \& Brooks, 1996) are indications of psychological mechanisms common in hearing-impaired persons that might have lead to the response shift observed in this study. If response shift is indeed caused by these mechanisms, there is a task for health care workers to distinguish between normal psychological adaptation and neglect concerning health related behaviour, in order to prevent an affected $\mathrm{QOL}$ as a result of the postponement of hearing rehabilitation until a very late age.

The supposed lack of sensitivity of the existing generic preference based instruments to determine the effect of interventions for specific sensory disabilities is a problem. Furthermore, it is likely that in the future economic evaluations will be performed more frequently for medical interventions leading to relatively small changes in quality of life and no change in the duration of life. Not being able to detect small effects of these interventions in particularly elderly persons can lead to biases in cost-effectiveness ratios, and therefore in possibly underestimating the cost-effectiveness of interventions for these substantial patient groups.

The past years the costs of hearing aid fitting and the organization of the hearing aid fitting procedure have been under debate. The intended reform of the care for hearing-impaired persons could benefit from the results of this study. It was found that changes in hearing aid fitting policy that would increase the probability to become a dissatisfied hearing aid user would considerably increase the amount of cost/QALY for hearing aid fitting. Selecting motivated first time hearing aid users and keeping hearing aid users satisfied therefore seem key issues in a new system of hearing aid fitting.

\section{Areas of future research}

In this study absence from work due to hearing impairment did not take place. Productivity loss at paid work without absence is scarcely discussed in the literature (Brouwer et al, 1999). In the Health and Labour Questionnaire some items are concerned with loss of efficiency (van Roijen et al, 1996). It has been argued that the results of this questionnaire can be considered an underestimation of costs of productivity loss without absence (Brouwer et al, 1999). The assessment of the costs of productivity loss in conditions that do not lead to absence from work deserves more attention.

Existing generic health status measures seem less suitable for the evaluation of the effects of interventions for sensory disabilities, such as fitting hearing 
aids, on generic quality of life. The development of preference based specific measures might be a solution for this problem. The outcomes of specific preference-based questionnaires can be used in cost-effectiveness analyses that provide information for resource allocation decisions within patient groups. The lack of suitable generic measures could be handled by framing specific health state preferences in an overall health perspective. Further research needs to be done to determine the way multiple health problems interact, and thus how the transformation from a specific to the generic health continuum should take place.

It was demonstrated that response shift took place in the measurement of quality of life after hearing aid fitting. Response shift in different groups of hearing disabled persons (for instance help-seekers and non-help-seekers), the origin and magnitude of factors initiating response shift, and the consequences of response shift in the measurement of hearing aid benefit could lead to new insights in the help-seeking behaviour of hearing-impaired persons. Furthermore there is need for consensus regarding which change should be used in economic evaluation: the conventional change or the then test change including the response shift effect.

It was confirmed that experience influences health state valuations, the direction of the influence was however different than presumed. Gain from a nonpatient perspective was not higher than from a patient perspective. The higher gain from a nonpatient perspective has been used as an empirical argument to use population valuations in economic evaluations (Gold et al, 1996). This argument is challenged by the results of this study. Furthermore, when designing population valuation studies one should be aware of the existence of preference subgroups, to avoid bias.

In future research the possible extra benefits of more expensive hearing aids, or binaural fitting, should be identified in terms of incremental cost effectiveness. In this kind of studies the ADPI could be a useful measure of effect.

\section{Concluding remarks}

Based on the base case estimate of $€ 15.807 /$ QLY fitting hearing aids is considered as a cost-effective health care intervention. Probably because the EQ-5D lacked sensitivity for the evaluation of hearing aid fitting, the confidence interval indicates that the result is not unambiguously positive. Until now no study found an effect of hearing aid fitting on generic quality of life. Therefore, there is need for measures suitable for the evaluation of the effects of interventions for specific health problems, such as fitting hearing aids, on generic quality of life. 
References 

- Abutan BB, Hoes AW, Van Dalsen CL, Verschuure J, Prins A. Prevalence of hearing impairment and hearing complaints in older adults: a study in general practice. Fam Practice. 1993; 10(4): 391-5.

Adang EM, Kootstra G, Engel GL, van Hooff JP, Merckelbach HL. Do retrospective and prospective quality of life assessments differ for pancreas. kidney transplant recipients? Transpl Int 1998;11(1):11-5.

Appollonio I, Carabellese C, Magni E, Frattola L, Trabucchi M. Sensory impairments and mortality in an elderly community population: a six-year follow-up study. Age Ageing. 1995;24(1):30-6.

Appollonio I, Carabellese C, Frattola L, Trabucchi M. Effects of sensory aids on the quality of life and mortality of elderly people : a multivariate analysis. Age and Ageing. 1996; 25: 89-96.

Badia X, Diaz-Prieto A, Rue M, Patrick DL. Measuring Health and Health State Preferences among Critically III Patients. Intensive Care Med. 1996; 22(12): 1379-84.

Badia X, Herdman M, Kind P. The Influence of Ill-Health Experience on the Valuation of Health. Pharmacoeconomics. 1998;13(6):687-96.

Baltussen R, Leidl R, Ament A. The impact of age on cost-effectiveness ratios and its control in decision making. Health Economics. 1996; 5(3): p. 227-39.

Barofsky I. The Role of Cognitive Equivalence in Studies of Health-Related Quality-of-Life Assessments. Med Care. 2000; 38(9 Suppl): II125-9.

Beem AR. The history of hearing aids [In Dutch: De historie van hoortoestellen]. Veenendaal, 1997.

Bennett KJ, Torrance GW, Moran LA, Smith F, Goldsmith CH. Health state utilities in Knee replacement Surgery: the development and evaluation of McKnee. The Journal of Rheumatology.1997; 24: 1796-805.

Bernhard J, Hurny C, Maibach R, Herrmann R, Laffer U. Quality of life as subjective experience: reframing of perception in patients with colon cancer undergoing radical resection with or without adjuvant chemotherapy. Swiss Group for Clinical Cancer Research (SAKK). Ann Oncol 1999;10(7): 775-82.

Bess FH, Lichtenstein MJ, Logan SA, Burger MC, Nelson E. Hearing impairment as a determinant of function in the elderly. J Am Geriatr Soc 1989;37(2):123-8.

Bess FH, Lichtenstein M, Logan SA. Making hearing impairment functionally relevant: Linkages with hearing disability and handicap. Acta Otolaryngologica. Supplement. 1991; 476: 226-231.

Bess $\mathrm{FH}$. The role of generic health-related quality of life measures in establishing audiological rehabilitation outcomes. Ear Hear. 2000. 21(4 Suppl): 74S-79S. 
Bleichrodt $\mathrm{H}$, Johannesson $\mathrm{M}$. An experimental test of a theoretical foundation for rating-scale valuations. Med Decis Making 1997; 17(2): 208-16.

- Boas G, van der Stel H, Peters H, Joore M, Anteunis L. Dynamic modelling in medical technology assessment. International Journal of technology Assessment in Health Care. 2001; 17(4): 618-625.

- Bouter L, Dongen van MC. Epidemiological research: design and interpretation (In Dutch: Epidemiologisch onderzoek: opzet en interpretatie). Third edition ed. Houten/Diegem: Bohn Stafleu Van Loghum, 1995.

- Brazier J. The SF-36 health survey - a tool for economists. Health Economics 1993; 2 (3): 213-215.

- $\quad$ Brazier J, Walters SJ, Nicholl JP, Kohler B. Using the SF-36 and the EuroQol on an elderly population. Quality of Life Research. 1996; 5: 195-204.

- $\quad$ Brazier J, Usherwood T, Harper R, Thomas K. Deriving a preference-based single index from the UK SF-36 Health Survey. Journal of Clinical Epidemiology. 1998; 51: 1115-1128.

- Breetvelt IS, Van Dam FS. Underreporting by cancer patients: the case of response-shift. Social Science and Medicine. 1991; 32 (9): 981-987.

Brickley GJ, Cleaver VC, Bailey S. An evaluation of a group follow-up scheme for new NHS hearing aid users. Br J Audiol. 1996; 30(5): 307-12.

- Briggs A, Fenn P. Confidence intervals or surfaces? Uncertainty on the costeffectiveness plane. Health Economics. 1998. 7(8): 723-40.

- Brouwer WB, Koopmanschap MA, Rutten FF. Productivity losses without absence: measurement validation and empirical evidence. Health Policy 1999; 48(1): 13-27.

- Cacciatore F, Napoli C, Abete P, Marciano E, Triassi M, Rengo F. Quality of life determinants and hearing function in an elderly population Osservatorio Geriatrico Campano Study Group. Gerontology. 1999; 45 (6): 323-328.

- Canfield N, Morrisett L. Military aural rehabilitation. In: Davis H, Editor. Hearing and Deafness: A guide for the layman. New York: Holt, Tinehart \& Company, 1947: 318-340.

- Carabellese C, Appollonio I, Rozzini R, Bianchetti A, Frisoni GB, Frattola L, et al. Sensory impairment and quality of life in a community elderly population. J Am Geriatr Soc 1993; 41(4): 401-7.

- Central Bureau of Statistics, The Dutch health inquiry [In Dutch: De Nederlandse Gezondheidsenquête]. 1994, Central Bureau of Statistics. 
- Chorus AMJ, Kremer A, Oortwijn WJ, Schaapveld K. Hearing impairment in the Netherlands. (In Dutch). Number 95.076 Leiden: TNO-PG, Department of Technology in Health Care, 1995.

- Cox R, Rivera I. Predictability and reliability of hearing aid benefit measured using the PHAB. Journal of the American Academy of Audiology, 1992; $3: 242$ 54.

- Cox R, Alexander GC. The abbreviated profile of hearing aid benefit. Ear and hearing. $1995 ; 16: 176-86$.

- Cox R, Hyde M, Gatehouse S, Noble W, Dillon H, Bentler R, Stephens D, Arlinger S, Beck L, Wilkerson D, Kramer S, Kricos P, Gagné JP, Bess F, Hallberg L. Optimal outcome measures, research priorities, and international cooperation. Ear Hear 2000; 21(4 Suppl): 106S-115S.

- $\quad$ Crandell CC. Hearing aids: their effects on functional health status. The Hearing Journal. 1998; 52: 22-32.

- CVZ. Monitor Devices [In Dutch: Monitor hulpmiddelen]. Amstelveen: College voor Zorgverzekeringen, 2001.

De Wit GA, Busschbach JJ, De Charro FT. Sensitivity and Perspective in the Valuation of Health Status: Whose Values Count? Health Econ. 2000; 9(2): 109. 26.

- Dillon H, James A, Ginis J. Client Oriented Scale of Improvement (COSI) and its relationship to several other measures of benefit and satisfaction provided by hearing aids. Journal of the American Academy of Audiology 1997; 8: 27-43.

- Dolan P. A social tariff for EuroQol: results from a UK population survey. York: University of York, 1995.

- Dolan P. The Effect of Experience of Illness on Health State Valuations. J Clin Epidemiology. 1996;49(5):551-64.

- Dolan P. Whose Preferences Count? Medical Decision Making. 1999; 19(4): 482-6.

Drummond M, O'Brien B, Stoddart G, Torrance G. Methods for the economic evaluation of health care programmes. 2nd ed. Oxford: Oxford University Press, 1997.

- Duijvestijn JA, Anteunis LJ, Hendriks JJ, Manni JJ. Definition of hearing impairment and its effect on prevalence figures. A survey among senior citizens. Acta Otolaryngol 1999; 119(4): 420-3.

EUR-ASSESS. Introduction to the EUR-ASSESS Report. Int J Technol Assess Health Care 1997; 13(2): 133-43.

- $\quad$ EuroQol Group. Euroqol - a new facility for the measurement of health related quality of life. Health Policy. 1990, 16, 199-208. 
Gilhome Herbst K. Psycho-social consequences of disorders of hearing in the elderly. In: Hinchcliffe, R. ed. Hearing and balance in the elderly. Edinburgh: Churchill Livingstone, 1983.

- $\quad$ Gold M, Siegel JE, Russell LB, Weinstein MC. Cost-effectiveness in health and medicine. New York: Oxford University Press, 1996.

Gold MR, Franks P, McCoy KI, Fryback DG. Toward Consistency in Cost-Utility Analyses. Using National Measures to Create Condition-Specific Values. Medical Care. 1998; 36: 778-792.

- $\quad$ Golembiewski RT, Billingsley K, Yeager S. Measuring change and persistence in human affairs: types of change generated by OD designs. Journal of Applied Behavioral Science. 1976; 12: 133-157.

- Grimby A, Ringdahl A. Does having a job improve the quality of life among postlingually deafened Swedish adults with severe-profound hearing impairment? $\mathrm{Br}$ J Audiol 2000; 34(3): 187-95.

Grootveld C, Orlebeke JF, Klandermans PG, Kapteijn TS. The use of hearing aids among compulsary insured persons [in Dutch: Het gebruik van hoortoestellen bij ziekenfondsverzekerden]. Amsterdam: Ziekenfondsraad, 1989.

- Hallam RS, Brooks DN. Development of the hearing attitudes in rehabilitation questionnaire (HARQ). British Journal of Audiology. 1996; 30 (3): 199-213.

- Howard GS, Ralph KM, Gulanick NA, Maxwell SE, Nance DW, Gerber SK. Internal invalidity in pretest-posttest self-report evaluations and a re-evaluation of retrospective pretests. Applied Psychological Measurement. 1979; 3 (1): 1-23.

- Jerger J, Chmiel R, Wilson N, Luchi R. Hearing impairment in older adults: new concepts. J Am Geriatr Soc 1995; 43(8): 928-35.

- Joore M, Brunenberg D, Chenault M, Anteunis L. Societal effects of hearing aid fitting among the moderately hearing impaired. International Journal of Audiology. 2002a. Accepted for publication.

- Joore M, Brunenberg D, Zank H, Boas G, Anteunis L, Peters, H. The development of a questionnaire to measure hearing related health state preferences framed in an overall health perspective. International Journal of Technology Assessment in Health Care. 2002b; 18 (3): 528-539.

- Kaplan RM, Anderson JP. A general health policy model: update and applications. Health Services Research. 1988; 23: 203-235.

- $\quad$ Kapteyn TS, Hackenitz E, van Wijkel D. Measures to influence the use of hearing aids [In Dutch: Maatregelingen ter beinvloeding van het gebruik van een hoortoestel. Huisarts en Wetenschap, 1995. 38: p. 535-538.

- Kezirian EJ, Yueh B. Accuracy of terminology and methodology in economic analyses in otolaryngology. Otolaryngol Head Neck Surg 2001; 124(5): 496-502. 


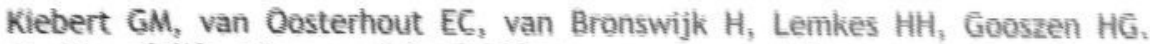
Quality of life after combined kidney-pancreas or kidney transplantation in diabetic patients with end-stage renal disease, Clin Transplant 1994; 8(3 Pt 1): $239-45$.

Kind $P$, Dolan $P$. The Effect of Past and Present lliness Experience on the Valuations of Health States. Medical Care. 1995; 33(4 Suppl): A5255-63.

Krabbe PF, Essink-Bot ML, Bonsel GJ. The comparability and reliability of five health-state valuation methods. Soc Sci Med 1997;45(11);1641-52

Kramer SE, Kapteyn TS, Festen JM, Tobi H. Factors in Subjective Hearing Disability. Audiology. 1995; 34: 311-320.

Lamden K, St. Leger AS, Raveglia J. Hearing Aids: Value for Money and Health Gain. Journal of Public Health Medicine. 1995; 17(4): 445-449,

Laupacis A, Feeny D, Detsky AS, Tugwell PX. How attractive does a new technology have to be to warrant adoption and utilization? Tentative guidelines for using clinical and economic evaluations. Can Med Assoc J 1992; 146(4): 473= 81.

Lutman ME. Hearing disability in the elderly. Acta Otolaryngologica. 1991; Suppl 476: $239-248$.

Metz D. Innovation to prevent dependency in old age. Technological innovations may reduce the cost burden of an ageing population. British Medical Journal 2000; 320: 460-461.

Mittmann N, Trakas K, Risebrough N, Liu BA. Utility scores for chronic conditions in a community dwelling population. Pharmacoeconomics. 1999; 15: 369-376.

Mohr PE, Feldman JJ, Dunbar JL, McConkey-Robbins A, Niparko JK, Rittenhouse RK, Skinner MW. The societal costs of severe to profound hearing loss in the United States. International Journal of Technology Assessment in Health Care 2000; 16 (4): 1120-1135.

Mot E, Meulenbeek AJG, The market for hearing aids: an exploration [In Dutch: De markt voor hoortoestellen: een verkenning]. Amsterdam: Ministerie van VWS en de Raad van Bestuur van de Universiteit van Amsterdam, 1997.

Mulrow CD, Aguilar C, Endicott JE, Tuley MR, Velez R, Charlip WS, Rhodes MC, Hill JA, Denino LA. Quality of Life Changes and Hearing Impairment. A Randomized Trial. Annals of Internal Medicine. 1990; 113: 188-194.

Mulrow CD, Aguilar C, Endicott JE, Velez R, Tuley MR, Charlip WS, et al. Association between hearing impairment and the quality of life of elderly individuals. J Am Geriatr Soc 1990; 38(1): 45-50. 
Oortwijn W. First thing first. Priority setting for Health Technology Assessment. Thesis Leiden University, 2000.

Oostenbrink J, Koopmanschap MA, Rutten FFH, Manual for cost studies: methods and guideline prices for economic evaluations in health care [In Dutch: Handleiding voor kostenonderzoek: methoden en richtlijnprijzen voor economische evaluaties in de gezondheidszorg]. Amstelveen: College voor Zorgverzekeringen, 2000.

- Parving A, Parving I, Erlendsson A, Christensen B. Some experiences with hearing disability/handicap and quality of life measures. Audiology 2001; 40(4): 208-14.

Parving A, Sorensen MS, Carver K, Christensen B, Sibelle P, Vesterager V. Hearing instruments and health technology--an evaluation. Scand Audiol 1997; 26(4): 231-9.

Peters $\mathrm{H}$, Zank H. A class of methods for evaluating multiattribute utilities for health states. Working paper, University of Maastricht, 1999.

Polder JJ, Meerding WJ, Koopmanschap MA, Bonneux L, Maas van de PJ. Costs of Illness in the Netherlands 1994 [In Dutch: Kosten van ziekten in Nederland]. Rotterdam: EUR - iMGZ/iMTA, 1997.

- Revicki DA, Leidy NK, Brennan Diemer F, Sorensen S, Togias A. Integrating patient preferences into health outcomes assessment. Chest. 1998a; 114: 9981007.

- $\quad$ Revicki DA, Leidy NK, Brennan Diemer F, Thompson C, Togias A. Development and preliminary validation of the multiattribute Rhinitis Symptom Utility Index. Quality of Life Research. 1998b; 7: 693-702.

Ringdahl A, Grimby A. Severe-profound hearing impairment and health repated quality of life among post-lingual deafened Swedish adults. Scandinavian Audiology 2000; 29 (4): 266-275.

- Roijen van L, Essink-Bot ML, Koopmanschap M, Bonsel G, Rutten FFH. Labor and health status in economic evaluation of health care. The Health and Labor Questionnaire. International Journal of Technology Assessment in Health Care. 1996; 12 (3): 405-415.

Russell L. Modelling for cost-effectiveness analysis. Statistics in Medicine. 1999;18: 3235-3244.

Rutten F, van Busschbach J. How to define a basic package of health services for a tax funded or social insurance based health care system. HEPAC. 2001; 2 : 45-46.

Schum DJ. Test-retest reliability of a shortened version of the Hearing Aid Performance Inventory. Journal of the American Academy of Audiology. 1993; 4: 18-20. 
Schwartz CE, Sprangers MAG. Methodological approaches for assessing response shift in longitudinal health-related quality-of-life research. Social Science and Medicine. 1999; 48: 1531-1548.

- Sculpher M, Gafni A. Recognizing Diversity in Public Preferences: The Use of Preference Sub- Groups in Cost-Effectiveness Analysis. Health Economics. 2001; 10(4): 317-24.

Sick Fund [In Dutch: Ziekenfondsraad]. Provision of hearing aids [In Dutch: Rapport: verstrekking van hoortoestellen]. Ziekenfondsraad, 1994.

SIHI (Societal Impact of Hearing Impairment Study Group). A comparative survey study of hearing aid users versus non hearing aid users in the general practice in the Netherlands. Commissioned by EHIMA (European hearing instruments manufacturers association). RM/1999/10.02. Maastricht: Mherca, 1999.

- $\quad$ Sonnenberg FA, Beck JR. Markov models in medical decision making: a practical guide. Med Decis Making. 1993. 13(4): p. 322-38.

Sprangers MAG. Response-shift bias: a challenge to the assessment of patients' quality of life in cancer clinical trials. Cancer Treatment Reviews. 1996; 22 (Suppl. A): p. 55-62.

Sprangers MAG, Schwartz CE. Integrating response shift into health-related quality of life research: a theoretical model. Social Science and Medicine. 1999; 48: 1507-1515.

- $\quad$ Stephens SDG, Meredith R. Qualitative reports of hearing aid benefit. Clinical Rehabilitation. 1991a; 5: 225-229.

- $\quad$ Stephens SDG, Meredith R. Physical handling of hearing aids by the elderly. Acta Otolaryngologica. 1991b; Suppl. 476: 281-285.

Stewart MG, Coker N, Jenkins HA, Manolidis S, Bautista MH. Outcomes and quality of life in conductive hearing loss. Otolaryngol Head and Neck Surgery 2000; 123 (5): 527-532.

- Streiner DL, Norman GR. Chapter 6: Biases in Responding. In: Health Measurement Scales. A practical guide to their development and use. Second Edition. Oxford: Oxford University Press, 1995.

- Streukens H, Leenen JAW. Provision and reimbursement of hearing aids [In Dutch: verstrekking en vergoeding van hoortoestellen]. Den Haag: NVAB, 1996.

Swan IRC, Gatehouse S. Factors Influencing Consultation for Management of Hearing Disability. British Journal of Audiology. 1990; 24: 155-160.

Tonning $\mathrm{F}$, Heggebo T, Warland A, Johansen JF. Repair and re-use of hearing instruments. Br J Audiol. 1995; 29(4): 247-53. 
Torrance GW. Measurement of health state utilities for economic appraisal. Journal of Health Economics. 1986; 5: 1-30.

- Torrance GW, Feeny DH. Utilities and quality-adjusted life years. Int. J. of Technology Assessment in Health Care. 1989; 5: 559-575.

- Torrance GW, Feeny DH, Furlong WJ, Barr RD, Zhang Y, Wang Q. Multiattribute utility function for a comprehensive health status classification system. Medical Care 1996; 34: 702-722.

- $\quad$ Torrance GW, Feeny D, Furlong W. Visual analog scales: do they have a role in the measurement of preferences for health states? Med Decis Making 2001; 21(4): 329-34.

- Ustun TB, Rehm J, Chatterji S, Saxena S, Trotter R, Room R, Bickenbach J. Multiple-Informant Ranking of the Disabling Effects of Different Health Conditions in 14 Countries. WHO/NIH Joint Project Car Study Group. Lancet. 1999; 354(9173): 111-5.

van Boxtel MP, van Beijsterveldt CE, Houx PJ, Anteunis LJ, Metsemakers JF, Jolles J. Mild hearing impairment can reduce verbal memory performance in a healthy adult population. J Clin Exp Neuropsychol 2000; 22(1): 147-54.

- $\quad$ van den Brink R. Attitude and Illness Behaviour in Hearing Impaired Elderly. Thesis Groningen University, 1995.

- $\quad$ van Roijen L, Essink-Bot ML, Koopmanschap MA, Bonsel G, Rutten FF. Labor and health status in economic evaluation of health care. The Health and Labor Questionnaire. Int J Technol Assess Health Care 1996;12(3):405-15.

Ventry IM, Weinstein B. The Hearing Handicap Inventory for the Elderly: a new tool. Ear and Hearing. 1982; 3: 128-134.

Verlare CD. National study on hearing impairment, and hearing aid fitting and use [In Dutch: Landelijk onderzoek naar slechthorendheid, hoortoestelaanpassing en -gebruik]. Amsterdam: Inter/view, 1985.

- Ware JE jr, Sherbourne CD. The MOS 36-item short-form health survey (SF-36). I. Conceptual framework and item selection. Med Care 1992; 30(6): 473-83.

- Weinstein B. Presbyacusis. In: Katz J, Editor. The Handbook of Clinical Audiology. 4th ed. Baltimore, 1994.

- WHO. Classification of impairments, disabilities and handicaps. Geneva: World Health Organization, 1980.

- WHO. International classification of impairments, disabilities and handicaps (revision). Geneva: World Health Organization, 2001.

- Wilson IB. Clinical understanding and clinical implications of response shift. Social Science and Medicine. 1999; 48: 1577-1588. 
- Yueh B, Souza P, McDowell J, Bryant M, Loovis C, Ramsey S, Deyo R. Does the choice of psychometric, clinimetric, utility of adherence outcomes influence conclusions in a hearing aid trial? Medical Decision Making 1999; 19(4): 527.

- Yueh B. Digital hearing aids. Arch Otolaryngol Head Neck Surg 2000;126(11):1394-1397.

- Yueh B, Souza, PE, McDowell JA, Collins MP, Loovis CF, Hedrick SC, Ramsey SD, Deyo RA. Randomized trial of amplification strategies. Arch Otolaryngol Head Neck Surg, 2001. 127(10): p. 1197-204.

Zank $\mathrm{H}$, Joore $\mathrm{M}$, Peters $\mathrm{H}$, Anteunis $\mathrm{L}$, Boas $\mathrm{G}$. A new method for the evaluation of health states and health programs. Submitted, 2002. 
Subject index 

Adaptation, 61, 62

Age (influence on health state valuations), 71

Age (specific cost/QALY outcomes), 82, 88

Amsterdam Inventory, 27, 30, 39, 55

Analogue hearing aid, 15

Anchor points (VAS), 41, 70

Audiology centre, 85

Audiological Disabilities Preference Index (development), 38 - 49

Audiological Disabilities Preference Index, 55, 82, 86

Battery costs, 85

Binaural (hearing aid fitting), 15, 85

Cohort model, 80

Cost-effectiveness analysis, 17, 18

Cost-effectiveness of hearing aid fitting, 18, $79-91$

Cost-effectiveness plane, 86,89

Costs (medical), 84, 85

Costs (societal), 31, 33, 85

Cost/QALY (calculation), 82

Cost/QALY (outcomes), 88

Cost-utility analysis, 17

Diagnostics and treatment phase, 83

Digital hearing aids, 15

Disability (hearing), 15

Disutility, 38, 91

Domains of subjective hearing disability, 39, 44

Economic evaluation (methodology), 17

Education level (influence on health state valuations), 71

ENT clinic, 84

Epidemiology (hearing impairment), 14, $82-83$

Experience (illness), $65-75$ 
EuroQol, 26, 28, 42, 46, 55, 58, 82, 86

Gain (in health state after hearing aid fitting), 44, 86

Gender (influence on health state valuations), 71

General practitioner, 84

Handicap (hearing), 15

Health \& Labour Questionnaire,

Health state (description), 39, 44

Health state (preferences), 39, 44

Health state (transformed preferences), 45,

Health Technology Assessment, 17

Hearing (aid), 15

Hearing (Disability), 15

Hearing (Epidemiology), 14

Hearing (Handicap), 15

Hearing (Impairment), 14

Hearing (Physiology), 13

Hearing (Rehabilitation), 15

Hearing aid (batteries), 85

Hearing aid (dispenser), 85

Hearing aid (fitting procedure), 83

Hearing aid (repair), 85

Hearing aid (satisfaction), 31

Hearing aid (use), 31

Hearing specific health state (description), 39, 44

Hearing-specific health state (valuation), 39, 44

Hearing-QALY, 79, 82, 88, 89

Incremental (costs), 17

Incremental (cost-effectiveness), 17

Incremental (effects), 17

Illness (experience), 65 - 75

Impairment (hearing), 14 


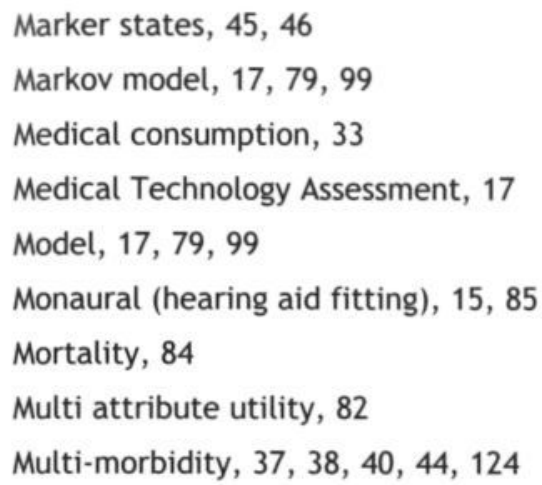


Utility estimate (EuroQol), 82, 87

Use (hearing aid), 31

Validity, 39, 47

Valuation compression, 68, 70, 74 
Summary 



\section{Introduction}

This thesis focuses on the economic evaluation of hearing aid fitting in hearing-impaired adults. Besides the outcomes of the economic evaluation study, it deals with methodological aspects of measuring preferences for health states in hearing impairment.

Besides the objective and outline of the thesis, this first chapter provides a brief introduction to the following subjects: hearing impairment, disability, handicap and rehabilitation, and the methodology of economic evaluation in health care.

\section{Chapter 2}

In this chapter the societal effects of hearing aid fitting in hearing impaired persons are presented. In a prospective evaluation study the effects of hearing aid fitting on generic health related quality of life (HRQOL), subjective hearing disability and handicap, hearing aid satisfaction and use, medical consumption and lost productivity at paid and unpaid work are obtained.

The effects of hearing aid fitting on generic HRQOL, as assessed with the EQ$5 \mathrm{D}$, are small and not statistically significant. Hearing aid fitting improves one aspect of generic HRQOL, social functioning (measured with the SF36 social functioning dimension). The effects of hearing aid fitting on the specific parameters hearing disability and handicap are substantial, in contrast to the minor effects on generic HRQOL. Hearing aid satisfaction and use was high, and the majority of the participants use their hearing aid the whole day. Medical consumption remains stable over a period of 6 weeks before and 25 weeks after first time hearing aid fitting. Perceived problems in social activities apart from paid labour, like volunteer work or household tasks, also are not influenced by hearing aid fitting. Before hearing aid fitting none of the persons with paid labour report absence from paid work as a result of hearing impairment. Hearing aid fitting relieves reported problems in paid labour, indicating that hearing aids may increase efficiency at work. The small proportion of first time hearing aid users with paid labour in this study $(12,5$ $\%$ ) prevents the quantification of possible savings as a result of improved efficiency at work.

\section{Chapter 3}

Chapter 3 focuses on the development of the Audiological Disabilities Preference Index (ADPI), a short questionnaire to measure hearing related health state preferences framed in an overall health perspective. 
Both the construct validity and the reliability of the ADPI are assessed, and found to be satisfactory. After hearing aid fitting subjective hearing disability decreased in every aspect. Since the aspects of subjective hearing disability are associated with technical aspects of hearing aid performance, the relative contribution of each of these aspects to the (change in) hearing specific health state indicates the relative importance of certain features of hearing aids for hearing aid users. This information is useful for clinical decision models about hearing aid fitting, and research and development of hearing aid technologies. The hearing specific visual analogue scale (VAS) of the ADPI shows an improvement of $27 \%$ after hearing aid fitting. The equivalent of this specific gain on the generic scale is $19 \%$. When this figure is adjusted for the presence of multi-morbidity the gain on the generic scale changed from 19\% to $12 \%$. The advantage of the proposed method of framing specific health state preferences in overall health and taking into account the influence of multi-morbidity is that change in health state is measured on a scale that is most suited for the purpose of the study, and is also interpretable on a generic scale. In summary, the ADPI is a feasible preference based measure to obtain direct preferences for hearing related health states, framed in an overall health perspective. These health state preferences are needed for clinical decision making and economic evaluation studies about rehabilitative options for audiological disabilities.

\section{Chapter 4}

Chapter 4 presents the results of our study on response shift in the measurement of quality of life after hearing aid fitting.

When using a pre-test - post-test design to assess changes in a person's selfevaluation of a target construct (such as HRQOL), it is presumed that the meaning of for instance 'having a perfect QOL' stays the same during the whole study period. More theoretically, it is assumed that (amongst other factors) the internal standard of measurement of an individual remains stable. Response shift takes place if an individual undergoes changes in for instance his or her internal standards of measurement. In this study response shift is measured with a then-test. The then-test is an extension of the conventional before-after design with a retrospective baseline (the then-test), which is obtained at the same time as the post-test. Because the then-test is completed at the same time as the post-test, both results have the same internal standard of measurement. In all items from the ADPI a negative and statistically significant response shift occurred. These results confirmed the hypothesis that when the hearing-impaired persons adapt to a lower level of hearing disability and handicap as a result of hearing aid fitting, they perceive their level of hearing disability and handicap before hearing aid fitting as 
more serious. As a result, the conventional change (post-test minus pre-test) was smaller than the then-test change (post-test minus then-test), Reluctance to confront the reality of hearing handicap, hiding the fact a hearing aid may be needed and minimization of hearing loss are indications of psychological mechanisms common in hearing-impaired persons that might have lead to the response shift observed in this study. If response shift is indeed caused by these mechanisms, there is a task for health care workers to distinguish between normal psychological adaptation and neglect concerning health related behaviour, in order to prevent an affected quality of life as a result of the postponement of hearing rehabilitation until a very late age. Furthermore, there is need for consensus regarding which change should be used in economic evaluation: the conventional change or the then-test change including the response shift effect.

\section{Chapter 5}

Chapter 5 describes results of our study on the influence of different types of experience (with illness in general and hearing impairment in particular) on health state valuations.

For this purpose the valuations of the patient's actual health states and hypothetical health states ('deaf', 'blind', 'mild asthma' and 'severe heart failure') obtained in the prospective evaluation study of hearing aid fitting are compared to valuations of descriptions of the patient's actual health states and the same hypothetical health states obtained in a survey. The survey is performed in three groups: employees of the Finance department (Finance group), the Ear, Nose and Throat (ENT group) department, and the Ophthalmology department (Ophthalmology group) of the university hospital Maastricht. The ENT group serves as an example of persons with medical knowledge of hearing impairment and hearing aid fitting, the Ophthalmology group as an example of persons with medical knowledge of visual impairment, and the Finance group as an example of persons without illness experience or medical knowledge. It is hypothesized that the valuations for the health states before and after hearing aid fitting are higher in persons with experience with $\mathrm{HI}$. This can, in the presence of a ceiling effect lead to a larger gain in health state after hearing aid in persons without $\mathrm{HI}$ experience than in persons with $\mathrm{HI}$ experience. The valuation of 'deaf' and 'blind' as the bottom anchor point of specific VAS, are also expected to be higher in persons with experience with that particular illness. Finally, it is hypothesized that persons experienced with illness use a smaller proportion of the VAS than persons without illness experience to give values for a mild ('asthma') and a severe ('heart failure') hypothetical health state (valuation compression).

The results confirm that illness experience, both personally as otherwise, influences the valuation of health states. Not only the valuations of health 
states, but also the ranking of health states seems to be altered by illness experience. The results do not confirm earlier findings that gain in health state after hearing aid fitting usually is larger from nonpatient perspective than based on patient values. With regard to valuation compression there is some indication that the influence of experience on health state valuations is less straight forward than presumed, in contrast to earlier findings, it is observed that patient group on average uses a larger part of the VAS than the nonpatient groups to give valuations for mild and severe health states.

\section{Chapter 6}

In chapter 6 the results of the cost-effectiveness analysis of hearing aid fitting are presented.

The assessment of the costs and effects of hearing aid fitting in persons with hearing complaints, by its very nature requires the use of a dynamic modelling approach. People have hearing complaints, may undergo the process of hearing aid fitting, may become better or worse, may in time re-apply for hearing aids or not, and so on. The model distinguishes between three different health states: persons with hearing complaints without a hearing aid, satisfied hearing aid users, and dissatisfied hearing aid users. From these health states persons can enter the process of diagnostics and hearing aid fitting. The population is divided over the three health states, and over time persons move from one health state to another according to certain transition probabilities. These transition probabilities are derived from the literature, together with the costs associated with these transitions. It is assumed that only satisfied hearing aid users experience gain in quality of life as a result of hearing aid fitting. The total amount of Quality adjusted Life Years (QALYs) gained is computed by counting the total number of satisfied users in a certain year, multiplying by the change in the population utility estimate from the EQ-5D, and adding over the total life expectancy. Given the base case estimate of input parameters, hearing aid fitting costs society between $€$ $11,997 /$ QAL in the youngest age group and $€ 35,001 / Q A L Y$ in the oldest age group. The average outcome across all ages is $€ 15,807 /$ QLY. Based on this outcome fitting hearing aids is considered as a cost-effective health care intervention. The factors that most strongly influence the cost-effectiveness of hearing aid fitting are the price of the hearing aid and the gain in HRQOL after hearing aid fitting. However, since the effect of hearing aid fitting on generic quality of life (as measured with the EQ-5D) is not statistically significant, the conclusion that fitting hearing aids is more cost-effective than not fitting hearing aids remains uncertain. The improvement on the hearing specific VAS is however substantial and statistically significant. So, the effectiveness of hearing aids improving hearing related quality of life is confirmed. 


\section{Conclusion and discussion}

This final chapter presents the main findings of the thesis and discusses some methodological issues. Furthermore, based on the results some implications for policy and areas of future research are identified .

It is argued that the response shift effect in this study may indicate the presence of psychological mechanisms that may lead to the postponement of hearing aid fitting until a very late age, and that health care workers should be aware of this fact. Furthermore the possible underestimation of the effectiveness of interventions for sensory disabilities effectiveness due to the supposed lack of sensitivity of existing generic preference based instruments for this purpose is once again mentioned. The intended reform of the care for hearing-impaired persons can benefit from the identification of factors that most strongly influence the cost-effectiveness ratio of hearing aid fitting. Also, some ideas for future research are identified. There is need for a reliable instrument to measure loss of productivity without absence from work. The complex relation between specific and generic quality of life, further complicated by the presence of multi-morbidity, deserves more attention. Furthermore, factors influencing the origin and magnitude of response shift can be included in research on hearing aid benefit. The direction of the influence of illness experience on health state valuations is in need of empirical evidence. And finally, future research on the costeffectiveness of hearing aids should focus on the possible extra costs and possible extra benefits of more advanced hearing aids or binaural fitting in terms of incremental cost-effectiveness. 



\section{Samenvatting}





\section{Introductie}

Dit proefschrift richt zich op de economische evaluatie van het aanpassen van hoortoestellen bij volwassen slechthorenden. Naast de uitkomsten van de economische evaluatie worden in dit proefschrift methodologische aspecten behandeld van het meten van preferenties voor gezondheidstoestanden gerelateerd aan slechthorendheid.

Naast de doelstelling en een overzicht van de inhoud van het proefschrift, geeft het eerste hoofdstuk een korte introductie over slechthorendheid, ervaren gehoorbeperking en handicap, mogelijkheden voor gehoorrevalidatie, en de methodologie van economisch evaluatie onderzoek in de gezondheidszorg.

\section{Hoofdstuk 2}

In dit hoofdstuk worden de maatschappelijke effecten van hoortoestelaanpassing gepresenteerd. In een prospectieve evaluatie studie worden de effecten van hoortoestelaanpassing op algemene gezondheid gerelateerde kwaliteit van leven, ervaren gehoorbeperking en handicap, tevredenheid met en gebruik van het hoortoestel, medische consumptie, en verlies van productiviteit bij betaald en onbetaald werk gemeten.

De effecten van hoortoestelaanpassing op algemene gezondheid gerelateerde kwaliteit van leven, gemeten met de EQ-5D, zijn klein en niet statistisch significant. Hoortoestelaanpassing verbetert wel een aspect van algemene aan gezondheid gerelateerde kwaliteit van leven: sociaal functioneren (gemeten met de sociale dimensie van de SF36). De effecten van hoortoestelaanpassing op de specifieke parameters ervaren gehoorbeperking en handicap zijn, in tegenstelling tot de effecten op algemene kwaliteit van leven, substantieel en statistisch significant. De tevredenheid met het hoortoestel is hoog, en de meeste deelnemers aan het onderzoek gebruiken het hoortoestel gedurende de hele dag. Medische consumptie blijft stabiel over een periode van 6 weken voor tot 25 weken na de hoortoestelaanpassing. Ervaren problemen bij sociale activiteiten naast betaald werk, zoals vrijwilligerswerk en huishoudelijke taken, worden niet beïnvloed door de hoortoestelaanpassing. Vóór hoortoestelaanpassing geeft geen van de personen met betaald werk aan vanwege slechthorendheid afwezig te zijn van het werk. De hoortoestelaanpassing had wel een positief effect op ervaren problemen op het werk. Mogelijk leidt de hoortoestelaanpassing tot verhoogde efficiency op het werk. Door de kleine proportie eerste hoortoestelgebruikers in deze studie $(12,5 \%)$ is het kwantificeren van de mogelijke besparingen ten gevolge van verbeterde efficiency op het werk niet mogelijk. 


\section{Hoofdstuk 3}

In hoofdstuk 3 wordt de ontwikkeling van de 'Audiological Disabilities Preference Index' (ADPI) behandeld. Dit is een korte vragenlijst om preferenties voor aan gehoor gerelateerde gezondheidstoestanden te meten, en die vervolgens in te passen in een algemeen gezondheidsperspectief.

Zowel de construct validiteit als de betrouwbaarheid van de ADPI blijken voldoende. $\mathrm{Na}$ hoortoestelaanpassing neemt elk aspect van ervaren gehoorbeperking af. Omdat deze aspecten samenhangen met technische kenmerken van het functioneren van hoortoestellen, zegt de relatieve bijdrage van deze aspecten aan de verandering in gehoorpecifieke gezondheidstoestand iets over het relatieve belang van bepaalde kenmerken van hoortoestellen voor hoortoestelgebruikers. Deze informatie kan worden gebruikt bij klinische besluitvorming over hoortoestelaanpassing, en bij onderzoek en ontwikkeling van nieuwe hoortoesteltechnologieën. $\mathrm{Na}$ de aanpassing van het hoortoestel is de verbetering op de gehoorspecifieke 'visual analogue scale' (VAS) in de ADPI 27\%. Het equivalent van deze verbetering op de generieke schaal is $19 \%$. Wanneer dit getal wordt aangepast voor de aanwezigheid van multi-morbiditeit verandert de verbetering op de generieke schaal van $19 \%$ in $12 \%$. Het voordeel van de voorgestelde methode om specifieke preferenties voor gezondheidstoestanden in te passen in een algemeen gezondheidsperspectief, is dat de verandering in gezondheidstoestand kan worden gemeten op een schaal die toegesneden is op het doel van de studie, terwijl de resultaten ook interpreteerbaar zijn op een generieke schaal.

Samenvattend is de ADPI een bruikbaar instrument om direct preferenties te meten voor aan gehoor gerelateerde gezondheidstoestanden. Deze gezondheidspreferenties zijn nodig voor klinische besluitvorming rond, en economische evaluaties van behandelopties voor gehoorbeperkingen.

\section{Hoofdstuk 4}

In hoofdstuk 4 worden de resultaten van onze studie naar response shift bij het meten van verandering in kwaliteit van leven na hoortoestelaanpassing gepresenteerd.

Als veranderingen in de evaluatie van een construct, zoals iemands eigen gezondheid of kwaliteit van leven, worden gemeten in een design met een voor- en nameting wordt aangenomen dat de betekenis van iemands waardering voor bijvoorbeeld de eigen kwaliteit van leven gedurende de studie gelijk blijft. Er is sprake van response shift als dit niet het geval is. In deze studie is onderzocht of een component van response shift, verschuiving in het beoordelingskader (scale recalibration), optreedt na hoortoestel- 
aanpassing. Scale recalibration is gemeten met een retrospectieve voormeting (toen-test). De toen-test is gelijktijdig met de nameting afgenomen, waardoor voor deze metingen het beoordelingskader gelijk is. Response shift is het verschil tussen de toen-test en de voormeting.

In alle items van de ADPI vond een negatieve en statistisch significante response shift plaats. Deze resultaten bevestigen de hypothese dat wanneer slechthorenden ten gevolge van hoortoestelaanpassing gewend raken aan een milder niveau van gehoorbeperking en handicap, zij hun niveau van gehoorbeperking voorafgaand aan de hoortoestelaanpassing als ernstiger ervaren. Ten gevolge van de response shift is de verandering na hoortoestelaanpassing gebaseerd op de toen-test (nameting minus toen-test) groter, dan de verandering gebaseerd op de voormeting (nameting minus voormeting).

Aarzeling om de werkelijke handicap ten gevolge van slechthorendheid onder ogen te zien, en het verbergen en vergoelijken van de slechthorendheid komen veel voor onder slechthorenden en zijn indicaties voor de aanwezigheid van psychologische mechanismen die mogelijk hebben geleid tot de aangetoonde response shift. Als response shift inderdaad wordt veroorzaakt door deze mechanismen, is het een taak voor hulpverleners om onderscheid te maken tussen normale psychologische adaptatie en het veronachtzamen van de gezondheid. Dit kan verlies in kwaliteit van leven ten gevolge van het tot op hoge leeftijd uitstellen van hoortoestelaanpassing voorkomen. Bovendien is behoefte aan consensus over welk gemeten behandelingeffect zou moeten worden gebruikt in economische evaluaties: het effect gebaseerd op de prospectieve voormeting, of het effect gebaseerd op de toen-test.

\section{Hoofdstuk 5}

In Hoofdstuk 5 worden de resultaten van de studie naar de invloed van verschillende vormen van ervaring met ziekte of beperkingen in het algemeen en slechthorendheid in het bijzonder op waarderingen voor gezondheidstoestanden beschreven.

Voor dit doel worden de waarderingen voor de eigen gezondheidstoestand en voor hypothetische gezondheidstoestanden ('doof', 'blind', 'milde astma', 'ernstig hartfalen') in de prospectieve evaluatie studie voor hoortoestelaanpassing, vergeleken met waarderingen voor beschrijvingen van de gezondheidstoestand van de slechthorenden en dezelfde hypothetische gezondheidstoestanden in een survey. De survey is uitgevoerd bij drie groepen: werknemers van de dienst financiën en economie (DFE groep), werknemers van de afdeling keel- neus en oorheelkunde (KNO groep) en werknemers van de afdeling oogheelkunde (Oogheelkunde groep) van het academisch ziekenhuis Maastricht. De KNO groep dient als een voorbeeld van personen met medische kennis van slechthorendheid en hoortoestelaanpassing, de Oogheelkunde 
groep als voorbeeld van personen met medische kennis van slechtziendheid, en de DFE groep als voorbeeld van personen zonder ervaring met ziekte of beperking, of specifieke medische kennis. Vooraf is verondersteld dat de waarderingen voor de gezondheidstoestand voor en na hoortoestelaanpassing hoger zijn in de groepen met ervaring met slechthorendheid. Dit leidt, als er een plafondeffect aanwezig is, tot een grotere verbetering na hoortoestelaanpassing in de groepen zonder ervaring met slechthorendheid. Een andere veronderstelling is dat de waarderingen voor de gezondheidstoestanden 'doof' en 'blind', als eindpunten van specifieke VAS, hoger zijn in de groepen met ervaring met deze specifieke aandoeningen. Tenslotte is verondersteld dat personen met ervaring met ziekte een kleiner gedeelte van de VAS gebruiken voor het waarderen van een milde ('astma') en een ernstige ('hartfalen') hypothetische gezondheidstoestand (valuation compression).

De resultaten van de studie bevestigen dat ervaring met ziekte (zowel persoonlijk als op andere wijze) invloed heeft op de waardering van gezondheidstoestanden. Niet alleen de waarderingen voor de gezondheidstoestanden, maar ook de rangorde waarin de gezondheidstoestanden worden geplaatst verschilt tussen de groepen. De resultaten zijn niet in overeenstemming met eerder onderzoek dat aantoonde dat de verbetering in de gezondheidstoestand over het algemeen het kleinst is vanuit het perspectief van de patiënt. Omdat in deze studie de slechthorenden een groter deel van de VAS gebruikten om de milde en ernstige gezondheidstoestand te waarderen dan de andere (gezonde) groepen, is er met betrekking tot de valuation compression enige indicatie dat de invloed van ervaring met ziekte minder eenduidig is dan tot nu toen is aangenomen.

\section{Hoofdstuk 6}

In Hoofdstuk 6 worden de resultaten van de kosteneffectiviteitstudie van hoortoestelaanpassing gepresenteerd.

Het vaststellen van de kosten en de effecten van hoortoestelaanpassing bij personen met een klachten van slechthorendheid, vereist het gebruik van een dynamische model. Personen hebben klachten, ondergaan wellicht het proces van hoortoestelaanpassing, hun gezondheidstoestand zal verbeteren of verslechteren, op termijn zullen ze zich melden voor een heraanpassing van het hoortoestel, of niet, en ga zo door. In het model wordt onderscheid gemaakt tussen drie verschillende gezondheidstoestanden: personen zonder hoortoestel met klachten van slechthorendheid, tevreden hoortoestelgebruikers, en ontevreden hoortoestelgebruikers. Vanuit deze gezondheidstoestanden kan een persoon beginnen aan het proces van diagnostiek van slechthorendheid en hoortoestelaanpassing. De bevolking is verdeeld over de drie gezondheidstoestanden, en in de tijd kunnen personen van de ene naar de andere gezondheidstoestand overgaan volgens bepaalde overgangskansen. 
Deze overgangskansen en de kosten die met de overgangen samenhangen zijn gebaseerd op de literatuur. Het is aangenomen dat alleen de tevreden hoortoestelgebruikers winst in kwaliteit van leven ten gevolge van de hoortoestelaanpassing ervaren. Het totaal aantal voor kwaliteit van leven aangepaste levensjaren (QALYs) dat wordt gewonnen door hoortoestelaanpassing is berekend door het totaal aantal tevreden hoortoestelgebruikers per jaar te vermenigvuldigen met de winst in kwaliteit van leven (gebaseerd op de winst in populatie utiliteit van de EQ-5D) en dit op te sommen over de totale levensverwachting.

Gebaseerd op de meest waarschijnlijke schattingen van alle ingevoerde waarden in het model kost hoortoestelaanpassing de maatschappij $€$ 11.997/QALY in de jongste leeftijdsgroep (15-19 jaar) en $€ 35.001 / Q A L Y$ in de oudste leeftijdsgroep (95-99 jaar). De gemiddelde uitkomst over alle leeftijden heen is $€ 15.807 /$ QLY. Op basis van deze uitkomst kan hoortoestelaanpassing worden beschouwd als een kosteneffectieve gezondheidsinterventie. De factoren die de kosteneffectiviteit van hoortoestelaanpassing het sterkst beïnvloeden zijn de prijs van het hoortoestel en de winst in kwaliteit van leven na hoortoestelaanpassing. Omdat het effect van hoortoestelaanpassing op de algemene kwaliteit van leven niet statistisch significant is, blijft de conclusie dat hoortoestelaanpassing kosteneffectiever is dan geen hoortoestellen aanpassen echter onzeker. De verbetering op de gehoor specifieke VAS is echter substantieel, en statistisch significant, hetgeen erop wijst dat hoortoestellen in ieder geval de gehoorspecifieke gezondheidstoestand verbeteren.

\section{Conclusie en discussie}

In dit laatste hoofdstuk worden de belangrijkste resultaten van het proefschrift gepresenteerd, en worden enige methodologische kwesties besproken. Daarnaast worden gebaseerd op de resultaten van deze studie implicaties voor beleid en richtingen voor toekomstig onderzoek aangegeven.

Er wordt aangegeven dat de response shift die in deze studie is aangetoond kan wijzen op de aanwezigheid van psychologische mechanismen die het tot op hoge leeftijd uitstellen van hoortoestelaanpassing in de hand werken, en dat hulpverleners hierop bedacht moeten zijn. Ook wordt gesteld dat het mogelijke gebrek aan sensitiviteit van de bestaande generieke kwaliteit van leven instrumenten om de effectiviteit van interventies voor sensorische beperkingen (zoals hoortoestellen) vast te stellen kan leiden tot een onderschatting van de effectiviteit van dit type interventies. Bij de voorgenomen veranderingen in de zorg voor slechthorenden kan gebruik worden gemaakt van de wetenschap welke factoren de kosteneffectiviteit van hoortoestelaanpassing in welke mate beïnvloeden. 
Er worden enige suggesties gedaan voor richtingen voor toekomstig onderzoek. Er is behoefte aan een instrument om op betrouwbare wijze de grootte van productiviteitsverliezen zonder afwezigheid van werk te bepalen. Ook verdient de complexe relatie tussen specifieke en generieke kwaliteit van leven, die verder wordt gecompliceerd door de aanwezigheid van multimorbiditeit, verder onderzoek. Factoren die de oorzaak en de sterkte van response shift bepalen kunnen worden betrokken bij onderzoek naar de vooren nadelen van hoortoestellen. En tenslotte, toekomstig onderzoek naar de kosteneffectiviteit van hoortoestelaanpassing zal zich moeten richten op het identificeren van de mogelijke extra kosten en mogelijke extra effecten van bijvoorbeeld meer geavanceerde hoortoestellen en tweezijdige hoortoestelaanpassing in de zin van de incrementele kosteneffectiviteit. 


\section{Co-authors and affiliations}





\title{
L.J.C. Anteunis PhD
}

Department of Otorhinolaryngology, Head \& Neck Surgery.

University Hospital Maastricht, the Netherlands

Ms D.E.M. Brunenberg MSc

Department of Clinical Epidemiology and Medical Technology Assessment, University Hospital Maastricht, the Netherlands

\author{
G.M. Boas PhD \\ Maastricht Health Economics Research and Consultancy Agency, \\ Maastricht, the Netherlands
}

Ms M. Chenault MSC

Department of Otorhinolaryngology, Head \& Neck Surgery.

University Hospital Maastricht, the Netherlands

\section{H.J.M Peters PhD}

Department of Quantitative Economics.

Faculty of Economics and Business Administration,

University of Maastricht, the Netherlands

\author{
Ms J. Potjewijd MSc \\ Student, \\ Faculty of Medicine,
}

University of Maastricht, the Netherlands

H. van der Stel PhD

University Library,

University of Maastricht, the Netherlands

Ms A.A. Timmerman

Department of Otorhinolaryngology, Head \& Neck Surgery.

University Hospital Maastricht, the Netherlands

H. Zank PhD

School of Economic Studies,

University of Manchester, United Kingdom 
Dankwoord 

Dit onderzoek was vaker een nevenactiviteit dan een hoofdactiviteit en pas nadat de eerste artikelen waren geschreven werd het een promotieonderzoek. Achteraf hield het de blik fris, en mij ontspannen. Ik heb veel plezier beleefd aan dit onderzoek, niet in de laatste plaats vanwege de samenwerking met allerlei personen, afkomstig uit allerlei verschillende disciplines. Rest me nog een aantal personen te bedanken voor hun betrokkenheid.

Allereerst, iedereen die de (lange) vragenlijsten voor dit onderzoek heeft ingevuld, en de medewerkers van het audiologisch centrum van het academisch ziekenhuis Maastricht en het audiologisch centrum Hoensbroeck (locatie Venlo) die de interviews hebben afgenomen, hartelijk bedankt voor jullie tijd en inzet.

Hans Peters, promotor, je relativerende manier van doen en interesse in andere vakgebieden heb ik erg gewaardeerd. Met veel plezier denk ik terug aan onze besprekingen, waar humor altijd zorgde voor een lichte noot en waar ik altijd vol nieuwe ideeën en energie vandaan kwam. Ik vind het een eer dat ik bij je kan promoveren

Lucien Anteunis, co-promotor, je enthousiasme is onnavolgbaar. Gelukkig, want het was de stuwende kracht achter het onderzoek, en mijn promotie. Dat ik bovendien met zo'n goed gevoel terugkijk op het schrijven van het proefschrift heeft alles te maken met onze prettige samenwerking. Bedankt!

De overige coauteurs wil ik bedanken voor hun waardevolle bijdragen aan de afzonderlijke publicaties waaruit dit proefschrift bestaat.

Gijs Boas, ik herinner me nog levendig hoe we in Kopenhagen het projectvoorstel voor het onderzoek waarop dit proefschrift deels is gebaseerd presenteerden. De kansen die jij me gaf hebben tot dit proefschrift geleid, waarvoor heel veel dank.

Daniëlle Brunenberg, jij nam toen ik weer eens aan een nieuw onderzoek was begonnen de uitvoering van het onderzoek op je. Ik heb een groot voordeel gehad van jouw consciëntieuze manier van werken.

Mickey Chenault, je bent bij het hele onderzoekstraject betrokken geweest, en ook later bij het schrijven van de artikelen kon ik altijd op je rekenen voor een laatste controle van de statistiek en het Engels.

Judith Potjewijd, een van de hoofdstukken is deels gebaseerd op de resultaten van jouw stage. Bedankt dat ik een deel van je gegevens mocht gebruiken.

Angelique Timmerman, bij het schrijven van het artikel over response shift was jouw expertise als psycholoog erg waardevol. Hans van der Stel, dank voor al je werk aan het kosteneffectiviteitmodel. Je was altijd bereid nog eens te overleggen en nog wat aanpassingen te maken.

Horst Zank, door onze samenwerking kwam een plezierige en leerzame wisselwerking tussen empirische en theoretisch onderzoek tot stand. 
Yvonne van Leeuwen en Donné Pans waren respectievelijk als huisarts en als audioloog betrokken bij de opzet van de studie en bij de dataverzameling. Hartelijk dank voor jullie inspanningen.

De leden van de beoordelingscommissie, prof. dr. P.P. Wakker (voorzitter), prof. dr. J.J. Manni, prof. dr. J.G.A. van Mierlo en prof. dr. J.L. Severens, wil ik bedanken voor de beoordeling van het proefschrift.

De MTA-werkgroep bood de afgelopen jaren steeds de gelegenheid om in een vroeg stadium ideeën en resultaten te presenteren en te bediscussiëren. Door deze kruisbestuiving ontstaan allerlei gezamenlijke initiatieven, die niet alleen de kwaliteit van het onderzoek, maar ook het plezier van onderzoek doen verhogen.

Dr. J.J. Carpay, voorzitter van de Raad van Bestuur van het azM, in uw functie als hoofd van de afdeling KEMTA heeft $u$ mij de tijd gegeven om het proefschrift af te schrijven, hartelijk dank daarvoor.

Mijn collega's van de afdeling Klinische Epidemiologie en Medical Technology Assessment (KEMTA), creëren met hun enthousiasme, hun betrokkenheid en hun vrolijkheid de perfecte setting om een proefschrift te schrijven. Laat dit dus het eerste KEMTA-proefschrift van vele zijn! Audrey, Bert, Brigitte, Carmen, Claire, Daniëlle D., Danielle W., Debby, Fons, Fred, Gemma, Ghislaine, Hans, Irene, Jody, Margriet, Martin, en Thea, jullie zijn met recht sociale wetenschappers. Alle buitenactiviteiten, zoals congresbezoek en KMETA-borrels, hielden in ieder geval mijn geest gezond. Deze donderdag is de KEMTA-borrel van mij!

De paranimfen: Daniëlle, nogmaals dank voor al het werk dat je hebt verricht. Ik hoop dat we samen nog veel artikelen schrijven! En Debby, als mijn kamergenoot kon ik altijd op je rekenen voor een boeiende inhoudelijke discussie en een daarop volgende relativerende lachbui. Bedankt!

Familie, vrienden en bekenden, jullie kleurden mijn leven met jullie verhalen, jullie humor en jullie zorgzaamheid. Dankzij jullie hield ik oog èn oor voor andere dingen.

Christian, jouw joie de vivre is een voorbeeld.

Pap en Mam, om overduidelijke redenen, is dit voor jullie.

Manuela 
Publications 



\section{Papers}

Rutten - van Molken MPMH, Postma MJ, Joore MA, Van Genugten MLL, Leidl R, Jager JC. Current and future medical costs of asthma and chronic obstructive pulmonary disease in the Netherlands. Respiratory Medicine, 1999; 93 (11): 779-787.

Joore MA, Anteunis LJC. De kosteneffectiviteit van hoortoestelaanpassing in Nederland. Logopedie en Foniatrie, 2001; 9: 200-207.

Boas G, van der Stel H, Peters H, Joore M, Anteunis L. Dynamic modelling in Medical Technology Assessment - fitting hearing aids in the Netherlands. International Journal of Technology Assessment in Health Care, 2001; 17: 618-625.

Joore M, Potjewijd J, Timmerman A, Anteunis L. Response shift in the measurement of quality of life in hearing-impaired adults after hearing aid fitting. Quality of Life Research. 2002; 11: 299-307.

Joore M, Brunenberg D, Zank H, van der Stel H, Anteunis L., Boas, G., Peters, $\mathrm{H}$. The development of a questionnaire to measure hearing related health state preferences framed in overall health. International Journal of Technology Assessment in Health Care. 2002; 18 (3): 528-539.

Joore $M$, Brunenberg $D$, Chenault $M$, Anteunis $L$. Societal effects of hearing aid fitting among the moderately hearing-impaired. International Journal of Audiology. Accepted for publication.

Joore M, van der Stel H, Peters H, Boas G, Anteunis L. The cost-effectiveness of hearing aid fitting in the Netherlands. Archives of Otolaryngology and Head and Neck Surgery. In review process.

Joore MA, Potjewijd J, Anteunis LJC. The influence of experience on health state valuation. Submitted.

Zank H, Joore MA, Peters HJM, Anteunis LJC, Boas GM. A new index for the evaluation of health states and health programs. Submitted.

\section{Abstracts}

Anteunis LJC, Joore MA. De voordelen van hoortoestellen wegen op tegen de kosten. FIDA Seminar, Utrecht, 20 november 1999. Stichting Vakopleiding FIDA, Seminar 1999-II, p. 1-6. 
Joore, M, Brunenberg, D, Anteunis, L. Utility measurement in hearing impairment. International Congress of Audiology. August 27-30, 2000, Abstractbook p. 304.

Joore M, van der Stel H, Peters H, Boas G, Anteunis L. The cost-effectiveness of hearing aid fitting in the Netherlands. International Health Economics Association Conference. July 22-25, 2001, York, United Kingdom. Abstractbook p. 129.

Joore M.A., Potjewijd J., Anteunis L.J.C. The influence of experience on health state valuation. European Society for Medical Decision Making. Eight Biennial Conference. June 2-5, 2002, Taormina, Sicily, Italy. Abstractbook p. 54.

Brunenberg DEM, Joore MA, Bekebrede L, van Steijn MJA, Bulstra, SK. Joint recovery in hip and knee replacement: a cost-effective approach. European Society for Medical Decision Making. Eight Biennial Conference. June 2-5, 2002, Taormina, Sicily, Italy. Abstractbook p. 55. 


\section{Curriculum vitae}

Manuela Joore was born on July 31st 1971 in Everdingen, The Netherlands. She graduated in 1990 from the Koningin Wilhelmina College in Culemborg. That same year she started studying at the faculty of Health Sciences of the University of Limburg. From November 1994 to March 1995 she had her internship at the National Institute of Public Health and the Environment (Bilthoven), at the Centre of Public Health Forecasting. In the last year of her study she additionally completed the Epidemiology MSc. programme, at the department of Epidemiology of the University of Limburg. She graduated in September 1996. In July of that year she started as a researcher at the department of Urology of the university hospital Maastricht. Since May 1998 she has been working at the department of Clinical Epidemiology and Medical Technology Assessment of the same hospital. Besides the research on the costs and effects of hearing aid fitting that is underlying this work, she has participated in various other research projects. 
Publication of this thesis was financially supported by: Beltone Netherlands B.V.

GN ReSound bv

Oticon Nederland B.V.

Siemens Audiologie Techniek B.V.

Veenhuis Medical Audio B.V. 



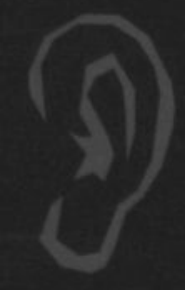

